\title{
Capillary microscopy and haemorheology in vasospastic and occlusive vascular diseases
}

Citation for published version (APA):

Jacobs, M. J. H. M. (1985). Capillary microscopy and haemorheology in vasospastic and occlusive vascular diseases. [Doctoral Thesis, Maastricht University]. Rijksuniversiteit Limburg. https://doi.org/10.26481/dis.19850329mj

Document status and date:

Published: 01/01/1985

DOI:

10.26481/dis.19850329mj

Document Version:

Publisher's PDF, also known as Version of record

\section{Please check the document version of this publication:}

- A submitted manuscript is the version of the article upon submission and before peer-review. There can be important differences between the submitted version and the official published version of record.

People interested in the research are advised to contact the author for the final version of the publication, or visit the DOI to the publisher's website.

- The final author version and the galley proof are versions of the publication after peer review.

- The final published version features the final layout of the paper including the volume, issue and page numbers.

Link to publication

\footnotetext{
General rights rights.

- You may freely distribute the URL identifying the publication in the public portal. please follow below link for the End User Agreement:

www.umlib.nl/taverne-license

Take down policy

If you believe that this document breaches copyright please contact us at:

repository@maastrichtuniversity.nl

providing details and we will investigate your claim.
}

Copyright and moral rights for the publications made accessible in the public portal are retained by the authors and/or other copyright owners and it is a condition of accessing publications that users recognise and abide by the legal requirements associated with these

- Users may download and print one copy of any publication from the public portal for the purpose of private study or research.

- You may not further distribute the material or use it for any profit-making activity or commercial gain

If the publication is distributed under the terms of Article $25 \mathrm{fa}$ of the Dutch Copyright Act, indicated by the "Taverne" license above, 
CAPILLARY MICROSCOPY AND HAEMORHEOLOGY

IN VASOSPASTIC AND

OCCLUSIVE VASCULAR DISEASES 



\section{CAPILLARY MICROSCOPY AND HAEMORHEOLOGY IN VASOSPASTIC AND OCCLUSIVE VASCULAR DISEASES}

\section{Proefschrift}

ter verkrijging van de graad van doctor in de geneeskunde aan de Rijksuniversiteit Limburg te Maastricht, op gezag van de Rector Magnificus Prof. Dr. F.I.M. Bonke, volgens besluit van het College van Dekanen, in het openbaar te verdedigen in de aula van de universiteit op vrijdag 29 maart 1985 des namiddags te twee uur

door

\section{Michael Johan Hubert Marie Jacobs}

geboren te Baghdad, Irak 
Promotores: Prof. Dr. H.A.J. Lemmens

Prof. Dr. R.S. Reneman

Co-promotores: Dr. P.J. Breslau

Dr. D.W. Slaaf

Referenten: Prof. Dr. H.A.J. Struyker-Boudier

Prof. Dr. A. Bollinger

Prof. Dr. H. Schmid-Schönbein

The publication of this thesis was financially supported by the Dutch Heart Foundation, Janssen Pharmaceutica BV, ABBOTT NV and Perimed. 
To Mirjam, Caroline and Harm

To my parents 



\section{Contents}

Chapter 1

GENERAL INTRODUCTION

PART I: VASOSPASTIC AND ISCHAEMIC HAND PHENOMENA.

Chapter 2

HISTORY AND DESCRIPTION OF PATIENTS AND NORMAL SUBJECTS AS INVESTIGATED IN THIS THESIS

2.1 History and review

2.2 Patients with vasospastic and ischaemic hand phenomena 19

2.2.1 Primary Raynaud's phenomenon

$\begin{array}{ll}2.2 .2 \text { Secondary Raynaud's phenomenon } & 20\end{array}$

$\begin{array}{ll}2.2 .3 \text { Acrocyanosis } & 20\end{array}$

$\begin{array}{ll}2.2 .4 \text { Asphyxia manus et digitorum } & 20\end{array}$

$\begin{array}{ll}2.3 \text { Normal subjects } & 20\end{array}$

Chapter 3

METHODS OF INVESTIGATION

3.1 Review of methods to evaluate finger circulation 21

$\begin{array}{ll}3.2 \text { Methods as used in this study } & 29\end{array}$

$\begin{array}{lr}3.2 .1 \text { Physical examination } & 29\end{array}$

$\begin{array}{ll}3.2 .2 \text { Blood investigation } & 30\end{array}$

$\begin{array}{ll}3.2 .3 \text { Haemorheology } & 30\end{array}$

3.2.4 Capillary microscopy 31

$\begin{array}{ll}3.2 .5 \text { Laser-Doppler } & 33\end{array}$

$\begin{array}{ll}3.2 .6 \text { Continuous wave Doppler } & 35\end{array}$

$\begin{array}{ll}3.2 .7 \text { Thermography } & 35\end{array}$

$\begin{array}{ll}3.2 .8 \text { Roentgenography } & 35\end{array}$

3.2 .9 Angiography 35

$\begin{array}{ll}3.3 \text { Statistical analysis } & 36\end{array}$ 
4.1 Results

4.2 Interpretation and discussion 48

4.3 Nomenclature 51

Chapter 5

THERAPY

5.1 Introduction $\quad 53$

5.2 Ketanserin 54

5.2 .1 Introduction $\quad 54$

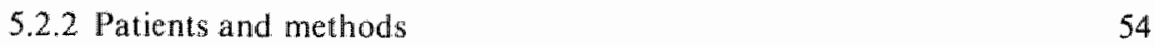

$\begin{array}{ll}5.2 .3 \text { Results } & 55\end{array}$

$\begin{array}{ll}5.2 .4 \text { Discussion } & 60\end{array}$

5.3 Buflomedil 61

5.3.1 Introduction $\quad 61$

5.3.2 Patients and methods 61

$\begin{array}{ll}5.3 .3 \text { Results } & 62\end{array}$

5.3.4 Discussion $\quad 63$

5.4 Plasmapheresis 64

5.4.1 Introduction 64

5.4.2 Patients and methods $\quad 65$

5.4.3 Results 65

5.4.4 Discussion $\quad 69$

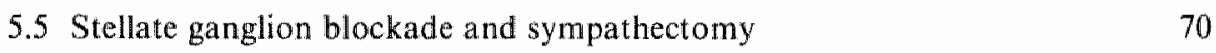

5.5.1 Introduction $\quad 70$

$\begin{array}{ll}5.5 .2 \text { Patients and methods } & 70\end{array}$

5.5 .3 Results 71

5.5.4 Discussion $\quad 74$

PART 11: OCCLUSIVE ARTERIAL DISEASE OF THE LOWER EXTREMITIES

Chapter 6

INTRODUCTION 
$\begin{array}{lll}7.1 & \text { Patients } & 77\end{array}$

$\begin{array}{ll}7.2 \text { Normal subjects } & 77\end{array}$

$\begin{array}{ll}7.3 \text { Physical examination } & 78\end{array}$

$\begin{array}{ll}7.4 \text { Haemorheology } & 79\end{array}$

7.5 Ankle/arm pressure index measurements $\quad 80$

$\begin{array}{ll}7.6 \text { Arteriography } & 81\end{array}$

7.7 Statistical analysis 81

Chapter 8

RESULTS

8.1 Haemorheology in normal subjects and patients 83

8.2 Haemorheology and Doppler ankle/arm pressure index measurements $\quad 83$

8.3 Haemorheology and angiography $\quad 89$

8.4 Discussion 91

Chapter 9

THERAPY

9.1 Vascular surgery $\quad 93$

$\begin{array}{ll}9.2 \text { Discussion } & 96\end{array}$

Chapter 10

GENERAL DISCUSSION AND CONCLUSIONS 99

$\begin{array}{ll}\text { Summary } & 103\end{array}$

$\begin{array}{lr}\text { Samenvatting } & 107\end{array}$

References 111

$\begin{array}{lr}\text { Appendix } & 121\end{array}$

$\begin{array}{ll}\text { Acknowledgements } & 123\end{array}$

$\begin{array}{ll}\text { Curriculum Vitae } & 125\end{array}$ 



\section{Chapter I}

\section{GENERAL INTRODUCTION}

After Maurice Raynaud described the discolouration of hands and fingers, nomenclature of vasospastic and ischaemic hand phenomena has always been a point of discussion. To improve this nomenclature and to obtain better insights into the pathophysiology of the disturbed digital circulation, different diagnostic procedures have been used. The phenomena, which take place at the level of the microcirculation, may not only be determined by disorders of the vessels, but also by its content: the blood. To investigate these aspects in patients with vasospastic and ischaemic hand phenomena, capillary microscopy and haemorheological techniques were used in this thesis.

Capillary microscopy, already described since the beginning of this century, has contributed to a better insight into these phenomena. Morphological studies of nailfold capillaries have proven to be useful to distinguish between Raynaud's phenomenon with and without underlying disease. The introduction of dynamic capillary microscopy in nutritional skin capillaries allowed the non-invasive investigation of the velocity patterns in patients with vasospastic and ischaemic phenomena of hands and fingers.

Haemorheological investigations have demonstrated that Raynaud's phenomenon can exist with or without haemorheological disturbances. Haemorheology, the study of flow properties, has gained an increasing attention in clinical medicine. It is becoming evident that many pathological processes as nutritional and metabolic disorders can not, or at least not exclusively, be attributed to diseases of the heart and large vessels, but rather have to be ascribed to disturbances at the level of the microcirculation.

Microcirculatory disturbances do not only occur in patients with vasospastic and ischaemic hand phenomena, but also in patients with intermittent claudication. Occlusive arterial disease of the lower extremities, which has a complete different aetiology and pathophysiology, also causes impairment of the microcirculation. Therefore, in this thesis haemorheological parameters were also investigated in a group of patients with intermittent claudication.

It was the aim of this thesis to study the haemorheological properties of blood in patients with vasospastic and ischaemic phenomena of hands and fingers and in patients with occlusive arterial disease of the lower extremities. Moreover, we investigated whether in patients with vasospastic and ischaemic thand phenomena our 
clinical classification could be confirmed by determining haemorheological and capillary microscopic parameters. In other words: does the use of capillary microscopy and haemorheology provide a more accurate diagnosis which may lead to a better nomenclature of these phenomena?

We also investigated the applicability of rheological and capillary microscopic parameters in evaluating the subjective changes as induced by therapy. 


\section{Chapter 2}

\section{HISTORY AND DESCRIPTION OF PATIENTS AND NORMAL SUBJECTS AS INVESTIGATED IN THIS THESIS}

In this chapter, the general history of Raynaud's phenomenon will be discussed, followed by a review of the literature concerning the aetiological and pathophysiological ideas of primary Raynaud's phenomenon, secondary Raynaud's phenomenon and acrocyanosis.

In this thesis, the term Raynaud's phenomenon is used for the clinical symptoms of symmetrical, triphasic discolouration of hands and fingers, which can exist with or without underlying disease. However, in literature many different terms and definitions like primary and secondary Raynaud's syndrome, phenomenon or disease have been used to describe the same Raynaud's phenomenon. In order to illustrate the discussion and the difficulties in creating a common nomenclature, in the first part of this chapter (history) the terms as described by the authors themselves are presented. To avoid further confusion, the term Raynaud's phenomenon is used consistently throughout the thesis. The terms primary and secondary indicate the absence or presence of an underlying disease, respectively. Acrocyanosis is described as an uni-or bilateral permanent cyanosis of hands and fingers, without the existence of an underlying disease. Asphyxia manus et digitorum is also considered as a different phenomenon, characterized by a local, sharply bordered discolouration of one or more finger(s).

In the second part of this chapter both the population of patients and normal subjects as investigated in the present study will be described.

\section{1 History and review}

Maurice Raynaud was born in 1834 and received his doctor's degree in Paris in 1862. His inaugural thesis (193) for the Academy of Medicine, entitled "De l'asphyxie locale et de la gangrène symétrique des extrémites', was published in 1862. This work was the beginning of a world wide discussion, which already lasts for more than twelve decennia.

In his introduction Raynaud wrote: 'To describe a new disease entity, especially to give a group of symptoms a new name is certainly less difficult than to bring the symptoms under a common denominator and to join them together under a common law, which dominates them in spite of a variety of manifestations." It is this variety of 
manifestations which today still leads to the misinterpretation of symptoms of ischaemia of the hand. Raynaud deseribed two types of manifestations. About the first type, which he named "local asphyxia", he wrote: "without appreciable cause one or many fingers become pale and cold all at once; in many cases it is the same finger which is first attacked; the others become dead successively and in the same order. He believed that the precipitating factor of the phenomenon was either exposure to cold or emotional stress. A bout the second type Raynaud wrote: 'In the light cases the ends of the fingers and toes become cold, cyanosed and livid and at the same time more or less painful. In grave cases the area affected by cyanosis extends upwards for several centimeters and finally, if this state is prolonged for a certain time, we see gangrenous points appear on the extremities; the gangrene is always dry and may occupy the superficial layer of the skin from the extent of a pin's head up to the end of the finger, rarely more. However, in several cases of symmetric gangrene as reported by Raynaud, there $u s$ no evidence that the onset was similar to that in the first type and that the gangrene involved more than the tips of the fingers. He unquestionably described cases of organic disease of the skin and of occlusive arterial disease of the digital arteries. In his later work, he restated that the two types of manifestations were the same: "local asphyxia and symmetrical gangrene are not two different stages of one and the same disease". This was probably Raynaud"s failure and the cause of a still existing misuse of the nomenclature of these phenomena.

In 1883, in a lecture for the Clinical Society of London, Sir Thomas Barlow introduced the term 'Raynaud's disease' which not only included cases of local asphyxia or symmetrical gangrene, but also essentially similar cases which differ in distribution and intensity (8).

Hutchinson (99) did not agree with the term Raynaud's disease. In his lecture at the London Hospital (1901) he said: 'I think we shall gain a clearer idea of our subject if we discard its name, for the expression "Raynaud's disease" would imply that there is some one malady complete in itself, and having all the symptoms the same in all cases which is suitable denominated by that name. That is not the case'. He emphasized that Raynaud had not described a new disease or syndrome, but rather symptoms caused by either sympathetically induced vasospasm or organic changes in the vessels, and therefore suggested the term Raynaud's phenomenon.

Allen (3) and Hunt (97) recognized that many of the original cases described by Raynaud did not meet the criteria which he himself had put forward in his thesis. In 1932 Allen and Brown (3) made an important attempt to improve the nomenclature by a critical review of Raynaud"s cases. They found that only 6 of the 31 patients described by Raynaud fulfilled his own criteria. The remaining 25 patients probably had gangrene due to arterioscle rosis, scleroderma or tromboangiitis obliterans. Allen and Brown concluded that there was a definite primary disease which could be called Raynaud's disease. The minimal requirements for diagnosis were those originally stated by Raynaud: I. intermittent attacks of discolouration of the extremities; 2. absence of evidence of organic arterial occlusion; 3. symmetric or bilateral distribution, and 4, trophic changes, when present, limited to the skin and never consisting of gross gangrene. They added two other characteristics: 1 . predeliction for women ( 9 to 
1 in their own material) and 2. absence of pain during an attack. They also mentioned that the symptoms should be present for at least two years (2). An extensive follow-up study of women with Raynaud's disease confirmed the validity of these requirements; in 95 percent of the cases the diagnoses were correct when established by these criteria (72). Using the same criteria, the population of Raynaud's patients as studied by Hines et al. (91) consisted of $21 \%$ men and $79 \%$ women.

Guntherothet al. (78) investigated Raynud's phenomenon in children and deseribed the importance of searching for an underlying disease.

Sir Thomas Lewis $(141,143,144)$ gave reasons when and why intermittent spasm should be attributed to a local fault of the vessels concerned. He and Pickering (144) considered to abandon the term Raynaud"s disease and introduced the term secondary Raynaud's phenomenon for patients where Raynaud's phenomenon was based on a known underlying disease and in which the "local vascular fault" was a more likely explanation for the ischaemic attacks of the fingers.

It is obvious that for accurate diagnosis, prognosis and evaluation of therapeutic results, all authors and investigators realised the importance of an uniform terminology. In order to stress the absence of known causative agents and to differentiate it from secondary Raynaud's phenomenon (with underlying disease), Raynaud's phenomenon without underlying disease was called primary Raynaud's phenomenon, but also primary Raynaud's disease or syndrome, vasoneurosis, or episodic idiopatic vasospasm (37).

\section{Primary and secondary Raynaud's phenomenon}

Especially the aetiology and pathophysiology of primary Raynaud's phenomenon have extensively been discussed during the past 120 years, resulting in many review articles $(22,82,127,192,195)$. The condition of primary Raynaud's phenomenon is usually mild, occurs five times more frequently in women than in men (91) and is not associated with any other disease. Although the symptoms may interfere with the patients occupation, it carries a good prognosis (13). In 70-80 percent of the cases the onset of Raynaud's phenomenon is before the age of $40(3,13)$. Patients with primary Raynaud's phenomenon have lower skin temperatures than healthy subjects and their finger blood flow (187) and blood pressure are diminished after cold provocation as compared to normal subjects $(92,175,216)$. In extreme cold provocation, the initial. vasoconstriction is followed by alternating periods of vasoconstriction and dilatation. This phenomenon is greatly attenuated in the absence of sympathetic nerves and exaggerated in patients with Raynaud's phenomenon (141,142,145). Raynaud himself hypothesized that the impairment of digital blood flow in patients with episodes of discolouration was the result of increased sensitivity of the vasculature to the sympathetic nervous system (193).

Hyndman et al. (100) found that after sympathectomy patients with Raynaud's phenomenon retained the same complaints. They concluded that Raynaud's phenomenon is a local disorder of the vascular system and not primarily a disorder of the sympathetic nervous system. Jamieson et al. (108) demonstrated that local cooling of 
the hand augmented the reflex sympathetic vasoconstriction induced by cooling of the neck in patients with Raynaud's phenomenon, but that such enhancement of the vasoconstrictive response did not occur in normal subjects; increased sensitivity of alpha receptors by cold exposure was hypothesized.

Peacock (185) found increased levels of plasma catecholamines in wrist venous blood of patients with Raynaud's phenomenon, which was consistent with Raynaud's proposal of sympathetic overactivity. Nielsen et al. (176) measured plasma noradrenaline and adrenaline levels in patients with Raynaud's phenomenon with and without sympathectomy. After sympathectomy, patients with relapse of Raynaud's phenomenon had a lower noradrenaline and higher adrenaline level at rest as compared to normal subjects and non-operated patients with primary Raynaud's phenomenon. Downey et al. (51) observed that the relative vasoconstrictor response to cooling, expressed as a percentage of resting flow, was normal in Raynaud's phenomenon. Mendlowitz and Naftchi (169) reported that patients with Raynaud's phenomenon can be divided into two groups: one group with unobstructed digital arteries and increased vasomotor tone, and a second group with digital vascular obstruction and normal vasomotor tone. They found a normal sensitivity of finger blood vessels to intravenously infused norepinephrine which is in contrast with the findings of Peacock and does not support the theory of sympathetic overactivity. Coffman (36) concluded that the sympathetic nervous system activity exerts a greater effect on finger arteriovenous shunt flow than on nutritional flow and that therefore nutritional flow is not adversely affected. He and Cohen (35) found that patients with Raynaud's phenomenon had a lower finger nutritional (capillary) flow than normal subjects and that this flow decreased significantly during sympathetic stimulation. Beside reduction in blood flow after cold provocation, Raynaud himself recognized that emotional stress could precipitate ischaemic attacks. However, Halperin et al. (83) found digital vasodilatation during menta stress in patients with Raynaud's phenomenon and suggested the existence of an active digital vasodilatory mechanism in these patients. Burch et al. (29) described ultrastructural changes in the vessels of the finger tips of patients with Raynaud's phenomenon, with or without scleroderma: reduced digital blood flow could be explained by ultrastructural changes in the capillaries.

The possible role of histamine in the etiology of primary Raynaud's phenomenon was questioned by Lafferty et al. (126). Raynaud's phenomenon also occured in hypertensive patients taking cardioselective beta-receptor antagonists (161).

Serotonin (5-hydroxytryptamine), which has a constrictive effect on smooth muscle cells of larger arteries, has also been suggested to play a role in the aetiology of Raynaud's phenomenon (84). Blocking the action of serotonin by a 5 - HT receptor antagonist resulted in increased digital blood flow (205).

Beside the role of vasomotor and structural changes of the digital arteries, haemorheological factors influencing flow properties of blood in small arteries and skin microcirculation have been suggested to play a part (191). Pringle et al. (191) measured increased blood viscosity in 21 of 22 patients with primary Raynaud's phenomenon in association with raised plasma fibrinogen concentrations and increased red blood cell aggregation. However, the primary character of Raynaud's 
phenomenon in these patients was questioned by Birnstingl (12). Moreover, the results published on the relation between Raynaud"s phenomenon and blood viscosity are contradictory. Ayres et al. (6) Tound no difference in blood viscosity between patients with Raynaud's phenomenon and normal subjects while Schmid-Schönbein (200) observed highly increased blood viscosity in Raynaud's phenomenon and noted that red blood cell aggregates were much more difficult to disperse as compared to normals subjects, which is in agreement with the findings of Pringle (191). These observations are not necessarily contradictory and may result from misuse of the terminology of these phenomena.

Goyle and Dormandy (75), Tietjen et al. (217) and Dintenfass $(44,45)$ a lso showed an increase in blood viscosity, particulary at low shear rates and low temperatures. In these studies, however, no distinction was made between primary and secondary Raynaud's phenomenon (with and without underlying disease). The importance of distinguishing both forms of Raynaud"s phenomenon was underlined by Jahnsen et al. (107). They emphasized that increased viscosity might be a causal factor in secondary forms of Raynaud's phenomenon, but that it does not seem to be an important factor in primary Raynaud's phenomenon. The effect of temperature on blood viscosity in Raynaud's phenomenon was investigated by Barbee (7). He found that the relative viscosity was independent of temperature at high shear rates, but dependent on the temperature at low shear rates (as measured in a capillary viscometer). Forconi et al. (67) also reported abnormal blood viscosity in Raynaud's phenomenon and a local increase of blood viscosity during cold ind uced attacks (68). Evaluating all studies concerning blood wiscosity and Raynaud's phenomenon, it appears that Raynaud's phenomenon can be associated with various rheological aberrations, varying from patient to patient.

Raynaud's phenomenon can be associated with a variety of underlying diseases and is then called secondary Raynaud's phenomenon.

One of the common clinical features of systemic autoimmune disease is the occurence of Raynaud's phenomenon. With improvement of the diagnostic methods, a number of investigations has shown a relative decrease in the incidence of primary Raynaud's phenomenon concomitant with an increase in the relative incidence of secondary Raynaud's phenomenon $(211,213,223)$. Kallenberg et al. (113) found a direct correlation between the severity of Raynaud's phenomenon and the extent of systemic involvement. They also observed a remarkably high incidence of asymptomatic organ abnormalities in patients with, clinically, primary Raynaud's phenomenon. Van der Meulen et al, (171) found a positive relationship between the severity of Raynaud's phenomenon and the levels of circulating immune complexes. Porter et al. (190) performed a prospective immunologic evaluation in patients with Raynaud's phenomenon. They found that $81 \%$ of the unselected patients had an associated autoimmune disease (e.g. scleroderma, lupus erythematosus), suggesting that the presence of Raynaud's phenomenon should be considered as an important clinical finding. They proposed that all patients with Raynaud"s phenomenon should be regarded as at high risk for having an associated autoimmune disease. Many immunologic studies have been performed to search for a marker for collagen and 
immune diseases like HLA-antigens, HLA-B8, or phagocytosed immune complexes $(50,89,130,172,199)$.

The relationship between Raynaud's phenomenon and scleroderma was already described by Lewis and Landis (140). According to Tuffanelli et al. (221), Raynaud's phenomenon is present in $95 \%$ of patients with scleroderma. In approximately $30(66)$ to 70 (9) \% of the cases, Raynaud's phenomenon is the first clinical symptom of scleroderma. It even may be the only manifestation of systemic sclerosis for many years (213). Nearly $50 \%$ of the patients with scleroderma develop symptoms related to the esophagus, due to loss of peristalsis and cardioesophageal sphincter tone (168). Treacy et al. (219) explored the sclerodermatous process in the esophagus. They found that the vast majority of patients with esophageal scleroderma had Raynaud's phenomenon and concluded that scleroderma of the esophagus was manifested by an abnormality of smooth muscle function: the smooth muscle is destroyed and the esophagus dilated. Hurwitz et al. (98) investigated the esophageal motility in patients with Raynaud's phenomenon and scleroderma and found an absence of coordinated esophageal peristalsis. A specific therapy for esophageal abnormalities in scleroderma and other collagen vascular diseases is not available, but problems can be minimized by paying attention to details of their management (227).

Hawley et al. (88) were the first who suggested an association between Raynaud's phenomenon (suddenly developed) and malignant disease. Decreased thyroid function has also been described as a cause of Raynaud's phenomenon (206). Linscheid et al.(146) started a study in order to investigate the relationship between the carpaltunnel syndrome and Raynaud's phenomenon. They found an association between carpal tunnel syndrome and Raynaud's phenomenon, but could not explain the exact nature of nerve compression in the production of vasomotor response. Vasospastic diseases are also common among workers using vibrating tools (162). Raynaud's phenomenon can also be present in the hypothenar hammer syndrome (96).

Whenever Raynaud's phenomenon occurs in male, occlusive arterial disease or tromboangiïtis obliterans (Buerger's disease) should be suspected $(1,37,41)$. It may also occur secondary to neurovascular compression at the thoracic outlet (11), especially if Raynaud's phenomenon occurs unilateral (25). However, according to Lemmens (133), these ischaemic attacks should be distinguished from Raynaud"s phenomenon, because the attacks are caused by anatomic disturbances.

\section{Acrocyanosis}

Despite the frequent misuse of the term acrocyanosis, it has mostly been distinguished from Raynaud's phenomenon (184). According to Lewis and Landis (139) the term acrocyanosis was first applied by Crocq in 1896 to a condition characterized by painless and persistent coldness, and cyanosis of the distal parts of the extremities. There is no pallor as in Raynaud's phenomenon and no ulceration and gangrene. The cyanosis is intensified by cold or emotional upsets; it may or may not be entirely relieved by warming the affected part.

Clinically, acrocyanosis can easily be distinguished from Raynaud's phenomenon, 
particularly if the persistent color changes of acrocyanosis, in contrast with the episodic nature of the demarcated, sequential changes as observed in Raynaud's phenomenon, are present. However, one should realise that vasospasm in association with several secondary vasospastic conditions may reach a stage of persistant cyanosis (scleroderma, obstructive arterial disease). The secondary causes must be carefully excluded.

Davis (43) differentiates between primary and secondary acrocyanosis. The latter may be seen in livido reticulares, hypertension, arteriosclerosis and in connective tissue disease like Marfan's disease. However, sometimes Raynaud"s phenomenon can be superimposed on acrocyanosis. In these cases, the diagnosis can be very difficult.

The mechanisms leading to the disease are still not clear. Lewis and Landis (139), and Stern (208) concluded that the phenomenon was caused by a lesion of the small arteries, but Parissius (183) and Sivula (207) considered the phenomenon to be a result of a disorder in the venous tone. Also in acrocyanosis, blood viscosity disturbances have been observed (170).

\section{Asphyxia manus et digitorum}

For the first time this local ischaemic phenomenon was described by Maurice Raynaud (193). In literature this local asphyxia is generally not distinguished from Raynaud's phenomenon. The local ischaemic attacks in asphyxia digitorum are caused by occlusions of the digital arteries and should therefore be distinguished from Raynaud's phenomenon. In this thesis these patients are separated from the other patients with vasospastic and ischaemic phenomena.

\subsection{Patients with vasospastic and ischaemic hand phenomena}

In this study 72 patients with vasospastic and ischaemic phenomena of hands and fingers were investigated and divided into 4 different groups, using the clinical classification of Lemmens (134): 1) primary Raynaud"s phenomenon (without underlying disease; 2) secondary Raynaud's phenomenon (with underlying disease); 3) acrocyanosis; 4) asphyxia manus et digitorum.

\subsubsection{Primary Raynaud's phenomenon}

In 43 cases the patients ( 37 females, 6 males) were classified as having primary Raynaud's phenomenon. The mean age of the patients in this group was 42.6 years (range 17-64). All patients had clinical symptoms of Raynaud's phenomenon: a symmetrical triphasic discolouration of hand and fingers triggered by exposure to cold or emotional stress. The lapse of time since the first symptom varied from 1 to 30 years. Twenty four patients underwent sympathectomy, with transient success, at 
least one year prior to this study.

In none of the patients an underlying disease could be detected, either by physical examination (3.2.1), or by contrast angiography.

The data on immunoglobulins, antinuclear antibody (ANA), antinuclear factor (ANF), as well as Rose, Latex, lupus erythematosus (LF) factor, was normal. The presence of cryoglobulins and cold agglutinins could not be demonstrated.

\subsubsection{Secondary Raynaud's phenomenon}

In 13 cases the patients ( 11 females, 2 males), were classified as secondary Raynaud's phenomenon. The mean age in this group was 54.5 years (range 38-68). The clinical symptoms were similar to those observed in primary Raynaud's phenomenon, but were based on progressive systemic sclerosis (P.S.S.) in 12 patients and on dermatomyositis in I patient. The diagnosis P.S.S. was verified by histological or esophagus $\mathrm{X}$-ray examinations. Dermatomyositis was diagnosed by a skin-fascy-muscle biopsy.

\subsubsection{Acrocyanosis}

In 6 patients ( 5 females, 1 male), acrocyanosis was diagnosed. The mean age was 36.8 years (range 19-54). Four patients complained of unilateral and 2 patients of bilateral permanent cyanosis of hands and fingers. All clinical, blood (see section 3.2.2) and noninvasive vascular investigations were negative.

\subsubsection{Asphyxia manus et digitorum}

Ten patients (all male subjects) were classified as having asphyxia manus et digitorum. The mean age of these patients was 47.6 years (range 32-71). The clinical picture was characterized by a sharply bordered white, and sometimes cyanotic discolouration of one or more fingers, especially after cold provocation. The underlying disease was tromboangiïtis obliterans in 2 patients and atherosclerosis in 8 patients. In all patients, the digital arteries of the ischaemic attacked finger(s) were obstructed as verified by angiography.

\subsection{Normal subjects}

The control group consisted of 25 healthy persons ( 20 females and 5 males). The mean age was 32.6 years (range $22-58$ years). The normal subjects were without any clinical symptoms and the complete medical check-up (physical examination, blood investigation) was within normal ranges. 


\section{Chapter 3}

\section{METHODS OF INVESTIGATION}

A variety of techniques have been used to evaluate finger and skin circulation in patients with ischaemic hand phenomena. In this chapter the most important techniques will be reviewed and the methods as used in this thesis will be described.

\subsection{Review of methods to evaluate finger circulation}

\section{Angrography}

Angiography has widely been applied in patients with ischaemic hand phenomena to visualize and localize vascular obstructions.

In a study of Dabich et al. (40), digita] arteriography was performed in patients with scleroderma and Raynaud's phenomenon. In 29 of the 31 patients the arteriograms demonstrated organic arterial stenosis or occlusion.

In 1955, Lynn et al. (149) made arteriograms of the digital arteries of the hands of patients with Raynaud"s phenomenon. Two groups of patients could be distinguished: one group with anatomically normal digital arteries and another group with obliteration of these arteries. He stressed the importance of distinguishing these two groups by arteriography, especially to select the patients for treatment with vasodilator agents or sympathectomy.

Kent et al. (116) found arteriographic abnormalities in 17 out of 18 patients with Raynaud"s phenomenon. The changes were nonspecific and were not related to the clinically diagnosed underlying arterial disease. Besides, the results of upper thoracic sympathectomy did not correlate with the type or severity of the angiographic changes. He concluded that angiographic examinations were of limited value in the diagnosis or management of patients with Raynaud's phenomenon.

Cryodynamic hand angiography in combination with post-reserpine studies was found to be diagnostically useful in Raynaud's phenomenon, revealing the degree of organic arterial disease and functional vasospasm (198). Lemmens (136) concluded that angiography of hands and fingers may be helpful in assessing the severity of the disease, but that its reliability depends on the quality of the angiographic procedure: angiograms have to show the arterial, capillary and venous systems. According to Kent et al. (116), arteriography is only of value to demonstrate a proximal source of digital emboli. Costoclavicular compression, for instance, is a potential danger to the 
circulation of the fingers because of the possibility to generate microembolisms. Local ischaemic attacks and even more progressive impairment of finger circulation due to microembolism should be distinguished from Raynaud's phenomenon. Angiography, howewer, is potentially dangerous and is uncomfortable for the patient, but necessary if an underlying pathology or obstructive arterial diseases are suspected. It is indicated in digital ischaemia if anatomical obstructions that are caused by surgically correctible proximal laesions, are expected (196).

\section{Measurement of digital blood flow}

Measurement of digital blood flow in patients with Raynaud's phenomenon has been performed by venous occlusion plethysmography (16), photoelectric plethysmography (228), calorimetry (169), radioisotope clearance techniques (35) and Doppler ultrasound (211).

Venous occlusion plethysmography, one of the oldest methods to measure the blood flow in extremities, is based on the principle that a cuff around an extremity can be inflated to such a pressure that the draining veins are completely occluded while the inflow of blood through the arterial system is not impeded. The increase in volume of the extremity during venous acclusion is determined with a plethysmograph. From this increase as a function of time, the blood volume flow can be calculated. This method has been used to study digital blood flow in patients with Raynaud's phenomenon $(16,36,51,108,187)$. These studies showed a reduced hand blood flow in Raynaud's phenomenon, especially after cold provocation. Coffman et al. (35) used this method simultaneously with a radioisotope technique to study total and capillary fingertip blood flow in Raynaud's phenomenon. He found a smaller finger nutritional (capillary) flow in Raynaud's phenomenon compared to normal subjects and a significantly decreased flow during sympathetic stimulation.

Searching for a possible interaction between blood hyperviscosity and reduced blood flow, McGrath et al. combined venous occlusion plethysmography and blood viscosity measurements in patients with scleroderma (164) and cryoglobulinemia (165). He found decreased blood flow and increased blood viscosity, suggesting that hyperviscosity syndromes could impair the circulation.

Photoelectric plethysmography is based on the fact that tissue is more transparant to red and near infrared light than whole blood. Thus the attenuation of light passing through tissue indicates the blood content of this tissue. The instrument consists of a light source and a photosensor. The electrical signal from the photosensor is amplified and recorded. Wouda (228) used this method in patients with Raynaud's phenomenon to study changes in the amplitudes of the signal recorded during cooling and rewarming the hand. Lafferty et al. (125) used photoelectric plethysmography with temperature measurements in a thermal entrainment study and found significant abnormality of vasomotor control in patients with Raynaud's phenomenon. 
With the above mentioned techniques, including plethysmography, it is difficult to measure and demonstrate closure of digital arteries after cold provocation (120). After Krähenbühl et al. developed a cuff technique for indirect measurement of tone in the digital arteries (120), this technique was improved by Nielsen et al. (175) to evaluate the digital artery closing event in patients with Raynaud's phenomenon. The temperature of the arterial wall. was diminished to a well-defined temperature by cooling during ischaemia, while measuring simultaneously finger systolic blood pressure. It was concluded that with this technique patients with Raynaud's phenomenon could be distinguished from normal subjects, and that clinically relevant information could be provided on the severity of the disease, i.e., the temperature at which closure of the digital arteries occured in these patients. Thulesius et al. (216) confirmed these conclusions in his study. Hoare et al. (92) adopted the technique of Nielsen (175), using photoplethysmography instead of strain gauge plethysmography to detect distal pulsations to measure digital blood pressure. These investigators also concluded that with this technique, patients with excessive vasospasm due to cooling could be distinguished from normal subjects and that the natural history and responses to therapy could be evaluated.

Hendriksen et al. (90) measured segmental systolic blood pressure in normal subjects and patients with generalized scleroderma by a strain gauge technique, before and after local heating and nerve blockade to exclude sympathetic vasoconstrictor activity. He found a significant lower finger systolic blood pressure in patients. From these findings he concluded that sympathectomy cannot be expected to relieve Raynaud's attacks in these patients. Measurements of digital blood flow and digital blood pressure are macrocirculatory methods which enable the investigation of global haemodynamics in a region. This approach, however, is not sensitive enough to evaluate the disturbed skin microcirculation as occurs in patients with vasospastic and ischaemic hand phenomena. Measuring skin capillary blood flow, and especially dynamic capillary microscopy, seems to be very useful for this purpose (65).

\section{Laser-Doppler methods to assess skin blood flow}

Skin capillary blood flow has been measured by radioisotope clearance techniques in patients with scleroderma $(79,122,123,124,138)$, primary Raynaud's phenomenon (4) and secondary Raynaud's phenomenon (80). The radioisotope clearance techniques, however, are time-consuming and invasive.

An alternative approach is the use of a Laser-Doppler technique, which is a non-invasive manner to study and evaluate the cutaneous blood flow(177). The system utilizes the Doppler shift of laser light backscattered from moving red blood cells in the cutaneous microcirculation, the shift being obtained by an optical heterodyning technique $(178,215)$.

Holloway et al. (93) compared the Laser-Doppler method with the washout of intracutaneously injected Xenon in the forearm, and found a close correlation 
between the two methods. These methods, however, cannot be compared directly because the skin was traumatized by the injection of the tracer, resulting in a local vasodilatation with increased blood flow (94). Moreover, the Laser-Doppler system only measures to a limited depth in the skin, while the Xenon washout takes place in both the cutis and subcutis. Therefore, Engelhart et al. (54) compared the LaserDoppler technique with an atraumatic epicutaneous Xenon application technique, the latter eliminating traumatic vasodilatation. They concluded that changes in blood flow as measured by the two methods were parallel in skin areas without shunt vessels. In skin areas with arteriovenous a nastomoses the Laser-Doppler method could not be calibrated against the epicutaneous Xenon method since the latter measures only capillary flow, whereas the Laser-Doppler seemed to measure blood flow in capillaries as well as in arteriovenous anastomoses. In normal subjects skin areas with and without arteriovenous anastomoses could be distinguished by Laser-Doppler measurements (121). Laser-Doppler flowmetry has already a wide-spread clinical applicability varying from measurements in patients with Raynaud's phenomenon (121) to monitoring the blood flow in skin flaps $(112,131)$.

\section{Capillary microscopy}

\section{Morphology}

Nutrient capillary blood flow and capillary morphology have been assessed by capillary microscopy. Historically, studies on nailfold capillaries initially focused on statical and morphological investigations. According to Gilje et al. (74), capillary microscopy of the nail-fold vessels was first attempted by Johan Christophorus Kollhaus as early as 1663 . In 1911 Lombard (147) wrote: 'with a drop of glycerine or transparant oil placed on the human skin, a remarkably beautiful picture of the superficial blood vessels can be obtained by using a microscope and strong light*. In the early thirties, L.Muller (173) described the capillary picture in vasomotor neuroses and the changes in velocity, periods of stasis and granular stream. In 1920, the functional properties of capillaries and venules were studied by Hooker (95). $\mathrm{He}$ concluded that the capillaries and venules were under sympathetic nervous control and that the peripheral resistance was not only determined by the arterioles but by capillaries and venules as well. One year later, Parrisius (183) studied the capillaries in patients with 'vasoneuroses'. By capillary microscopy he observed that in these patients, spastic and atonic phenomena could exist at the same time.

In his book 'Die Kapillaren der menschlichen Körperoberflächen', O. Müller (174) described different vasospastic and ischaemic phenomena as observed throught the microscope and illustrated this with beautiful pictures of the capillary bed. Concerning the pathophysiology of acrocyanosis he agreed with Parissius (183) that atony (dilatation) of intracutaneous veins could be simultaneously present with spasm (contraction) of the stibcutaneous veins ('spasticatonic symptom complex"). Raynaud's phenomenon was explained by $O$. Müller as a result of continuous changes of hyperirritability and paralysis of the micro-vascular structures. Tissue damage and gangrene were the result of longstanding spastic-atonic changes. In patients with 
scleroderma he observed tortuous and abnormal, enlarged capillary loops.

Around 1925, Brown (27) studied skin capillaries in normal subjects and in patients with Raynaud's phenomenon during the different color phases. He found disturbed capillary tone and abnormal flow or complete stasis of the capillary blood. According to Brown, the degree of these abnormalities determined the colour of the skin. The longer the cessation of capillary flow, the more pronounced the capillary dilatation was and the greater the carbon dioxide content of the capillary blood (cyanotic phase). The recovery (rubor phase) was due to resumption of capillary flow and partial recovery of capillary tone. Brown also found evidence of independent behaviour of the skin capillaries.

In the early fifties, Gilje et al. (74) used a microscope to study the pathological and physiological changes in the cutaneous vessels of patients with skin diseases like psoriasis, lichen planus, lupus erythematosus (L.E.), scleroderma, and acrosclerosis. In generalized scleroderma (without Raynaud's phenomenon) the nail-fold capillaries appeared to be normal. In acrosclerosis (with Raynaud"s phenomenon) the outer zone of capillaries was arranged regularly, but those behind this first row were arranged irregularly. Most capillaries were dilated and blood flow velocity was very low in these microvessels. Gilje concluded that capillary microscopical examination was a rapid, painless method to obtain additional diagnostic information in skin diseases.

Landau and Davis (128) compared the diameters of nail-fold and conjunctiva capillaries, as assessed microscopically, in patients with hypertension. Severe nail-fold capillary thinning was significantly correlated with severe conjunctival capillary thinning. The same authors examined the micro-wessels of the conjunctiva and nail-fold in patients with acrocyanosis and Raynaud's phemomenon (129). In acrocyanosis the conjunctival arterioles and venules were usually both of a similar orange hue, which was rare in Raynaud's phenomenon. In both phenomena the conjunctival vessels were generally unkinked and straight. In acrocyanosis the conjunctival capillaries often narrowed abruptly.

In the late sixties, Buchanan et al. (28) examined the nail-fold capillaries of normal subjects and of patients with a wide variety of disorders in which, clinically, changes in finger blood flow were likely to be present. They found haemorhages from and dilatation of the nailfold capillaries in the majority of cases of systemic lupus erythematosus, seleroderma and dermatomyositis. They hypothesized that the capillary wall is the site of antigen-antibody reaction and that such a reaction in connectivetissue disorders was responsible for the capillary damage.

Marcicq et al. described different capillary abnormalities in connective tissue diseases, like increased visibility of nailfold subpapillary plexus in rheumatoid arthritis, massive capillary dilatation in scleroderma-dermatomyositis, and focal loss of capillaries and prominence of subpapillary vessels with 'punched-out" lesions in systemic lupus erythematosus (153). They described the predictive and diagnostic value of in vivo capillary microscopy in patients with Raynaud's phenomenon, systemic sclerosis, dermatomyositis and other related disorders $(154,155,156,157,158,159,160)$. Their conclusion was that this non-invasive method was most suitable for following the microvascular pathology in early scleroderma and related disorders (160). 
This useful role of capillary examinations in evaluating Raynaud's phenomenon was also described by Harper et al. (87). They found that a bnormal capillaries indicated an increased risk for connective tissue disease and that normal capillaries favoured primary Raynaud's phenomenon.

In conclusion, it appears from all morphological studies that capillary microscopy can be used to study and differentiate between Raynaud's phenomenon with and without underlying disease.

\section{Dynamics}

In the last twenty years, nail-fold capillaries became subject of quantitative measurements, allowing non-invasive blood flow studies in nutritional skin capillaries.

In 1974 Bollinger et al. (14) introduced a non-traumatic and non-invasive method to measure red blood cell ( $\mathrm{RBC}$ ) velocity in human nail-fold capillaries. It was proposed as a technique for evaluating therapy and for dynamic and quantitative studies of the human microcirculation $(15,17)$. It consisted of obtaining a videotape recording of a capillary under microscopic obserwation and the measurement of the rate at which the plasma gaps between red cells advanced in the televised scene during a frame-byframe playback. In collaboration with Butti et al. (30) three methods were introduced to assess RBC velocity: I. a frame-by-frame analysis; 2 . a two-channel video densitometer which provided signals proportional to the average light level in two windows positioned upstream and downstream on the televised capillary and 3 . a direct on-line cross-correlation of the densitometer signals from the upstream and downstream windows. All three methods were found to yield average values well within the experimental error of the techniques. Intaglietta et al. (101) evaluated the technique of dual video window velocimetry and concluded that the data were comparable to the type of results obtained by direct photosensor methods.

Fagrell started his capillary investigations in patients with vascular disorders of the leg $(55,56,57)$ and in patients with systemic diseases $(58)$. In these studies he described the importance of evaluating local nutritional circulation by vital capillary microscopy. His microscope-television system (60) was used to study capillary flow behaviour after reactive hyperaemia $(59,61,62)$, and to monitor the effects of vasoactive drugs (64). He (63) and Butti et al. (3») also determined the effects of contralateral cooling on capillary blood flow velocity in healthy subjects. They concluded that postocclusive hyperemia response is a reliable parameter for the evaluation of circulation at the capillary level. Velocity patterns in nail-fold capillaries have been investigated in patients with Raynaud's phenomenon and acrocyanosis $(18,150)$. Bollinger et al. (18) concluded that evaluation of the skin capillary flow pattern and the changes in $\mathrm{RBC}$ velocity after local cold provocation permitted differentiation between primary Raynaud's phenomenon and acrocyanosis with a higher diagnostic accuracy than overall flow measurements. Mahler et al., who also investigated the blood flow velocity in nailfold capillaries (151), used a standardized locall cold exposure test for evaluation of the nail-fold capillary circulation in Raynaud's phenomenon (152) and with this test they could distinguish healthy subjects from patients with Raynaud's phenomenon. 
Beside capillary RBC velocity measurements, Bollinger et al. and Jager et al. $(20,2 \rrbracket, 106)$ also studied other dynamic parameters like permeability and transcapi:lary exchange in nail-fold capillaries. They used a fluorescence video microscope technique to quantitate transcapillary diffusion, pericapillary distribution and clearance of $\mathrm{Na}$-fluorescein in human skin microcirculation (20). Essentially the system consisted of a incident light fluorescence microscope, a sensitive video camera, a monitor, taperecorder and a video densitometer. After an intravenous bolus injection of $1 \mathrm{ml}$ of $20 \% \mathrm{Na}$-fluorescein the dye could be detected during its arrival in the skin area chosen for investigation. Bollinger et al. used this technique to study the microcirculatory changes in patients with Raynaud's phenomenon, scleroderma, diabetes and lymphedema $(19,23,24)$. In patients with long-term diabetes the transcapillary and interstitial diffusion was significantly enhanced. This transcapillary and interstitial passage was asymmetric and irregular in the giant capillary loops as found in microangiopathy due to scleroderma.

Franzeck et al. (69) studied the videodensitometric pattern of Na-fluorescein diffusion in nail-fold capillaries of patients with acrocyanosis, primary vasospastic and secondary Raynaud's phenomenon. Using such criteria as appearance time of the dye, way of distribution and structure of the pericapillary halo"s, the different ischaemic hand phenomena could be distinguished.

In conclusion, it appears from these studies that by the use of dynamic capillaroscopy the velocity of red blood cells as well as other variables can be measured in human skin capillaries under physiological and pathological conditions. Therefore, this method is especially useful in studying patients with microvascular disturbances.

\section{Haemorheology:}

Haemorheology is the study of flow properties of the blood. The viscosity of a fluid is mainly determined by the internal friction between adjacent layers of the fluid. The velocity differences between adjacent layers is a measure of the shearing within the flowing fluid and this velocity gradient is called the shear rate. The velocity of flow in the fluid and the shearing within the fluid are produced by a force which is called the shear stress (figure 3.1). The viscosity of the fluid is then defined as the ratio of shear stress and shear rate. An increase in viscosity will decrease the shear rate produced by a constant shear stress. The viscosity is expressed in dynes. $\mathrm{sec} / \mathrm{cm}^{2}$, which equals one poise or hundred centipoises ( $\mathrm{CP}$ ). In $\mathrm{S} \rrbracket$ units, the shear stress is expressed in pascals: one pascal being equivalent to 10 dynes $/ \mathrm{cm}^{2}$. The shear rate is expressed in $\mathrm{sec}^{-1}$ and the unit of viscosity is the Pascal second. One centipoise equals one millipascal second.

In a Newtonion fluid, the ratio of shear stress to shear rate is linear. However, blood is a non-Newtonion fluid which means that it requires a relatively larger force to move blood slowly than to move it fast. The viscosity of blood is shear-dependent and increases greatly with decreasing shear rate. At lower shear rates, red blood cells have an increased tendency to aggregate (202), which can be studied by direct microscopy, viscometry and photometry (201). At a given temperature the following fundamental 


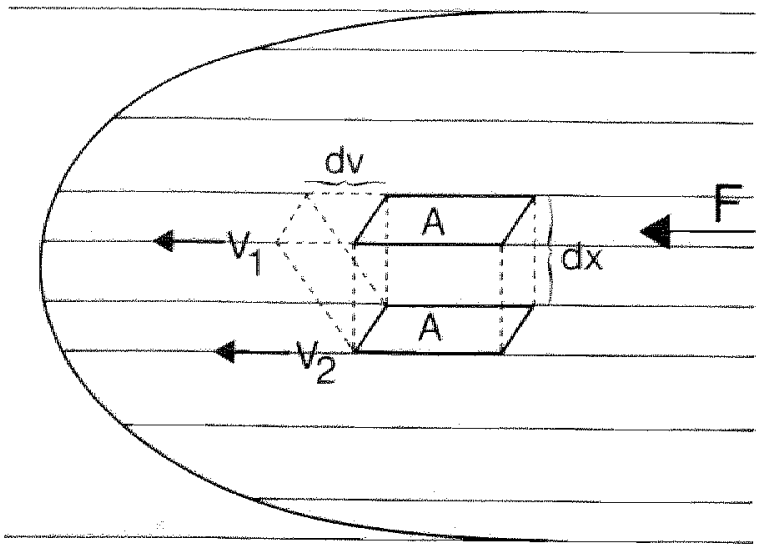

Shear rate $=$ velocity gradient $=\frac{d v}{d x}$

Shear stress $=$ Force per area $=\frac{F}{A}$

Viscosity $=\frac{\text { Shear stress }}{\text { Shear rate }}$

Figure 3.1 Cross section of a cylindrical tube showing the velocity profile in laminar flow.

mechanisms determine blood viscosity: 1) red blood cell (RBC) concentration; 2) plasma viscosity; 3) $\mathbb{R B C}$ aggregation and 4) $\mathrm{RBC}$ deformability.

The viscosity of blood can be measured in viscometers at different shear rates. It increases with increased plasma viscosity because of a complex interaction between the cells and plasma proteins. Fibrimogen and globulin, for example, influence plasma viscosity significantly (32), but serum albumin has little haemorheologic effects. Elevated fibrinogen and globulin levels are also responsible for the increased tendency of red blood cells to aggregate and form rouleaux at low shear rates. Red blood cells need to undergo considerable deformation in order to pass the capillary channels of the microcirculation, the diameter of which is frequently half the diameter of individual red blood cells. Reid et al. (194) developed a method to determine RBC deformability on the basis of a filtration technique, and measured $\mathbb{R} B C$ deformability in patients with peripheral vascular diseases.

The interest in the haemorheological behaviour of blood in patients with ischaemic hand phenomena was started by Pringle et al. (191) in 1965. Many others have shown interest in this aspect as was described in section 2.1.

Measuring RBC deformability, however, has only become possible recently because of methodological problems. The assessment of RBC deformability is still in its infancy with a wide variety of techniques and consequent lack of standardization of units of measurement. The possibility of reduced red blood cell deformability in Raynaud's phenomenon was first suggested by viscosity measurements of red blood 
cells in buffer (217). More direct measurements, filtering red blood cells suspended in their own plasma through $5 \mu \mathrm{m}$ diameter pores was reported by Dodds et al. (47). Considering the possible link between haemorheological abnormalities and Raynaud's phenomena the usual question inevitably arises as to whether the haemorheological changes are a cause or a consequence of the disease. Another important question concerns the clinical significance of the observations. In this study, haemorheological parameters were determined in order to investigate as to whether the different groups of patients could be distinguished on the basis of these investigations and whether these parameters could be used to evaluate treatment.

\subsection{Methods as used in this study}

In this section the methods are described as used to investigate the patients with vasospastic and ischaemic hand phenomena.

The standard investigations in all patients were the physical examination (3.2.1), and the blood (3.2.2), haemorheological (3.2.3) and capillary microscopic (3.2.4) investigations. Laser-Doppler (3.2.5), continuous wave Doppler (3.2.6) and thermography (3.2.7) were only used before and after treatment (chapter 5). Roentgenography (3.2.8) and angiography (3.2.9) were only performed when indicated.

\subsubsection{Physical examination}

After a complete clinical history, the extremities and digits were inspected carefully whenever Raynaud's phenomenon, acrocyanosis or asphyxia was suspected.

Permanent changes in colour, swellings, thickening and hardening of the skin, the condition of the nails, and the presence of lesions and ulcerations were carefully documented. A cold provocation test was used to observe the patient during an attack and to record the extent, nature and duration of the color changes during the attack. Occlusive arterial disease (atherosclerosis, M. Buerger) can be suspected by palpation of the radial and ulnar arteries, and by a well established Allen-test. In this test after occluding both arteries, the hand is made ischaemic and blood-empty by several times opening and closing the wrist. After opening the ulnar artery, the pattern and time of color change from white to red is observed. The same procedure is followed to test the radial artery. Using this Allen-test, obstructions in the radial, ulnar, and in the digita! arteries as well as in the volar arches can be detected.

Evidence of possible secondary factors was searched for. The reflexes were tested and other signs of neurologic disease were looked for (carpal tunnel syndrome, Pancoast tumor). To exclude a possible cervical rib or costo-clavicular compression synd rome, especially if vasospastic phenomena occurred unilaterally, the costo-clavicular, Adson or scalene, and hyperabduction maneuvers were performed.

The costoclavicular maneuver was performed with the patient in the sitting position with the hands resting on the legs. The radial pulse was examined and auscultation 
was performed over the infra or supraclavicular area, before and after the patient puts his shoulders backward and downwards, like in the military position. The maneuver is positive if the radial pulse diminishes or completely disappears and a bruit is heard ower the clavicular area. The Adson or scalene maneuver was performed with the patient in the same position. The patient was asked to take and hold a deep breath, to extend the neck as completely as possible and to turn the chin toward the side being examined. The radial pulse was palpated continuously and the subclavian artery auscultated (bruit). A positive Adson test (disappearance of the pulse and the occurence of a bruit) suggests compression in the costoclavicular space.

In the hyperabduction maneuver, the arm was hyperabducted and the change in amplitude of the radial pulsation, if any, was assessed. The axillary artery may be completely or incompletely compressed by this maneuver. In this case a bruit may be heard above or below the clawicle.

In all patients systolic and diastolic biood pressure was measured in both arms, using a standard blood pressure meter. The width of the cuff used in this study was $14 \mathrm{~cm}$.

\subsubsection{Blood investigation}

Routine laboratory investigations were the assessment of the haemoglobine, the number of red blood cells, leukocytes and thrombocytes, the protein spectrum, and fibrinogen and cholesterol contents. To detect possible autoimmune-diseases, the following tests were performed: immunoglobulines, antinuclear antibody (ANA), antinuclear factor (ANF), Rose, latex, lupus erythematosus (LE) -factor, cryoglobulins and cold agglutinins, using routine procedures.

\subsubsection{Haemorheology}

The blood viscosity determining parameters haematocrit (Hct), RBC aggregation and plasma viscosity were investigated.

Blood was taken from a vein in the cubital fossa without use of a tourniquet and collected in a non-siliconized tube, coated with 143 USP units sodium heparin (Monoject ${ }^{\text {(M) }}$.

Hot determinations were performed in capillary tubes which were centrifuged at $12.000 \mathrm{~g}$ for 3 minutes.

RBC aggregation $(\lambda)$ was determined with a cone-plate aggregometer (Type MAI) (203) after the haematocrit was corrected to $45 \%$. This system (figure 3.2 ) rotates the blood at a shear rate of $600 \mathrm{~s}^{-1}$ for 10 seconds, whereafter during 15 seconds the aggregation was determined by measuring the quantity of transmitted infrared light with photosensors. The signals were recorded on a digital display. The average aggregation was expressed in arbitrary units. On each blood sample 5 measurements were performed and the average value was assessed.

Plasma viscosity ( $\left.\eta_{0}\right)$ was measured with a capillary tube method (Coulter Harkness 


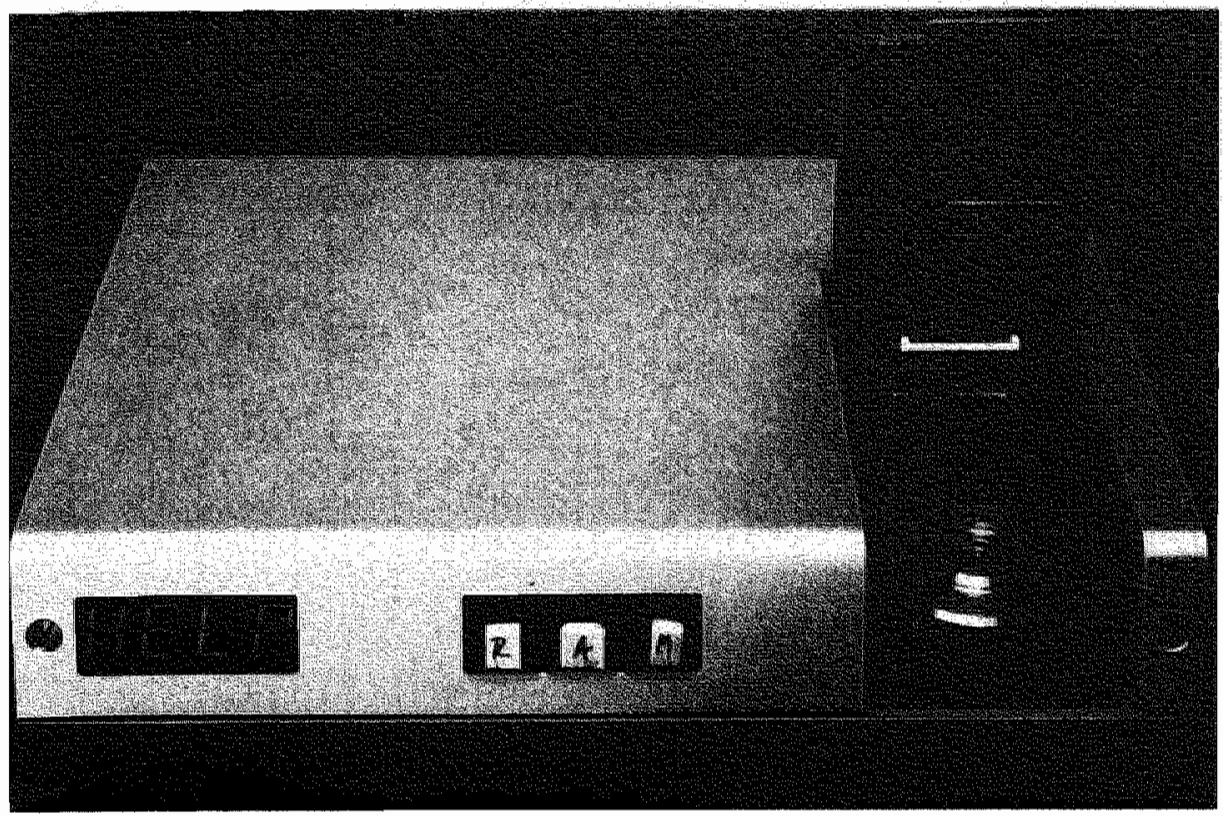

Figure 3.2 Cone plate aggregometer.

(B) at a temperature of $37^{\circ} \mathrm{C}$. The calibration factor was assessed by passing through the capillary a solution of $3.6 \%$ sodium chloride, the viscosity of which is $0.74 \mathrm{milli}$ Pascal seconds $\left(\mathrm{mPa}_{n} \mathrm{~s}\right)$ at $37^{\circ} \mathrm{C}$. On each plasma sample three measurements were performed and the average value was determined.

Red blood cell deformability was not measured since, at the time of this study, no reliable and reproducable clinically applicable methods were available.

\subsubsection{Capillary microscopy}

Before the investigations were started the patients acclimatized in a climate room with a constant temperature $\left(22^{\circ} \mathrm{C}\right)$ for 30 minutes. The fingers of the sitting patients were positioned on the stage of the microscope at heart level and fixed in a mass of clay. A drop of paraffin oil was applied to the nailfold to minimize reflections. Incident oblique illumination was done with a light guide and a condenser lens to focus the light on the nailfold. Angle and direction of illumination could be changed to minimize reflections. The fiber optics were coupled to a halogen lamp through a heat absorption filter. To enhance the contrast of the red blood cells a green filter could be used. The nail-fold capillaries were investigated using an intravital microscope (Leitz) (figure 3.3) with objectives $\mathrm{L} 4 \mathrm{x}$ (numerical aperture $\mathrm{NA}=0.04), \mathrm{L} 10 \times(\mathrm{NA}=0.22$ ) and $\mathrm{L} 20 \times(\mathrm{NA}=0.32)$. The images were displayed on $\mathrm{TV}$ monitor (Siemens) through a 


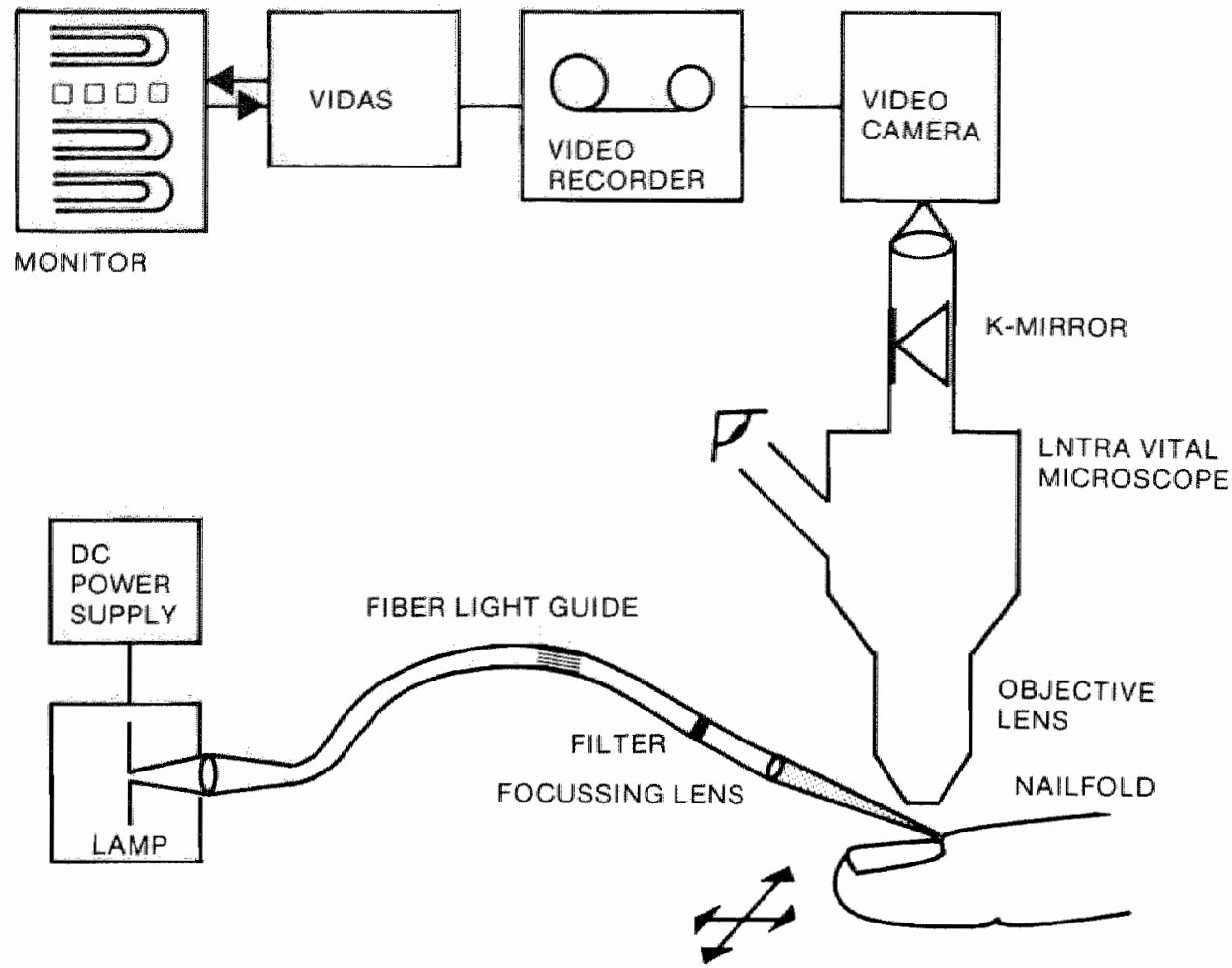

Figure 3.3 Schematic representation of the set up for dynamic capillaroscopy.

low light-level "TV camera (Bosch TYC 9/4, 1 inch SIT tube RCA 4804 HP). A $\mathrm{K}$-mirror was used to align the capillaries horizontally on the monitor. For off-line analysis, the images were stored on a videotape recorder (JVC-6060 E). The calculated interline spacing on the monitor was $5 \mu \mathrm{m}, 2 \mu \mathrm{m}$ and $1 \mu \mathrm{m}$ with the objectives $4 \mathrm{x}$, $10 \mathrm{x}$ and $20 \mathrm{x}$, respectively. Three or 4 nail-fold capillaries were randomly chosen in all fungers for diameter and $\mathrm{RBC}$ velocity measurements.

The following parameters were assessed:

1. the density (d) of the capillary loops in the nailfold. With objective $4 x$ the number of capillary loops in the distal row along the edge of the fold was counted. The density was expressed as the number of capillary loops per video screen. The video screen had an effective diameter of $1400 \mu \mathrm{m}$.

2. the diameters of the arterial (Da) and venular (Dv) limbs, and the crest (Dc) of the capillary loop, using the objective $20 x$ (figure 3.4). Diameters were expressed in micrometers. Because the capillary walls could not clearly be delineated, the diameters given refer to the dimensions of the red blood cell-column.

3. Red blood cell (R BC) velocity in the arterial limb of the capillary loop as measured with a video flying spot method $(26,222)$. In this technique a spot moving over the videoscreen is synchronized with the moving red blood cells or plasma gaps (figure 


\section{$\overrightarrow{\mathbf{a}} \mathbf{\mathrm { a }}$ \\ moving spots}

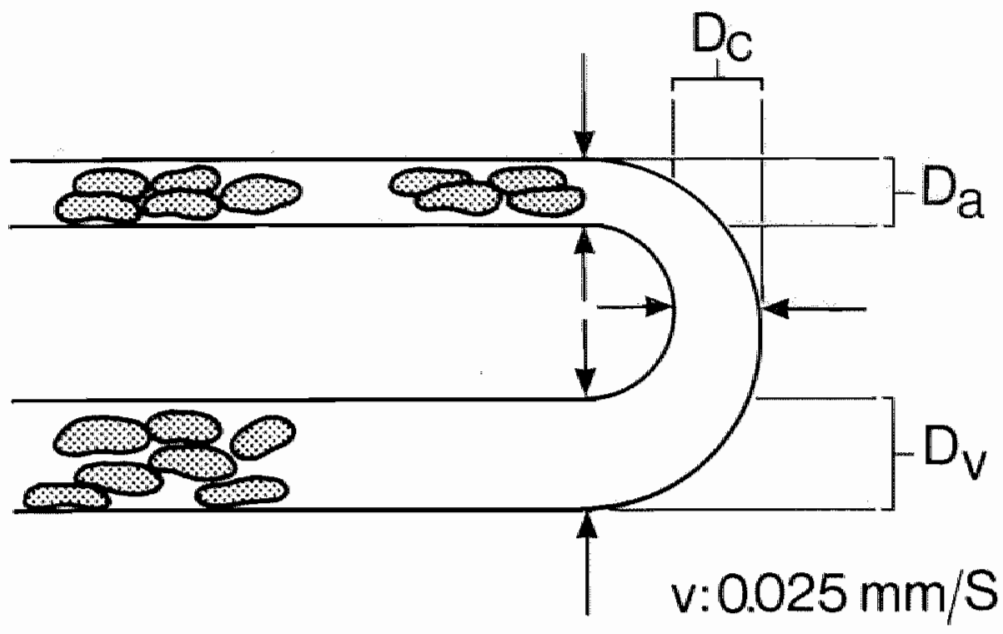

Figure 3.4 Capillary with arterial and venular limb and crest. Arrows indicate where the diameters of the arterial (Da) and venular (Dv) limbs, and the crest (Dc) of the capillary loop were measured. For $R B C$ velocity measurements, moving spots are synchronized with the moving red blood cells or plasma gaps whereafter the velocity is recorded on the videoscreen.

3.4). Per capillary, flow was recorded during about three minutes. In this period the velocity was measured every 20 seconds and the mean velocity per capillary was calculated thereafter. In each patient the median of all mean velocities as measured in the different capillaries, was used for data analysis. Due to magnification and image stability the maximum velocity that could be measured with the flying spot method was $1.300 \mathrm{~mm} / \mathrm{s}$. The advantage of this system is that very low $\mathrm{RBC}$ velocities can be measured accurately.

4. RBC velocity after cold provocation. The hands and fingers were immersed in water and ice for 2 minutes. Immediately after this cold provocation, $\mathbb{R} B C$ velocity was determined again and each 15 seconds thereafter till the velocity which was measured before cold provocation was reached. The velocity used for analysis was the median value of the mean velocities (see above) as measured during the first two minutes after cold provocation.

\subsubsection{Laser-Doppler}

Skin perfusion was assessed using a Periflux PF Id laser-Doppler vellocimeter (LDV). Light from a $2 \mathrm{~mW} \mathrm{He}-\mathrm{Ne}$ laser enters the skin and is backscattered from moving red 


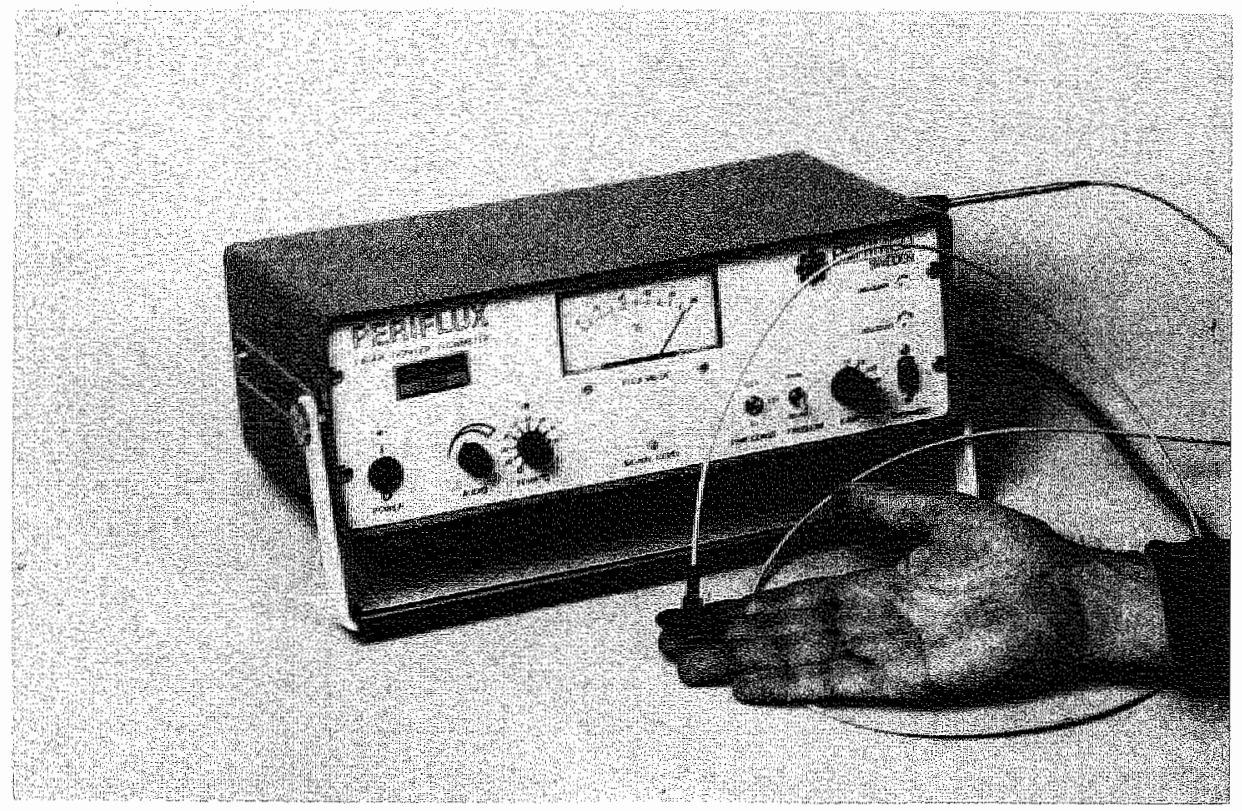

Figure 3.5 Periflux PF Id laser-Doppler how meter.

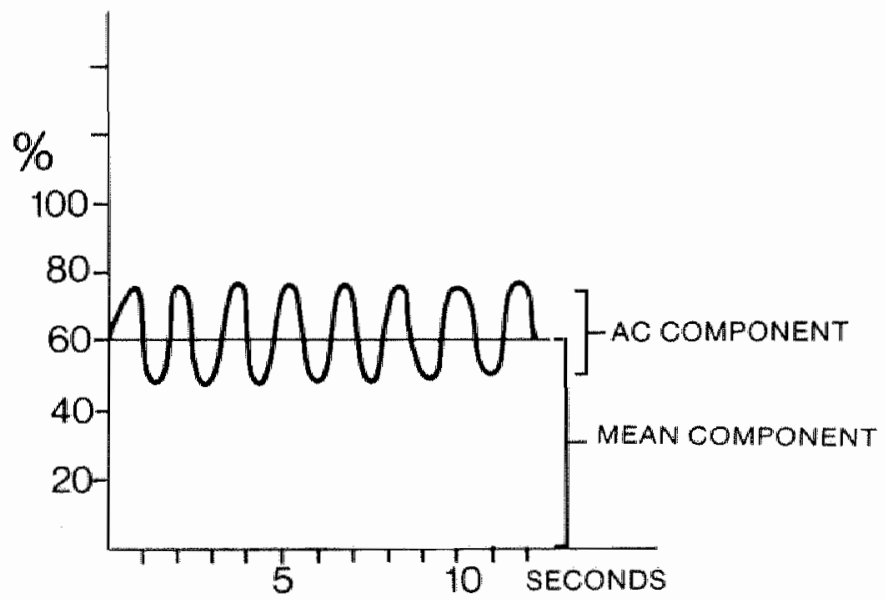

Figure 3.6 Laser-Doppler signal with $\mathrm{AC}$ and mean components. Vertical axis: flow value expressed in percentage of full scale, horizontal axis: time of reconding expressed in seconds.

blood cells or static skin structures. Light scattered from moving objects is shifted in frequency (Doppler shift) in proportion to the velocity of the moving target. Mixing at the surface of a photodetector the backscattered Doppler shifted light (from red blood cells) with light backscattered from the non-moving skin surface produces an optical beating or heterodyning frequency which is the Doppler-shifted frequency. 
All measurements were performed with an upper frequency limit of $12 \mathrm{kHz}$, an output circuit time constant of 1.5 seconds and a gain of $10 \mathrm{x}$.

After acclimatizing in the climate room (temperature $22^{\circ} \mathrm{C}$ ) the probe was positioned on the center of the distal phalanx at the volar site (figure 3.5 ). The probe was fixed into a light plastic probe holder. Registrations were made of all fingers.

The LDV signal was recorded for about $5-10$ seconds on a penrecorder the running velocity of which was $600 \mathrm{~mm} / \mathrm{min}$. The rhythmic oscillations in the tracings represent the heart synchronous changes in blood flow. All measurements are expressed as percentage of the full scale. As parameters, the $\mathrm{AC}$ - and mean components were determined, as well as the pulsatility index defined as the amplitude of the AC-component divided by the mean amplitude of the DC-component (figure 3.6).

\subsubsection{Continuous wave Doppler}

The continuous wave instrument uses a transducer containing two piezo-electrical crystals, one for continuous emission of ultrasound and one for subsequent reception of backscattered signals from mowing erythrocytes, containing information about their velocity. Velocity wave forms were recorded in the radial and ulnar arteries using a $8 \mathrm{MHz}$ bi-directional Doppler device with a zerocrossing circuitry. (Medasonics D-10@).

\subsubsection{Thermography}

The temperature of hands and fingers was determined with thermoplates (Leximed ${ }^{\left({ }^{\otimes}\right.}$ ). The principle of this technique is based on the light transmission properties of the cholesterol-fluid crystals in the plates, changing the colour of the plates as a function of temperature with an accuracy of $1^{\circ} \mathrm{C}$. Plates with different sensitivity intervals were used: $19-25,25-31$ and $30-36^{\circ} \mathrm{C}$. The temperatures of both hands and fingers were scored on a sheat.

\subsubsection{Roentgenography}

If, after physical examination, a thoracic outlet syndrome was suspected, a $X$-ray was performed of the chest and upper-chest aperture to prove or to exclude the existence of a first rib or cervical ribs. In patients suspected of progressive systemic sclerosis, an esophagus X-ray was performed.

\subsubsection{Angiography}

Angiography was performed if proximal compression or distal anatomical disturbances were suspected. Angiography of the upper extremities and of the hand and fingers 
was performed by the percutaneous trans-femoral catheterisation technique (Seldinger). The examination tecthique of this angiography has been described in detail by Janevski (109). The arteriograms were routinely studied by the subtraction technique.

\subsection{Statistical analysis}

In the tables, the data are presented as mean values (x) and standard deviations (s.d.). In the figures, schematic plots are used (163) because they exhibit an excellent visual summary of the data with preservation of the most important characteristics. A schematic plot (figure 3.7 ) shows the median, the interquartile range (i.e. the interval between the two values which include $25 \%$ and $75 \%$ of the population, respectively) and the range, minus the values which are straying out and the indefinite values, which are indicated separately. The Wilcoxon's signed ranks test (two tailed probability) was applied to evaluate differences within a group. To evaluate for statistical significance between two groups the Mann-Whitney test was used.

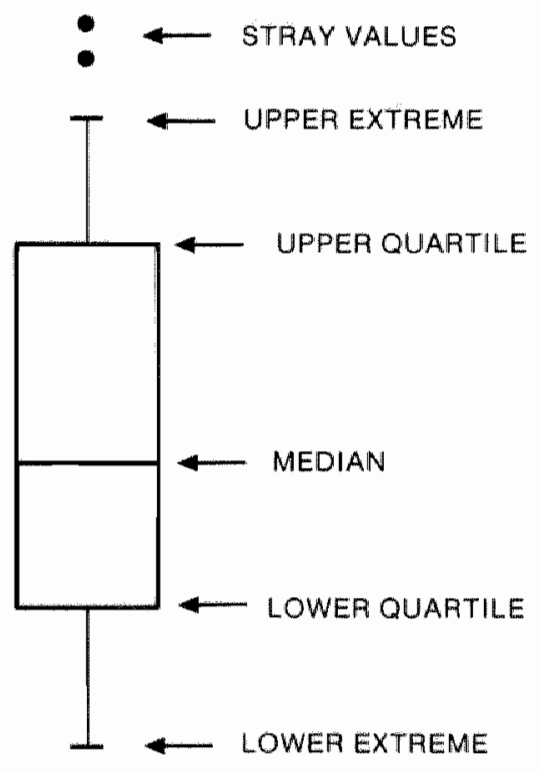

Figure 3.7 Schematic plot showing median, interquartile range (box) and range (upper and lower extreme), minus stray values. 


\section{Chapter 4}

\section{RESULTS AND NOMENCLATURE VASOSPASTIC AND ISCHAEMIC HAND PHENOMENA}

In this chapter the results are presented of the thaemorheological and capillary microscopic investigations for the normal subjects and the different groups of patients with vasospastic and ischaemic phenomena of hands and fingers.

\subsection{Results}

The results of the haemorheological and capillary microscopy investigations are separately presented for normal subjects and patients with primary Raynaud's phenomenon, secondary Raynaud's phenomenon, acrocyanosis and asphyxia manus et digitorum, respectively.

\section{Normal subjects}

Haemorheology

The results of haemorheological investigations are presented in table 4.1 and in the figures $4.1-4.3$. The mean value for the haematocrit was $42 \pm 3 \%, \mathrm{RBC}$ aggregation $17.41 \pm 2.37$ and plasma viscosity $1.22 \pm 0.06 \mathrm{mPa} . \mathrm{s}$.

Capillary microscopy

The data as obtained by capillary microscopy are shown in table 4.2 and figures 4.4-4.9. The mean density in the most distal row along the edge of the fold was 12

Table 4.1 Haemorheological parameters in normal subjects. $(\mathbb{N})$ and patients with primary Raynaud's phenomenon (PRP), secondary Raynaud's phenomenon (SRP), acrocyanosis $(A C)$ and asphyxia digitorum(AD). The mean values and standard deviations are presented.

\begin{tabular}{|c|c|c|c|c|c|}
\hline & $\mathbf{N}$ & PRP & SRP & $\mathrm{AC}$ & $\mathrm{AD}$ \\
\hline Haematocrit $(\%)$ & \pm 3 & \pm 2 & \pm 4 & \pm 4 & \pm 4 \\
\hline RBC aggregation & $17.41 \pm 2.37$ & $17.05 \pm 2.37$ & $26.16 \pm 2.73$ & $15.93 \pm 4.06$ & $19.92 \pm 4.07$ \\
\hline $\begin{array}{l}\text { Plasma viscosity } \\
(\mathrm{mPa} \cdot \mathrm{s})\end{array}$ & $1.22 \pm 0.06$ & $1.24+0.05$ & $1.64 \pm 0.18$ & $1.22+0.06$ & $1.26 \pm 0.14$ \\
\hline
\end{tabular}




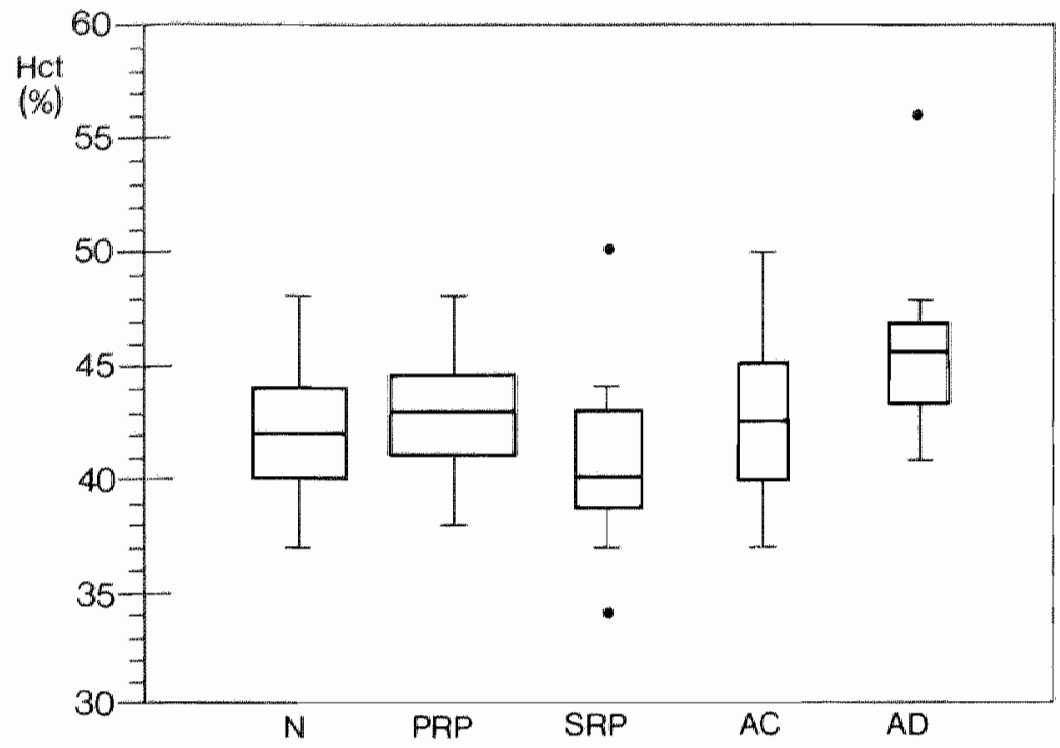

Figure 4.I Haematocrit (Hct) in normal subjects (N) and patients with primary Raynaud's phenomenon (PRP), secondary Raynaud's phenomenon (SRP), acrocyanosis (AC) and asphyxia manus el digitorum (AD), presented in box plots (for explanation see figure 3.7 ).

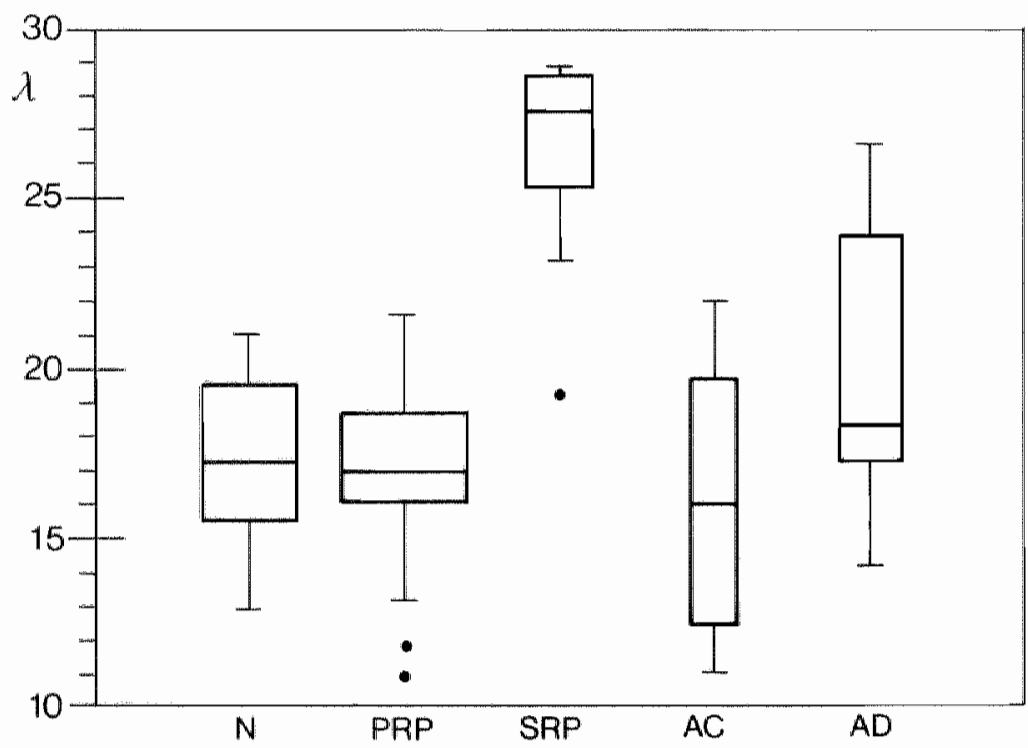

Figure 4.2 R BC aggregation ( $\lambda$ ) in normal subjects $(N)$ and patients with primary Raynaud's phenomenon (PRP), secondary Raynaud's phenomenon (SRP), acrocyanosis $(A C)$ and asphyxia manus et digitorum (AD), presented in box plots. 


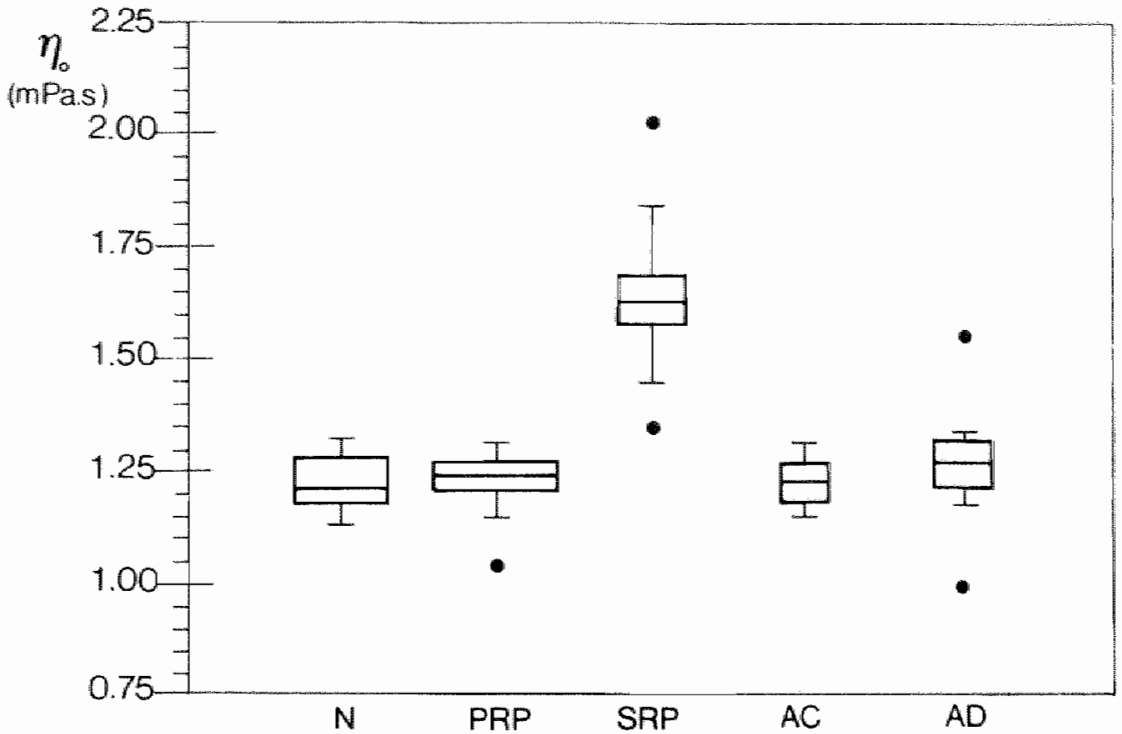

Figure 4.3 Plasma viscosity $\left(\eta_{0}\right)$ in normal subjects (N) and patients with primary Raynaud"s phenomenon (PRP), secondary Raynaud"s phenomenon (SRP), acrocyanosis (AC) and asplyxia manus et digitorum (AD), presented in box plots.

Table 4.2 Density and diameters of capillary loops, and R BC velocity before (C) and after cold provocation (CP) in normal subjects (N) and patients with primary (PRP) and secondary Raynaud"s phenomenon (SRP), acrocyanosis (AC) and asphyxia digitorum (AD). The mean values and standard deviations are presented.

\begin{tabular}{|c|c|c|c|c|c|c|c|c|c|c|}
\hline & $\mathrm{N}$ & & PRP & & SRP & & $\mathrm{AC}$ & & $\mathrm{AD}$ & \\
\hline $\begin{array}{l}\text { Density } \\
(m / w)\end{array}$ & $\llbracket 2$ & \pm 2 & 111 & \pm 1 & 4 & \pm 2 & 9 & \pm 2 & 11 & \pm 1 \\
\hline \multicolumn{11}{|l|}{$\begin{array}{l}\text { Diameter } \\
(\mu \mathrm{m})\end{array}$} \\
\hline $\mathrm{Da}$ & 12.9 & \pm 1.0 & 16.9 & \pm 3.7 & 59.1 & \pm 9.9 & 30,0 & \pm 8.5 & 13.1 & 1.8 \\
\hline Dv & 15.8 & \pm 1.8 & 18.5 & \pm 4.2 & 61.5 & \pm 9.8 & 34.6 & \pm 4.2 & 14.5 & $=2.1$ \\
\hline $\mathrm{Dc}$ & 16.9 & \pm 2.1 & 21.6 & \pm 5.4 & 66.9 & \pm 9.4 & 37.4 & \pm 6.3 & 16.5 & +2.6 \\
\hline
\end{tabular}

Velocity

$(\mathrm{mm} / \mathrm{s})$
C
$0.659 \pm 0.222$
$0.188 \pm 0.191$
$0.115 \pm 0.113$
$0.080 \pm 0.052$
$0.392 \pm 0.232$
CP
$0.163 \pm 0.125$
$0.032 \pm 0.031$
$0.025 \pm 0.020$
$0.018 \pm 0.015$
$0.100 \pm 0.114$

$\mathrm{n} / \mathrm{vs}=$ number of capillary loops per videosereen.

$\mathrm{Da}, \mathrm{Dw}, \mathrm{Dc}=$ diameter of arterial limb, venular limb and crest of the capillary loop. respectively. 


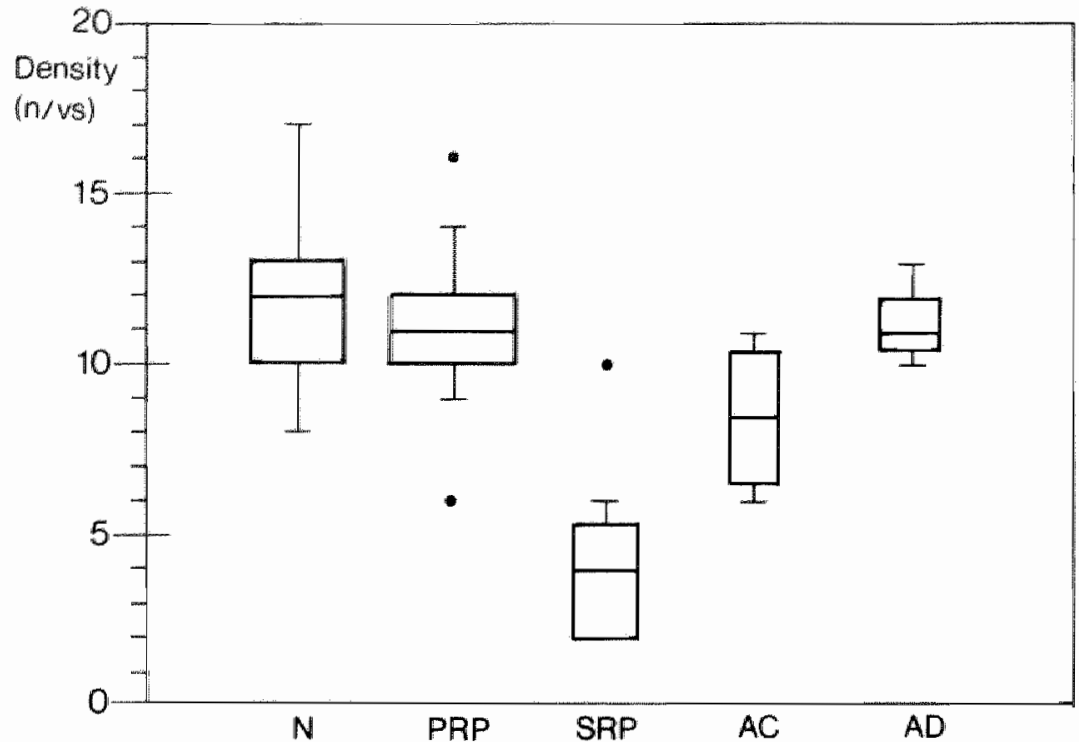

Figure 4.4 Density (d) in normal subjects (N) and patients with primary Raynaud's phenomenon (PRP), secondary Raynaud's phenomenon (SRP), acrocyanosis (AC) and asphyxia manus et digitorum (AD), presented in box plots.

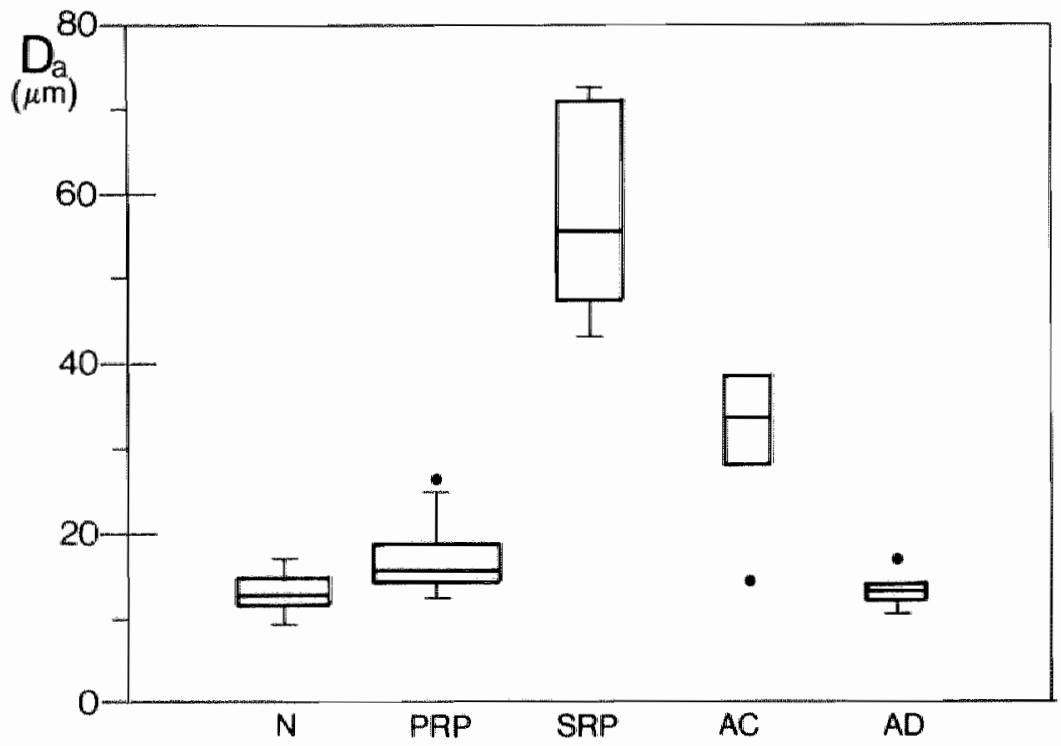

Figure 4.5 Arterial diameter ( Da) in normal subjects (N) and patients with primary Raynaud's phenomenon (PRP), secondary Raynaud's phenomenon (SRP), acrocyanosis. (AC) and asphyxia manus et digitorum (AD), presented in box plots. 


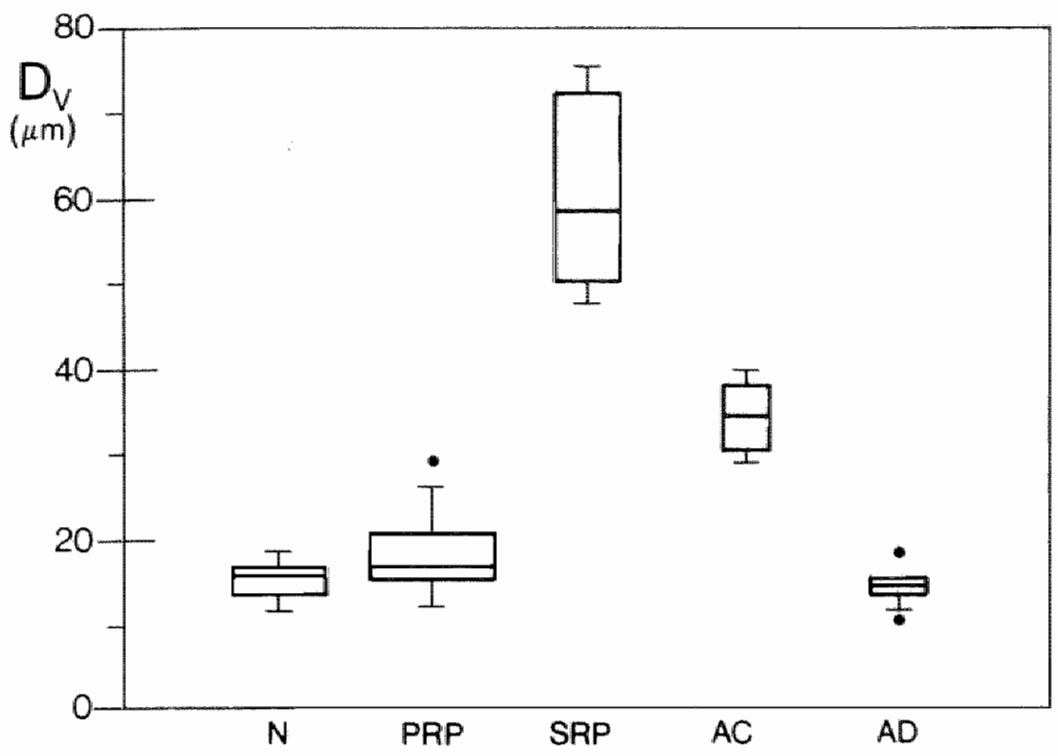

Figure 4.6 Venous diameter (Dv) in normal subjects (N) and patients, with primary Raynaud's phenomenon (PRP), secondary Raynaud's phenomenon (SRP), acrocyanosis (AC) and asphyxia manus et digitorum (AD), presented in box plots.

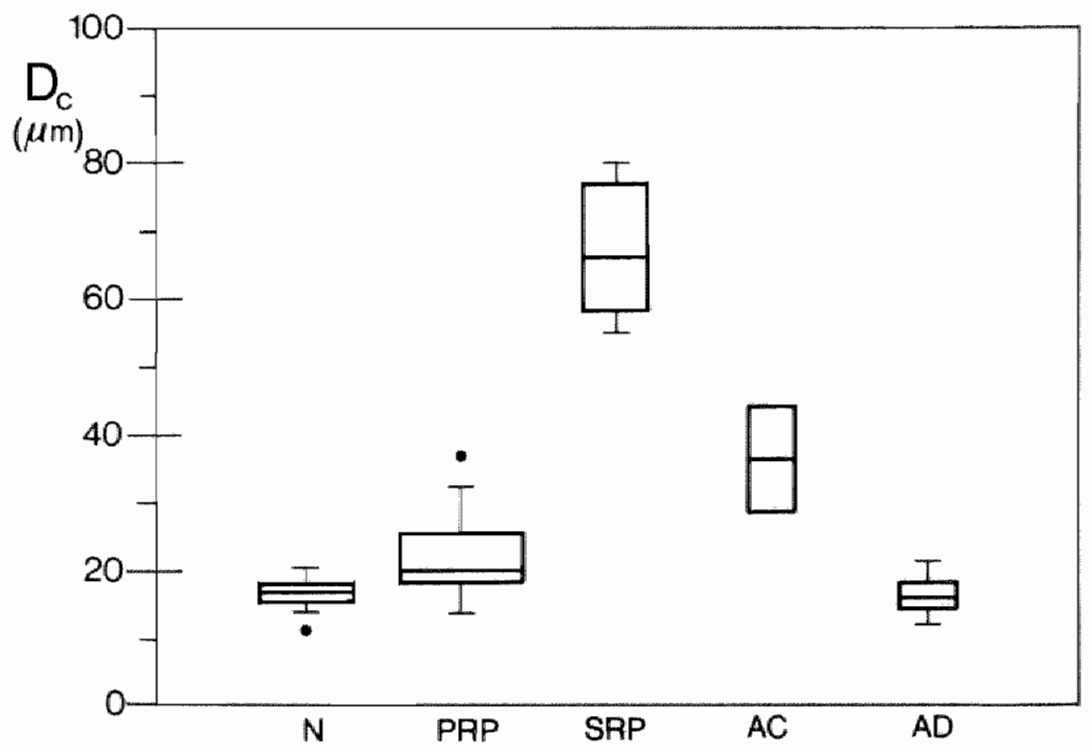

Figure 4.7 Diameter of the capillary crest (Dc) in normal subjects (N) and patients with primary Raynaud's phenomenon (PRP), secondary Raynaud's phenomenon (SRP), acrocyanosis ( $A C$ ) and asphyxia manus et digitorum (AD), presented in box plots. 


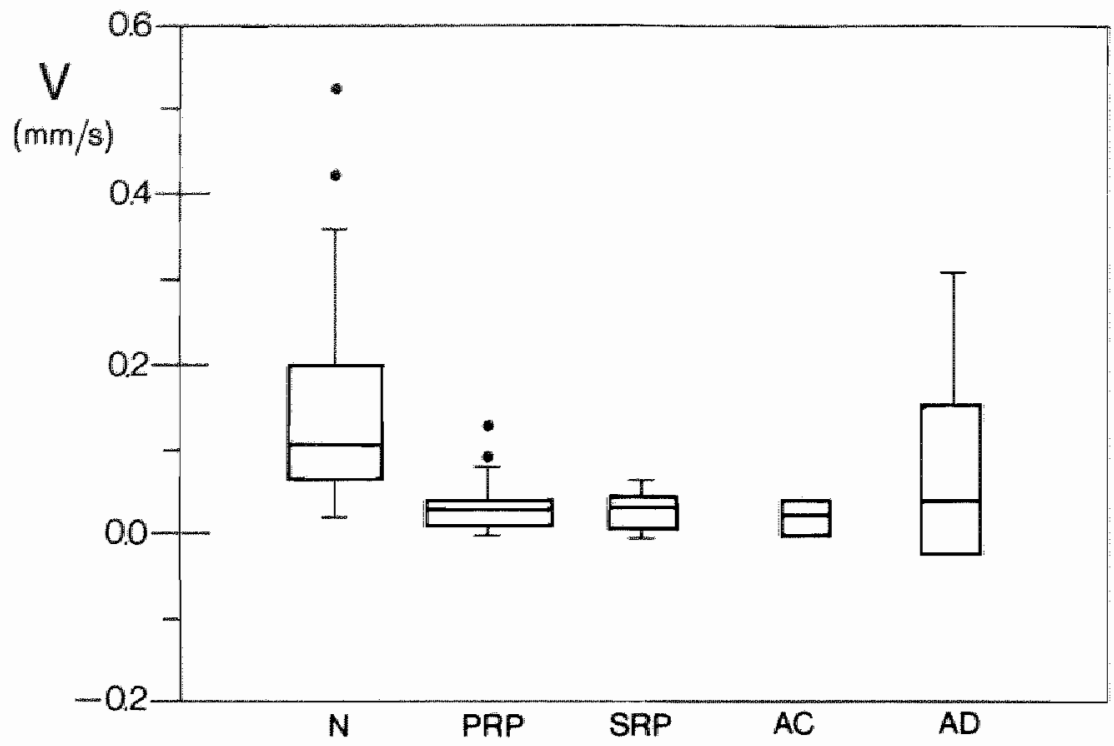

Figure 4.8 RBC velocity before (V) cold provocation in normal subjects (N) and patients with primary Raynaud's phenomenon (PRP), secondary Raynaud's phenomenon (SRP), acrocyanosis $(A C)$ and asphyxia manus et digitorum.

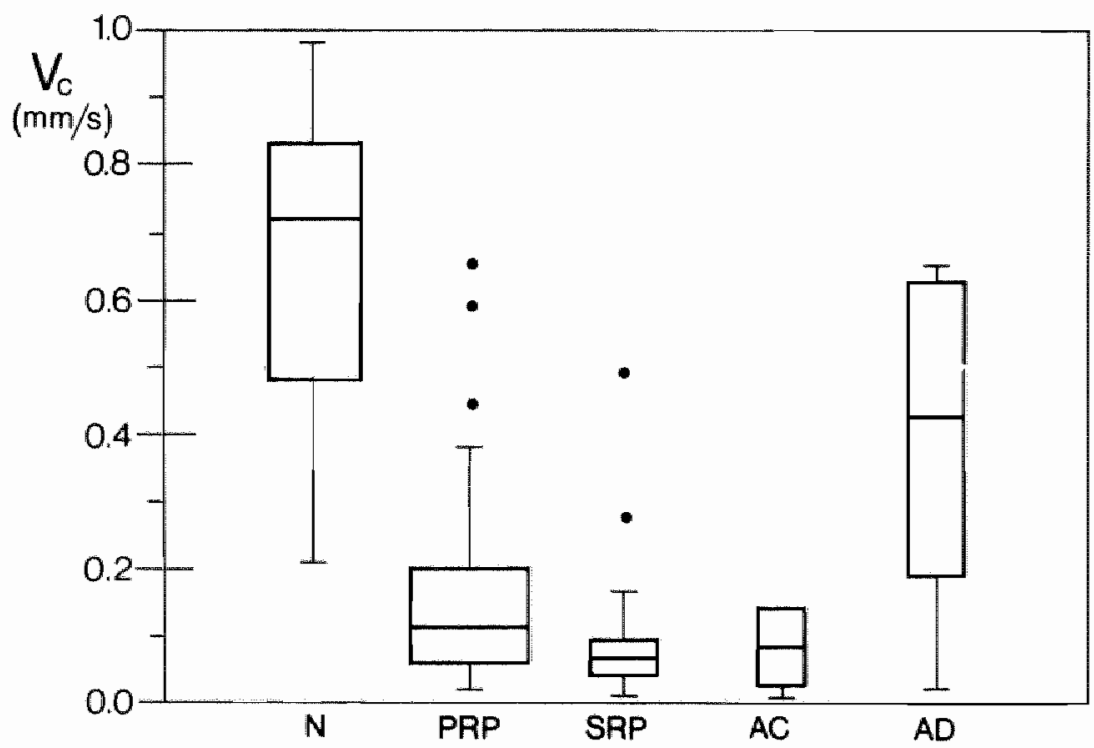

Figure 4.9 RBC velocity after cold provocation $(\mathrm{Vc})$ in normal subjects (N) and patients with primary Raynaud"s phenomenon (PRP), secondary Raynaud's plienomenon (SRP), acrocyanosis (AC) and asphyxia manus et digitorum. 
Table 4.3 Capillary microscopic variables and parameters in normal subjects (N) and patients with primary Raynad's phenomenon (PRP). The mean walues and standard deviations are presentod.

\begin{tabular}{|c|c|c|c|c|c|}
\hline \multirow[b]{2}{*}{ Density (n/vs) } & \multicolumn{2}{|l|}{$N$} & \multicolumn{2}{|c|}{ PRP } & \multirow{2}{*}{$\begin{array}{l}\text { Significanoe } \\
\text { n.s. }\end{array}$} \\
\hline & 12 & \pm 2 & $\|$ & \pm 1 & \\
\hline \multicolumn{6}{|l|}{ Diameter $(\mu \mathrm{m})$} \\
\hline Da & 12.9 & \pm 1.0 & 16.9 & \pm 3.7 & $p<0.001$ \\
\hline Dw & 15.8 & \pm 1.8 & 18.5 & \pm 4.2 & $p<0.001$ \\
\hline $\mathrm{Dc}$ & 16.9 & \pm 2.1 & 21.6 & \pm 5.4 & $p<0.001$ \\
\hline \multicolumn{6}{|l|}{ Nelocity $(\mathrm{mm} / \mathrm{s})$} \\
\hline $\mathrm{C}$ & \multirow{2}{*}{\multicolumn{2}{|c|}{$0.659 \pm 0.222$}} & \multicolumn{2}{|c|}{$0.188=0.191$} & $p<0.001$ \\
\hline $\mathrm{CP}$ & & & \multicolumn{2}{|c|}{$0.032 \pm 0.031$} & $p<0.001$ \\
\hline
\end{tabular}

Statistical difference was evaluated using the Manm-Whitney test (two tailled approximation).

capillaries per videoscreen. The mean diameter of the arterial limb of the capillary was $12.9 \pm 1.0 \mu \mathrm{m}$, of the venular limb $15.2 \pm 1.8 \mu \mathrm{m}$ and of the crest $16.9 \pm 2.1 \mu \mathrm{m}$. The mean $\mathrm{RBC}$ velocity was $0.659 \mathrm{~mm} / \mathrm{s}$ and $0.163 \mathrm{~mm} / \mathrm{s}$ after cold provocation.

\section{Primary Raynaud's phenomenon}

\section{Haemorheology}

In the group of patients with primary Raynaud's phenomenon, the haemorheological parameters (table 4.1) did not differ significantly from normal subjects. In these patients the mean value for the haematocrit was $43 \pm 2 \%$, for the RBC aggregation $17.05 \pm 2.37$ and for the plasma viscosity $1.24 \pm 0.05 \mathrm{mPa} . \mathrm{s}$.

Capillary microscopy

In primary Raynaud's phenomenon the density was about the same as in normal subjects (11 capillaries per videoscreen). The arterial $(16.9 \pm 3.7 \mu \mathrm{m})$, venular $(18.5 \pm$ $4.2 \mu \mathrm{m})$ and crest $(21.6 \pm 5.4 \mu \mathrm{m})$ diameters were all significantly $(\mathrm{p}<0.001)$ larger as compared to normal subjects (table 4.3). RBC velocity before $(0.188 \pm 0.191 \mathrm{~mm} / \mathrm{s}$ ) and after cold provocation $(0.032 \pm 0.031 \mathrm{~mm} / \mathrm{s})$ was significantly lower $(\mathrm{p}<0.001)$ as compared to normal subjects (table 4.3 ).

\section{Secondary Raynaud's phenomenon}

Haemorheology

Patients with secondary Raynaud's phenomenon had a normal haematocrit (41 \pm $4 \%)$ and a highly significantly increased ( $p<0.001) \mathrm{RBC}$ aggregation $(26.16 \pm 2.73)$ and plasma viscosity $(1.64 \pm 0.18 \mathrm{mPa}$.s.) compared to normal subjects (table 4.4 ) and the other groups of patients. 
Table 4.4 Haemorheological parameters of normal subjects (N), and patients with secondary Raynud"s phenomenon (SRP) and primary Raynud"s phenomenon (PRP). The mean values and standard deviations are presented.

\begin{tabular}{lllr}
\hline & Ne & SRP & PRP \\
\hline Hatmatocrit $(\%)$ & $42 \pm 3$ & $41 \pm 4$ & $43 \pm 2$ \\
RBCaggregation & $17.41 \pm 2.37$ & $29.16 \pm 2.73$ & $17.05 \pm 2.37$ \\
Plasma viscosity & $1.22 \pm 0.06$ & $1.64 \pm 0.18$ & $1.24 \pm 0.05$ \\
$(\mathrm{mPa} \cdot \mathrm{s})$ & & & \\
\hline
\end{tabular}

- Significantly different from N and PRP (Mann-Whitney test; $p<0.001$ ).

In table 4.4 these differences are shown for normal subjects and patients with primary and secondary Raynaud"s phenomenon. The degree of statistical difference between patients with secondary Raynaud's phenomenon and patients with acrocyanosis and aphyxia was at the same level. Figures 4.2 and 4.3 exhibit a visual summary of the data, showing the discrimination between patients with secondary Raynaud's phenomenon and the other groups of patients.

\section{Capillary microscopy}

In patients with secondary Raynaud's phenomenon the density was 4 capillaries per videoscreen, being significantly lower $(\mathrm{p}<0.01)$ as compared to all other groups. This indicates the existence of avascular areas in these patients.

The capillary loops in the terminal row were giant and extremely dilated and had a mean arterial, venular and crest diameter of $59.1 \pm 9.9 \mu \mathrm{m}, 61.5 \pm 9.8 \mu \mathrm{m}$ and $66.9 \pm$ $9.4 \mu \mathrm{m}$, respectively. Compared to all groups, these capillary diameters were highly significantly larger $(\mathrm{p}<0.001)$ without overlap with the other groups (figures 4.5-4.7). The arterial diameter (Da) appeared to be the best discriminator between the various

Table 4.5 Capillary microscopic variables and parameters in normal subjects $(\mathrm{N})$ and patients with primary (PRP) and secondary (SRP) Raynaud's phenomenon. The mean values and standard deviations are presented.

\begin{tabular}{|c|c|c|c|c|c|c|}
\hline \multirow[b]{2}{*}{ Density (n/vs) } & \multicolumn{2}{|l|}{$\mathrm{N}$} & \multicolumn{2}{|c|}{ SRP } & \multicolumn{2}{|c|}{ PRP } \\
\hline & 12 & \pm 2 & 4 & $\pm 2^{1.2}$ & $\|$ & \pm 1 \\
\hline \multicolumn{7}{|l|}{ Diameter $(\mu \mathrm{m})$} \\
\hline $\mathrm{Da}$ & 12.9 & \pm 1.0 & 59.1 & \pm 9.91 .2 & 16.9 & \pm 3.71 \\
\hline Dv & 15.8 & \pm 18 & 61.5 & $\pm 9.8^{1.2}$ & 18.5 & $\pm 4.2 \mathrm{i}$ \\
\hline $\mathrm{Dc}$ & 16.9 & \pm 2.1 & 66.9 & $\pm 9.4^{11.2}$ & 21.6 & \pm 5.41 \\
\hline \multicolumn{7}{|l|}{ Velocity $(\mathrm{mm} / \mathrm{s})$} \\
\hline C & \multirow{2}{*}{\multicolumn{2}{|c|}{$\begin{array}{l}0.659 \pm 0.222 \\
0.163 \pm 0.125\end{array}$}} & \multicolumn{2}{|c|}{$0.115 \pm 0.1131$} & \multicolumn{2}{|c|}{$0.188 \pm 0.1911$} \\
\hline $\mathrm{CP}$ & & & \multicolumn{2}{|c|}{$0.025 \pm 0.020^{\prime}$} & \multicolumn{2}{|c|}{$0.032 \pm 0.03$} \\
\hline
\end{tabular}

Significantly different from $N(p<0.001)$.

2 Significantly different from PRP $(p<0.001)$. 
phenomena (see A ppendix). Mean RBC velocity was $0.115 \pm 0.113 \mathrm{~mm} / \mathrm{s}$ before and $0.025 \pm 0.020 \mathrm{~mm} / \mathrm{s}$ after cold provocation.

In table 4.5 the data are shown, as well as the differences between normal subjects and patients with primary and secondary Raynaud"s phenomenon.

\section{Acrocyanosis}

\section{Haemorheology}

Haematocrit, RBC aggregation and plasma viscosity were not significantly different in patients with acrocyanosis and in normal subjects and patients with primary Raynaud's phenomenon (table 4.1).

\section{Capillary microscopy}

In patients with acrocyanosis the mean density was 9 capillaries per videoscreen which was significantly higher $(p<0.001)$ than in patients with secondary Raynaud's phenomenon, and significantly lower $(\mathrm{p}<0.01)$ than in normal subjects and patients with primary Raynaud's phenomenon.

The arterial, venous and crest diameters $(30.0 \pm 8.5 \mu \mathrm{m}, 34.6 \pm 4.2 \mu \mathrm{m}, 37.4 \pm 6.3 \mu \mathrm{m}$, respectively) of the capillary loops were significantly larger $(\mathrm{p}<0.001)$ compared to normal subjects and patients with primary Raynaud"s phenomenon, and significantly smaller $(\mathrm{p}<0.001)$ compared to patients with secondary Raynaud"s phenomenon. Mean $R B C$ velocity was $0.080 \pm 0.052 \mathrm{~mm} / \mathrm{s}$ before and $0.018 \pm 0.015 \mathrm{~mm} / \mathrm{s}$ after cold provocation.

Table 4.6 shows the increasing disturbances in capillary density and diameter in primary Raynaud's phenomenon, acrocyanosis and secondary Raynaud's phenom-

Table 4.6 Capillary microscopic variables and parameters in patients with primary (PRP) and secondary Raynaud's phenomenon (SR P) and acrocyanosis (AC). The mean values and standard deviations are presented.

\begin{tabular}{|c|c|c|c|c|c|c|}
\hline \multirow[b]{2}{*}{ Density ( $n / v s$ ) } & \multicolumn{2}{|c|}{ PRP } & \multicolumn{2}{|l|}{$\mathrm{AC}$} & \multicolumn{2}{|c|}{ SRP } \\
\hline & 11 & \pm 1 & 9 & \pm 211 & 4 & $\pm 2^{1.22}$ \\
\hline \multicolumn{7}{|l|}{ Diameter $(\mu \mathrm{m})$} \\
\hline $\mathrm{Da}$ & 16.9 & \pm 3.7 & 30.0 & \pm 8.51 & 59.1 & \pm 9.91 .2 \\
\hline Dv & 18.5 & \pm 4.2 & 34.6 & $\pm 4.2^{\prime}$ & 61.5 & $\pm 9.8^{1.2}$ \\
\hline Dc & 21.6 & \pm 5.4 & 37.4 & \pm 6.31 & 66.9 & $\pm 9.4^{11.2}$ \\
\hline \multicolumn{7}{|l|}{ Velocity $(\mathrm{mm} / \mathrm{s})$} \\
\hline C & \multicolumn{2}{|c|}{$0.188 \pm 0.191$} & \multicolumn{2}{|c|}{$0.080 \pm 0.052$} & \multicolumn{2}{|c|}{$0.115 \pm 0.113$} \\
\hline $\mathrm{CP}$ & \multicolumn{2}{|c|}{$0.032 \pm 0.031$} & \multicolumn{2}{|c|}{$0.018 \pm 0.015$} & \multicolumn{2}{|c|}{$0.025 \pm 0.020$} \\
\hline
\end{tabular}

1 Significantly different from PRP $(p<0.01)$.

1 Significantly different from PRP $(p<0.001)$.

22 Significantly different from $A C(p<0.01)$.

2 Significantly different from $A C(p<0.001)$. 
enon. RBC velocities before and after cold provocation did not differ significantly in these three groups.

\section{Asphyxia manus et digitorum}

\section{Haemorheology}

RBC aggregation and plasma viscosity did not differ significantly from normal subjects. The haematocrit was increased $(p<0.01)$ in this group of patients.

\section{Capillary microscopy}

Patients with asphyxia digitorum could not be distinguished from normal subjects with regard to the density and dia meters of the capillary loops (table 4.2). Compared to normal subjects, RBC velocity was not different in the non-affected fingers, in contrast with the $R B C$ velocity in the affected finger(s). In the latter fingers the mean $R B C$ velocity was $0.392 \pm 0.232 \mathrm{~mm} / \mathrm{s}$ before and $0.100 \pm 0.114 \mathrm{~mm} / \mathrm{s}$ after cold provocation. These velocities, before and after cold provocation, in the affected finger(s) were significantly lower $(p<0.05)$ compared to normal subjects and the non-affected fingers.

\section{Group comparisons}

\section{Haemorheology}

RBC aggregation and plasma viscosity were normal in all groups except in patients with secondary Raynaud's phenomenon in whom these parameters were significantly increased $(p<0.001)$. There was no overlap between patients with primary and secondary Raynaud"s phenomenon. The haematocrit was increased $(p<0.01)$ in patients with asphyxia digitorum.

\section{Capillary microscopy}

The capillary density was similar in normal subjects and patients with primary Raynaud's phenonemon and asphyxia. Compared to normal subjects this density was significantly decreased $(p<0.001)$ in patients with acrocyanosis.

The capillary density in patients with secondary Raynaud's phenomenon was highly significantly decreased ( $\mathrm{p}<0.001$ ) compared to normal subjects and all groups of patients, including patients with acrocyanosis. The capillary dia meters were similar in patients with asphyxia and in normal subjects. They were increased in patients with primary Raynaud's phenomenon $(\mathrm{p}<0.001)$ and even more increased in patients with acrocyanosis $(p<0.001)$. The most enlarged capillary diameters were found in patients with secondary Raynaud's phenomenon $(p<0.001)$.

$R B C$ velocity was significantly decreased $(p<0.001)$ in patients with primary Raynaud's phenomenon, secondary Raynaud's phenomenon, acrocyanosis, and in the affected finger(s) of patients with asphyxia digitorum $(p<0.05)$. These differences were also observed after cold provocation. 


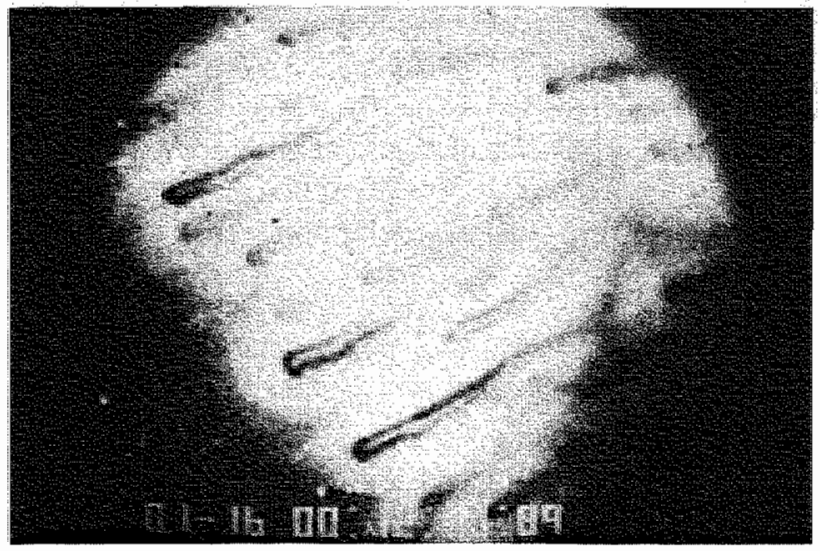

Figure 410 The capillary bed of a patient with primary Raynaud's phenomenon.

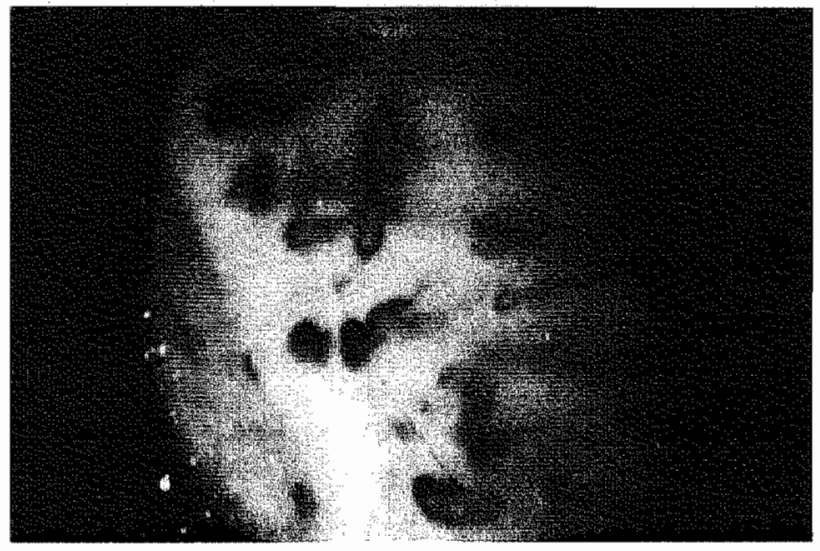

Figure 4.11 The capillary bed of a patient with acrocyanosis.

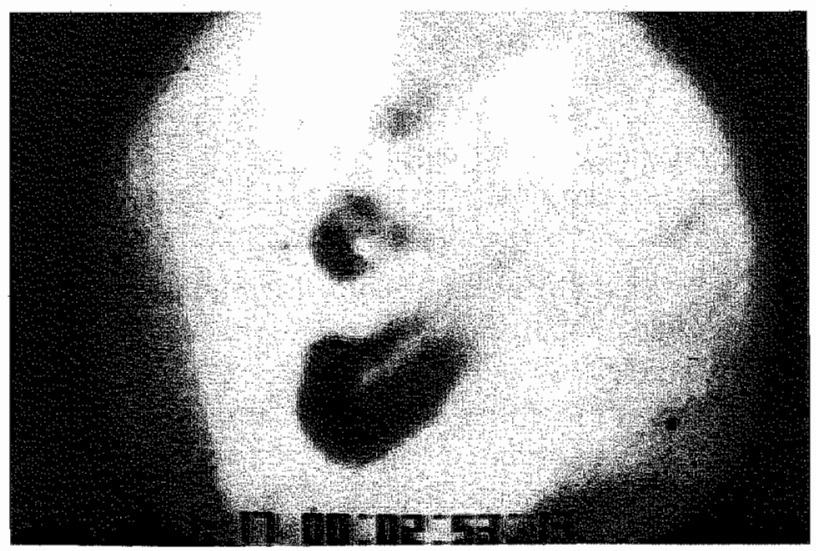

Figure 4.12 The capillary bed of a patient with secondary Raynaud's phenomenon. 
In figure 4.10 the capillary bed of a patient with primary Raynaud's phenomenon is shown, as seen through the microscope: evenly distributed capillaries with a density of 11 capillary loops per videoscreen. The diameter is slightly larger as compared to normal subjects. Figure 4.11 shows the capillaries of a patient with acrocyanosis: a lower density, but dilated capillaries. Figure 4.12 shows the capillary bed of a patient with secondary Raynaud's phenomenon, in which avascular areas can be seen with extremely dilated capillaries.

\subsection{Interpretation and discussion}

The findings in the present study show that patients with primary Raynaud's phenomenon, secondary Raynaud"s phenomenon, acrocyanosis and asphyxia manus et digitorum can be distinguished on the basis of haemorheological and capillary microscopic investigations. Combining the results of these methods it can be concluded that patients with primary Raynaud's phenomenon had evenly distributed but slightly dilated capillaries, in which $\mathrm{RBC}$ velocity was low as compared to normal subjects, especially after cold provocation. The haemorheological parameters were normal. In these patients, therefore, we have a vasospastic flow disturbance with slight capillaropathy and without rheopathy. Patients with secondary Raynaud's phenomenon had avascular areas with giant and extremely dilated capillaries with low RBC velocities. RBC aggregation and plasma viscosity were significantly increased. In these patients the flow disturbance is associated with marked capillaropathy and rheopathy. Patients with acrocyanosis showed dilated capillaries with low $\mathrm{RBC}$ velocities. The haemorheological parameters were not significantly different from normal subjects. The flow disturbance in these patients is associated with pronounced capillaropathy but not with rheopathy. In patients with asphyxia digitorum the capillary microscopic findings in the non-affected fingers were similar to those observed in normal subjects. However, RBC velocity before and after cold provocation was significantly lower in the affected than in the non-affected fingers. In these patients blood flow is intermittently diminished without capillaropathy or rheopathy. However, the haematocrit was increased. The differences between the various parameters as determined in these patients are schematically presented in table 4.7. By these objective parameters it is confirmed that the clinical differentiation of Lemmens (134) is relevant. This nomenclature can thus be used to differentiate between primary and secondary Raynaud's phenomenon, acrocyanosis and asphyxia manus et digitorum (see below).

As described in chapter 2.1. of this thesis, many haemorheological studies have been performed in patients with Raynaud's phenomenon, all be it with contradictary results, probably because in most studies the nomenclature was misused and no distinction was made between primary and secondary Raynaud"s phenomenon (with and without underlying disease). However, Jahnsen et al. (107) estimated that increased viscosity might be a causal factor in secondary forms of Raynaud's phenomenon, but does not seem to be an important factor in primary Raynaud's phenomenon. McGrath et al. (164) also concluded that hyperviscosity could help to distin- 
Table 4.7 Schematical representation of the haemorheological and capillary microscopic variables and parameters in the phenomena under investigation.

\begin{tabular}{|c|c|c|c|c|c|c|c|}
\hline & $d$ & $\mathrm{D}$ & $\mathrm{Kc}$ & $V_{\mathrm{cp}}$ & $\lambda$ & $\eta_{0}$ & $\mathrm{Het}$ \\
\hline Primary Raynaud & 0 & $0-1$ & 1 & 11 & 0 & 0 & 0 \\
\hline Secondary Raynaud & 4 & $\|$ & $\|$ & $\|$ & 1 & 1 & 0 \\
\hline Acrocyanosis & $!$ & 1 & $\downarrow$ & 11 & 0 & 0 & 0 \\
\hline Asphyxia digitorum & 0 & 0 & $0-1$ & 1 & 0 & 0 & $0-1$ \\
\hline $\begin{array}{l}\mathrm{d}=\text { density. } \\
\mathrm{D}=\text { diameter. } \\
\mathrm{V}_{\mathrm{c}}=\mathrm{RBC} \text { velocity, } \\
\mathrm{V}_{\mathrm{cp}}=\mathrm{RBC} \text { velocity } \\
\mathrm{A}=\mathrm{RBC} \text { aggregat } \\
\eta_{0}=\text { plasma viscos } \\
\mathrm{Hct}=\text { haematocrit. } \\
0=\text { normal. } \\
\quad=\text { increased. } \\
\quad=\text { decreased. }\end{array}$ & $\begin{aligned} \mathrm{r} \\
\mathrm{r}\end{aligned}$ & $\begin{array}{l}\text { tion. } \\
\text { vocat }\end{array}$ & & & & & \\
\hline
\end{tabular}

guish scleroderma from primary Raynaud's phenomenon.

Patients with primary Raynaud's phenomenon had normal haemorheological parameters suggesting that the impaired blood flow has no primary haemorheological cause. In these patients an underlying disease can not or not yet be detected. The discollouration after trigger-exposure is probably mainly caused by an enhanced adrenergic neurotransmitter mechanism (108) or sympathetic overactivity (185) and not influenced by haemorheological disturbances. The idea of sympathetic (hyper)activity is supported by the microscopic observations that the very low $\mathrm{RBC}$ velocities increased significantly after blocking the sympathetic activity (chapter 5.5).

However, patients with primary Raynaud's phenomenon can develop a secondary Raynaud's phenomenon. This evolution can be followed by capillary microscopy since morphological disturbances develop simultaneously with the clinical symptoms. Maricq et al. described this predictive and diagnostic value of capillary microscopy (154-160). They concluded that these non-invasive methods appeared most suitable for following the microvascular pathology in early scleroderma and related disorders (160). A case report of one of our patients can serve as an example: the patient was 38 years old and was referred to our out-patient department with complaints of Raynaud's phenomenon. No underlying disease could be detected and the haemorheological parameters and capillary morphology were normal; the diagnosis primary Raynaud's phenomenon was made. This patient, however, gradually developed complaints of a tough and tense skin with little non-healing ulcers, which after one year appeared to be caused by scleroderma (skin biopsy). Regular (every 3 months) haemorheological and capillary microscopic investigations during this year, showed increasingly disturbed haemorheological parameters, and extreme widening and diminished den- 
sity of the nailfold capillaries.

The morphological studies of the nailfold capillaries by intravital microscopy showed to be useful to distinguish all groups of patients. The differences between primary and secondary Raynaud's phenomenon have already been described by a variety of investigators (chapter 3.1). As observed through the microscope, the aggregated red blood cells moved very slowly through the extrem widened capillaries of patients with Raynaud's phenomenon. The abnormally dilated skin capillaries in scleroderma lead to a reduction in blood flow welocity and to low shear rates. Since the blood viscosity increases disproportionaliy with decreasing shear rate, the wiscous resistance will be abnormally high in these skin regions. In the presence of these low shear rates and the abnormal microvasculature, as found in patients with scleroderma, the elevated RBC aggregation and plasma viscosity likely further deteriorate the blood supply to the skin, especially after cold provocation which further increases local blood viscosity (68). Under these conditions local haemodynamic forces may be of insufficient magnitude to maintain flow, resulting in stasis, vascular obstruction and tissue ischaemia. A superimposed increased vasomotor tone, if any, will furt her deteriorate the microcirculation.

In patients with acrocyanosis, who complained of uni- or billateral permanent cyanosis of hands and fingers, all haemorheological parameters were normal. They could be distinguished from patients with primary Raynaud's phenomenon because of the significantly larger capillaries, in which the RBC velocities were very low. The pathophysiology of acrocyanosis remains still unclear, although different studies have suggested arterial $(139,208)$ or venous $(183,207)$ lesions as the underlying cause. The mechanism involved could be permanent vasospasm, mainly at the venular level. On the cause of the widening of the capillaries can only be speculative: chronic tissue hypoxia, decompensation of the capillary wall or swelling of endothelial cells? The already decreased $\mathbb{R B C}$ velocity is probably further diminished by widening of the capillaries.

Localized asphyxia is a result of morphological alterations of hand and/or finger arteries as can be visualized by angiography. It manifests as a sharply bordered white, or sometimes cyanotic, discolouration of the affected finger(s) or hand and is never symmetric. The local effects and clinical symptomatology of this disorder are completely different from those of Raynaud's phenomenon and should therefore be distinguished in the nomenclature. This can be illustrated by the fact that only in the affected finger(s) RBC velocity was significantly reduced, especially after cold provocation, while in the non-affected fingers these dynamic measurements were similar to normal subjects. The basic condition of asphyxia is a local vascular obstruction, with a, cold induced, superimposed vascular spasm. Digitus moriens $(132,134)$ or dying finger is a progressed phase of asphyxia digitorum and occurs if both digital arteries are occluded permanently and no collateral circulation can develop. 


\subsection{Nomenclature}

Although vasospasm is the overall mechanism in vasospastic and ischaemic hand phenomena, differentiating between these phenomena appears to be relevant. The basis for diagnosis, prognosis and evaluation of therapeutic results is an uniform nomenclature and an exact description of the different phenomena. This study shows that the following nomenclature can be used to define the different vasospastic and ischaemic phenomena of hands and fingers.

Primary Raynaud"s phenomenon mainly appears in females and is characterised by a symmetrical, painless, triphasic discolouration of hands and fingers, triggered by exposure to cold or emotional stress, in which no underlying cause is present.

Secondary Raynaud's phenomenon is a phenomenon in which the clinical symptoms are similar to those observed in primary Raynaud's phenomenon. In these cases the phenomenon is based on a proven underlying disease.

Acrocyanosis is a phenomenon in which uni-or bilateral permanent cyanosis of hands and fingers occurs and no underlying disease can be detected

Asphyxia manus et digitorum is characterised by a sharply bordered white, and sometimes cyanotic discolouration of one or more fingers or hand, especially after cold provocation. The underlying disease is obstructive digital artery disease. 



\section{Chapter 5}

\section{THERAPY}

\section{I Introduction}

The choice of treatment in patients with vasospastic and ischaemic hand phenomena depends on the severity of the complaints and the presence of an underlying disease. In mild cases of primary Raynaud's phenomenon it is generally sufficient to explain the phenomemon to the patient and to recommend the wearing of loose and warm clothing, and to avoid unnecessary cold exposure. The complete avoidance of tobacco should certainly be emphasized. Theoretically, the therapy of the different types of asphyxia digitorum and secondary Raynaud's phenomenon should primarily be causal and counteract the pathogenetic factors of atherosclerosis, trombo-angitis obliterans, collagen disease and so on. However, in many cases the underlying cause remains unknown and therapy is aimed at improving the impaired microcirculation. The number of therapies currently available is rather extensive $(42,86,167,189,196)$, but the results are still unsatisfactory. Drug therapy is successfully applied in only some $50 \%$ of the cases $(81)$. Vasodilators can act either directly by relaxing the smooth muscles in the blood vessel wall or indirectly by interfering with the action of the sympathetic nervous system (38). Treatment with prostaglandins (33) and reserpine $(179,186,188)$ has been proved beneficial in patients with Raynaud's phenomenon. A double blind trial showed the effectiveness of nifedipine in the management of Raynaud's phenomenon (197). Ehrly (53) treated patients with secondary Raynaud's phenomenon with Ancrod, a drug which lowers the plasma fibrinogen concentration, and found reduced ischaemic pain. Even beneficial effects of biofeed back $(71,77)$ and hypothalomotomy (118) have been described as approaches to therapy in patients with Raynaud"s phenomenon. The role of sympathectomy and plasmapheresis are discussed elsewhere in this chapter.

The main problem in this extensive range of therapy possibilities is critical evaluation of treatment, free from subjective impression or observer bias. Reliable objective parameters to evaluate the changes as induced by therapeutical intervention, should be used.

In this chapter, haemorheological and microcirculatory techniques, as described in chapter 3 , are used to evaluate the effects of two vasoactive drugs, plasmapheresis and stellate ganglion blockade. It was the aim to investigate the applicability of these parameters in objectivating subjective changes as induced by therapy and not to evaluate the efficacy of either treatment. 


\subsection{Ketanserin}

\subsubsection{Introduction}

Since serotonin (5-HT) has a constrictive effect on smooth muscle cells of larger arteries it has been suggested (84) to play a role in the aetiology of Raynaud's phenomenon. Therefore, $5-H T_{2}$ receptor antagonists might benefit patient's suffering from this phenomenon.

In the present study we investigated the effectiveness of ketanserin, a 5-HT, receptor antagonist with appreciable affinity for $\alpha_{1}$ adrenoceptors (117), in the treatment of patients with Raynaud's phenomenon. The possible subjective changes as induced by the treatment were objectivated by correlating these changes with variables and parameters as obtained by haemorheological and microcirculatory techniques.

\subsubsection{Patients and methods}

Twelve women and 3 men with Raynaud's phenomenon (mean age 45 years, range 38-61 years) were examined before and after treatment. Ten patients had primary Raynaud's phenomenon: a symmetrical triphasic discolouration of the hands and fingers triggered by exposure to cold or emotional stress without detectable underJying disease. Five patients had secondary Raynaud's phenomenon: the same symptoms as in primary Raynaud's phenomenon, but on the basis of proven underlying disease, in this case progressive systemic sclerosis. The lapse of time since the first symptoms varied from 3 to 30 years. Nine patients underwent sympathectomy, at least one year prior to this study. The patients did not smoke nor took other medication. The study was performed from december 1982 till february 1983. During these months, the outdoor temperature did not change significantly.

Subjective findings. The patients were asked whether they benifited by the treatment with ketanserin, using their description of general well being and the temperature of hands and fingers as well as the reaction upon cold provocation as criteria. They were also asked for adverse reactions.

The following objective methods were used to evaluate the effectiveness of ketanserin (for details the reader is referred to section 3.2):

Capillary microscopy. Capillary diameters and $\mathrm{RBC}$ velocity before and after cold provocation were determined by capillary microscopy (3.2.4). Due to magnification and image stability the maximum velocity that could be measured was $0.650 \mathrm{~mm} / \mathrm{s}$. Velocities above $0.650 \mathrm{~mm} / \mathrm{s}$ were scored as $>0.650 \mathrm{~mm} / \mathrm{s}$.

Haemorheology. The haemorheological parameters haematocrit (Hct), RBC aggregation $(\lambda)$ and plasma viscosity $\left(\eta_{0}\right)$ were determined (3.2.3).

Thermography. The temperature of hands and fingers was determined with thermoplates (3.2.7).

Contimuous wave Doppler. Velocity wave forms were recorded in the radial and 
ulnar arteries (3.2.6).

Blood pressure and heart rate. Systolic and diastolic blood pressure were measured in both arms using a standard cuff technique (3.2.1).

Statistical analysis. Differences between the values of the objective variables and parameters before and after treatment and the effect of cold provocation (see below) were evaluated for statistical significance, using Wilcoxon's signed ranks test (two tailed probability). The objective findings in the respondents and non-respondents (see results) were compared and evaluated for statistical significance using the MannWhitney test.

Protocol. After acclimatizing in a climate room with constant temperature $\left(22^{\circ} \mathrm{C}\right)$ and humidity for 30 minutes, the variables and parameters were measured (control situation $=c$ ). Then the hands and fingers were immersed in water and ice for 2 minutes. Immediately after this cold provocation, $\mathrm{RBC}$ velocity was determined (3.2.4). Then the patients received a single orall dose of $40 \mathrm{mg}$ ketanserin (Chemical name: 3-2-4-(4-fluorobenzoyl)-I-piperidinyl ethyl 2,4 (1H, 3H)-quinazolinedione). Except for the cold provocation test, all measurements were repeated one hour later (situation after 1 hour $=1 \mathrm{~h}$ ). After three weeks ketanserin, $40 \mathrm{mg}$ twice a day, all measurements, as in the control situation, were performed again (situation after 3 weeks $=3 \mathrm{w}$ ).

\subsubsection{Results}

Subjective findings. One hour after a single dose of ketanserin (40 mg), 13 of the 15 patients claimed explicit improvement: warm and painless hands $s_{\text {, }}$ and a general sense of well-being. Six patients complained of light dizziness.

After 3 weeks of ketanserin treatment, 6 patients reported permanent improvement ('respondents"), which meant permanently warm hands during the three weeks of treatment, while Raynaud's phenomenon, especially the reaction upon the regular daily cold provocation, had disappeared or the number of attacks was reduced remarkably.

Nine patients had the same complaints as before treatment ("non-respondents'). These patients reported that the beneficial effects of ketanserin had already disappeared two days after starting treatment.

Adverse reactions after three weeks of Ketanserin treatment were a dry mouth and transient dizziness in 12 patients. Dizziness was noticed one hour after taking Ketanserin.

No differences as far as the acute or long term effects are concerned, could be demonstrated between patients with primary or secondary Raynaud"s phenomenon. The respondents were 3 of the 10 patients with primary Raynaud"s phenomenon and 3 of the 5 patients with secondary Raynaud's phenomenon.

Capillary microscopy. RBC velocity before and after treatment is shown in table 5. I and figure 5.1 . The median $\mathrm{RBC}$ velocity in the control situation was $0.096 \mathrm{~mm} / \mathrm{s}$ which decreased significantly to $0.015 \mathrm{~mm} / \mathrm{s}$ after cold provocation. The median 
Table 5. RBC velocity (min/s) belore (c) and after cold prowocation (cold pr.) and one thour after angle aral dose of $40 \mathrm{mg}$ Ketanserin. The median walues and $95 \%$ limits are presented.

\begin{tabular}{|c|c|c|c|}
\hline & \multicolumn{2}{|c|}{ Before treatment } & \multirow{2}{*}{$\frac{\text { After treatment }}{1 \text { hour }}$} \\
\hline & $c$ & cold pr. & \\
\hline $\begin{array}{l}\mathrm{RBC} \text { velocity } \\
(\mathrm{mm} / \mathrm{s})\end{array}$ & $\begin{array}{l}0.096 \\
(0.0400 .160) \\
L_{p<0.00} 00\end{array}$ & $\begin{array}{c}0.015 \\
(0.0050 .035)\end{array}$ & $\begin{array}{l}>0.650 \\
(0.280->0.650)\end{array}$ \\
\hline
\end{tabular}

$\mathbb{R B C}$ velocity had increased significantly (in nearly all measurements above 0.650 $\mathrm{mm} / \mathrm{s}$ ) one hour after a single dose of ketanserin. After 3 weeks of treatment the median velocity before and after cold provocation was still increased as compared to the control situation $(0.29 \Perp \mathrm{mm} / \mathrm{s}, 0.054 \mathrm{~mm} / \mathrm{s}$ respectively). Unlike in the nonrespondents, in the respondents the $\mathrm{RBC}$ velocity before and after cold provocation remained significantly higher after 3 weeks of treatment as compared with the control

Table 5.2 Influence of Ketanserin treatment (40 mg twice daily for 3 weeks) on RBC velocity $(\mathrm{mm} / \mathrm{s})$ : respondents versus non-respondents. The median vallues and $95 \%$ limits are presented.

Before treatment After treatment

cold pr. cold pr.

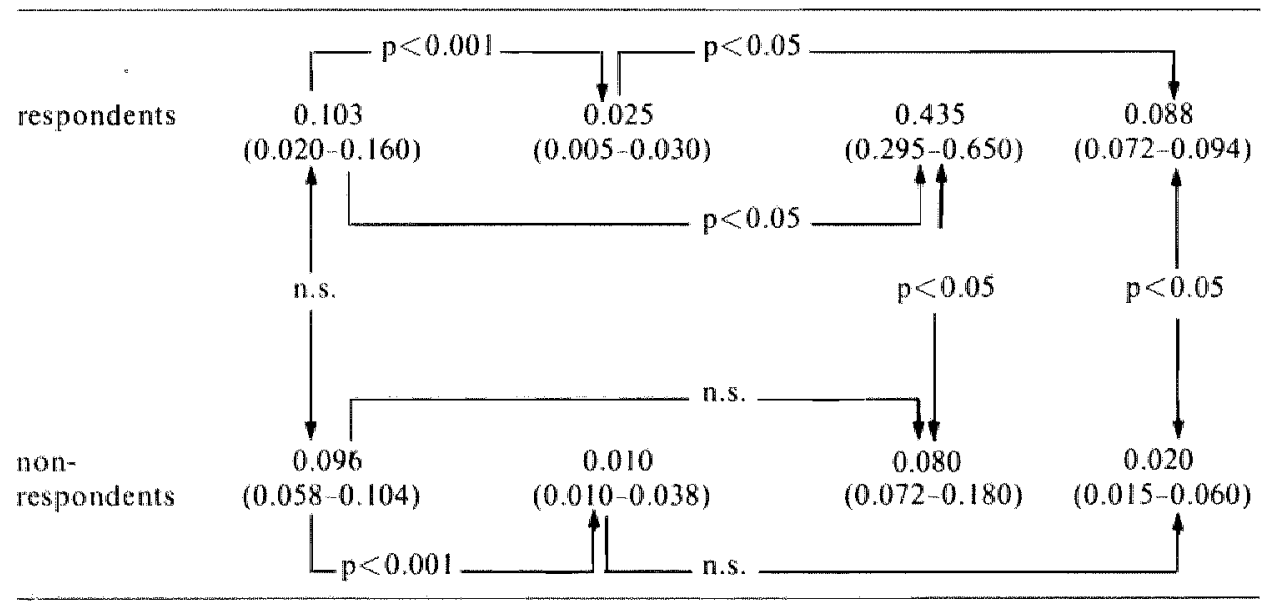

c $=$ control.

cold pr. = cold provocation. 


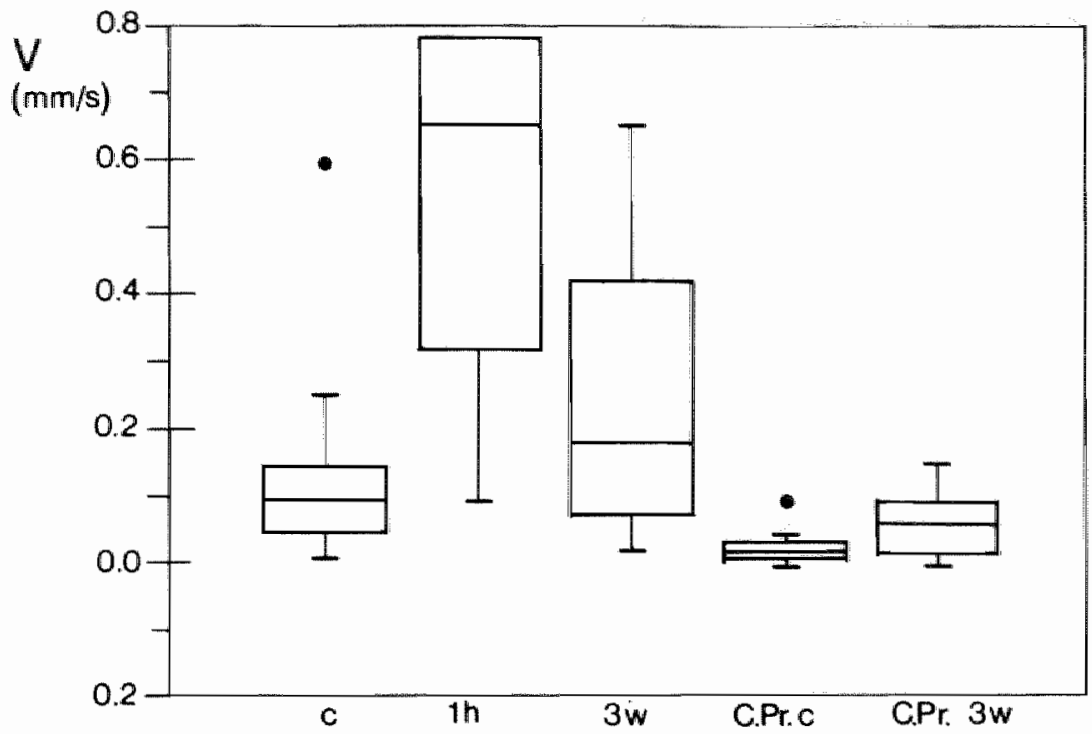

Figure 5.l RBC velocity in control situation (c), and after I hour $(\mathrm{lh})$ and 3 weeks $(3 \mathrm{w})$ Ketanserin treatment. The $\mathrm{RBC}$ velocity after cold provocation in control situation (C.Pr.c) and after 3 weeks Ketanserin treatment (C.Pr. $3 w$ ) is presented as well (for explanation see figure 3.7 ).

situation (table 5.2). These velocities were significantly higher in the respondents than in the non-respondents.

The arterial and venous diameters of the capillaries did not significantly differ before and after treatment.

Haemorheology. The haemorheological data are shown in table 5.3. R BC aggrega-

Table 5.3 The effect of Ketanserin on Haematocrit $(\mathrm{Hct}), \mathrm{RBC}$ aggregation $(\lambda)$ and plasma viscosity $\left(\eta_{0}\right)$ in patients with primary (Group 1: $n=10$ ) and secondary (Group 2: $n=5$ ) Raynaud's phenomenon. The mean values and standard deviations are presented.

\begin{tabular}{lccc}
\hline Group I: & c. & lh. & 3 w. \\
\hline Hct $(\%)$ & $43.5 \pm 3.3$ & $43.5 \pm 3.4$ & $43.4 \pm 3.9$ \\
$\lambda$ & $16.77 \pm 3.62$ & $16.51 \pm 3.24$ & $16.291 \pm 3.73$ \\
$\eta_{0}(\mathrm{mPa} \cdot \mathrm{s})$ & $1.24 \pm 0.06$ & $1.25 \pm 0.05$ & $1.24 \pm 0.04$ \\
\hline Group 2: & & & \\
\hline Hct $(\%)$ & & & $43.4 \pm 4.1$ \\
$\lambda$ & $44.2 \pm 4.4$ & $43.8 \pm 4.3$ & $21.97 \pm 4.93$ \\
$\eta_{01}(\mathrm{mPa} \cdot \mathrm{s})$ & $23.12 \pm 3.41$ & $24.26 \pm 3.29$ & $1.43 \pm 0.15$ \\
\hline
\end{tabular}

1 Significantly different from the values in Group $2(p<0.001)$.

$c=$ control siltuation. 


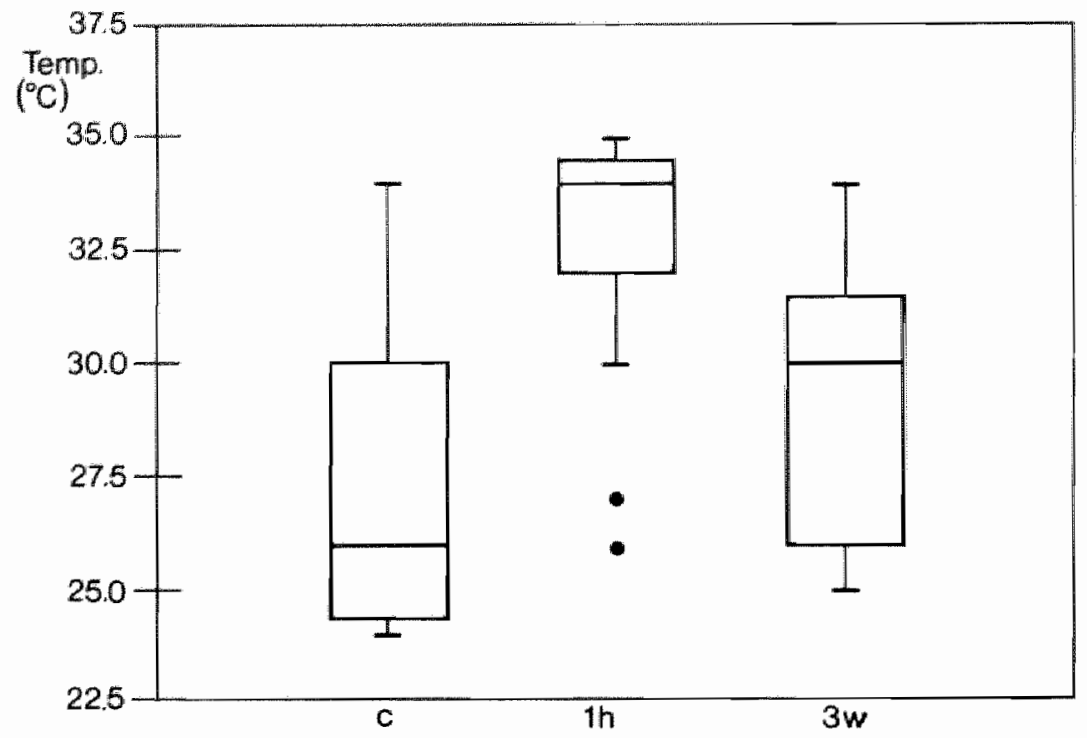

Figure 5.2 Skin temperature in control situation (c) and after 1 howr (1h) and 3 weeks ( $3 w$ ) Ketanserin treatment, presented in box plots (see figure 3.7).

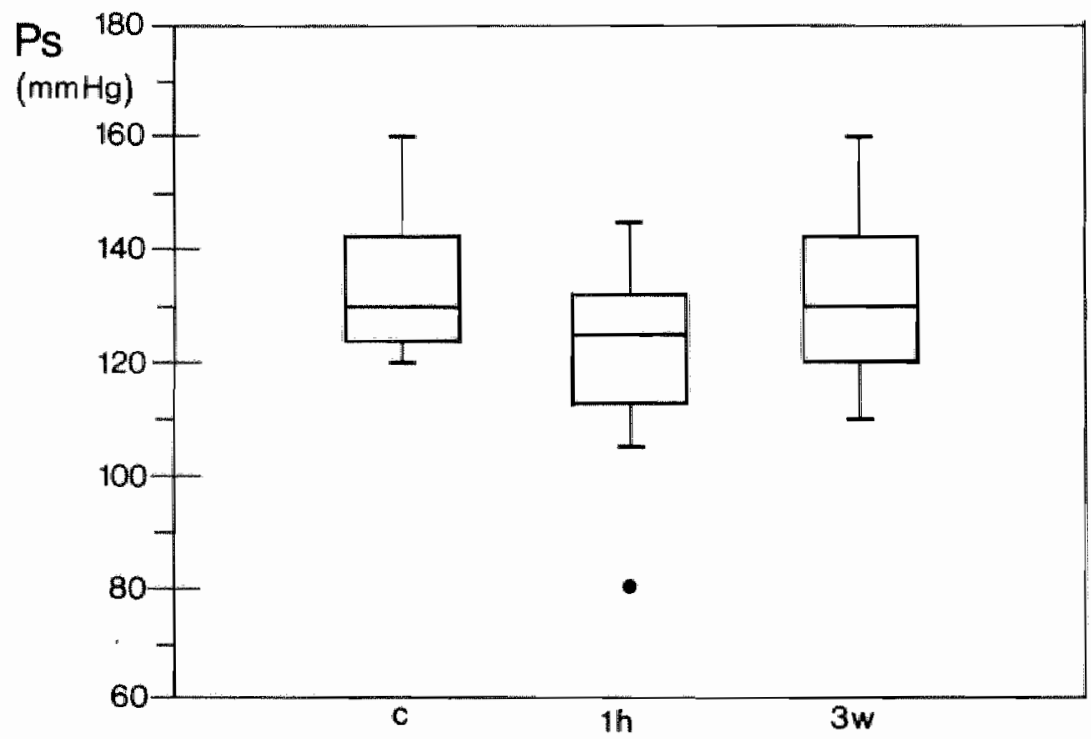

Figure 5.3 Systolic ( $\left(P_{s}\right)$ blood pressure in control situation (c) and after 1 hour $(\mathrm{I} / \mathrm{h})$ and 3 weeks (3w) Ketanserin treatment, presented in box plots (see figure 3.7). 
tion $(\lambda)$ and plasma viscosity $\left(\eta_{0}\right)$ were significantly $(p<0,001)$ higher in patients with secondary than in patients with primary Raynauds"s phenomenon. Treatment with ketanserin did not induce significant changes in haematocrit (Hct), RBC aggregation and plasma viscosity.

Thermography. The median skin temperature in the control situation was $26^{\circ} \mathrm{C}$, which increased significantly $(\mathrm{p}<0.001)$ to $34^{\circ} \mathrm{C}$ one hour after one oral dose of ketanserin (figure 5.2). The difference in temperature after 3 weeks of treatment was not significant anymore when the whole population was considered. Unlike in the non-respondents, in the respondents the temperature remained significantly higher after 3 weeks of treatment as compared with the control situation $(p<0.05)$. The temperature was significantly higher in the respondents than in the non-respondents $(\mathrm{p}<0.05)$.

Contimuous wave Doppler. The shape of the velocity wave forms in the ulnar and radial arteries did not change after treatment with ketanserin.

Blood pressure and heart rate. Systolic and diastolic blood pressure ( $\bar{x}: 135 / 84 \mathrm{~mm}$ $\mathrm{Hg}$ ) decreased significantly $(\mathrm{p}<0.001)$ one hour after $40 \mathrm{mg}$ of ketanserin orally $(\mathrm{x}: 121 / 76 \mathrm{~mm} \mathrm{Hg})$. These values had returned to the control level $(\bar{x}: 132 / 82 \mathrm{~mm} \mathrm{Hg})$ after 3 weeks ketanserin treatment (figure 5.3-5.4). Heart rate did not change significantly, neither after one oral dose nor after 3 weeks of treatment.

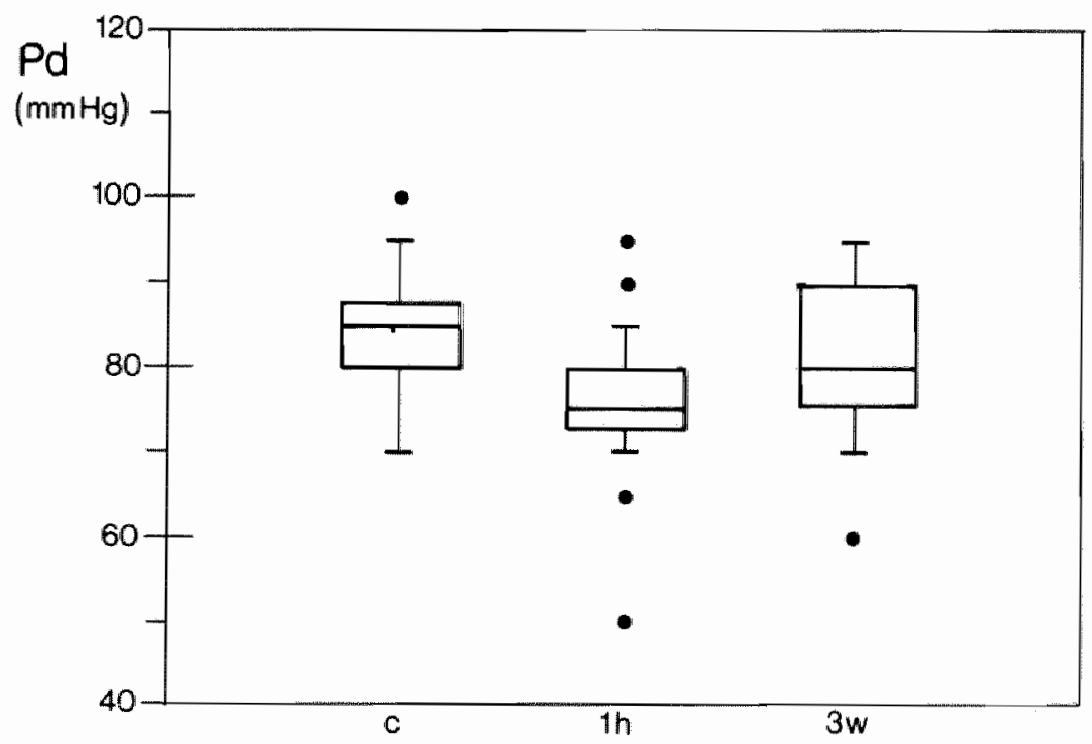

Figure 5.4 Diastolic blood pressure (Pd) in control situation (c) and after 1 hour ( 1 h) and 3 weeks ( 3 w) Ketanserin treatment, presented in box plots (see figure 3.7). 


\subsubsection{Discussion}

In the present study one oral dose of $40 \mathrm{mg}$ ketanserin was found to induce acute clinical improvement in nearly all patients with Raynaud's phenomenon. This improvement was generally shortlasting because maintenance therapy, two times $40 \mathrm{mg}$ orally per day during three weeks, resulted in a positive clinical effect in only six out of the fifteen patients. The subjective clinical improvement, that is warm and painless hands as well as a general sense of well-being, could be confirmed by the increase in RBC vellocity in the nailfold capillaries before and after cold provocation, even allowing the discrimination between respondents and non-respondents to longer lasting treatment with ketanserin. After treatment the temperature of hands and fingers was also higher in the respondents. The acute beneficial effects of the drug as found in the present study are in keeping with those observed by Stranden et al. (209), who described increased digital blood flow as measured photoplethysmographically. The finding that ketanserin did not affect the haemorheological parameters like RBC aggregation, plasma viscosity and haematocrit significantly, despite enhanced capillary RBC velocity, indicates that the compound mainly interferes with the vasoconstriction which is considered to be the basic disorder in primary Raynaud's phenomenon and superimposed on an underlying disease in secondary Raynaud's phenomenon. Whether a longer-lasting treatment or higher doses of ketanserin do have a beneficial effect on the haemorheological. parameters and hence may increase the effectiveness of the substance in the treatment of secondary Raynaud's phenomenon remains subject to further investigation.

The observation that the $5-\mathrm{HT}_{2}$ receptor antagonist ketanserin benefits patients suffering from primary and secondary Raynaud"s phenomenon, supports the idea that serotonin plays a role in the aetiology of these phenomena (84). One may wonder, however, whether the beneficial effects of ketanserin can be explained on the basis of the $5-\mathrm{HT}_{2}$ receptor blocking properties of the compound alone, because recent observations indicate that a combination of $5-\mathrm{HT}_{2}$ and $\alpha$ l-receptor antagonistic properties may be required for adequate clinical efficacy in the treatment of hypertension (117).

The significant decrease in arterial blood pressure associated with enhanced capillary RBC velocity and no significant change in capillary diameter supports the idea that ketanserin causes peripheral vasodilatation and hence a drop in peripheral vascular resistance, as described in patients with essential hypertension (226).

Despite the fact that only $40 \%$ of the patients responded well to longer lasting treatment with ketanserin, the compound may be considered as an asset in the treatment of a subpopulation of patients with Raynaud's phenomenon, especially because there is no therapy of choice for this disorder. However, additional doubleblind studies have to be performed to evaluate the potential of ketanserin in the treatment of Raynaud's phenomenon. 


\subsection{Buflomedil}

\subsubsection{Introduction}

The vasoactive drug Buflomedil (Chemical name: 4- (1-pyrrolidiny) -1- (2,4,6-trimethoxyphenyl) - 1 butanone hydrochloride) has been used for the treatment of peripheral circulatory insufficiency and with good results in cases of chronic occlusive arterial disease $(220)$. Many studies $(34,49,76,212)$ indicate that its mechanism of action is the improvement of microvascular perfusion, because haemorheological parameters improve and tissue oxygen pressure increases after treatment with Buflomedil.

Microcircullatory and haemorheological disturbances also occur in patients with Raynaud's phenomenon $(18,75)$. The aim of the present study was to investigate the effect of Buflomedil in patients with primary Raynaud's phenomenon. We also explored whether the subjective changes induced by the treatment could be evaluated by haemorheological and microcirculatory measurements (104). Capillary microscopy of the nailfold capillaries was used to determine changes in red blood cell velocity.

\subsubsection{Patients and methods}

Eight women and 3 men with Raynaud's phenomenon (mean age 44 years, range 25-64 years) were investigated before and after treatment. All patients had primary Raynaud"s phenomenon: a symmetrical triphasic discolowration of hands and fingers, triggered by exposure to cold. The Raynaud's phenomenon was called primary because in these patients no underlying disease could be detected. The non-invasive (Allen-test, thoracic outlet syndromeprovocation tests) and invasive (angiography) vascular work-up were negative. The tests on immunoglobulins, anti-nuclear-antibody (ANA), anti-nuclear-factor (ANF), Rose, Latex and Lupus erythematosus (LE) factor were all normal. The presence of cryoglobulins and cold agglutinates could not be demonstrated. The patients did not smoke or take medical drugs. Since Raynaud's phenomenon is very much dependent on climate influences, the study was performed during the cold months january till march (1983), in which the mean outdoor temperatures did not differ significantly. Patients were asked for subjective changes during and after treatment with Buflomedil, using their description of the temperature of the hands and fingers as well as the reaction upon the daily domestic cold provocations as criteria. They were also asked for side effects and adverse reactions. To investigate the patients and to evaluate the effects of Buflomedil, the following objective methods were used.

Capillary microscopy. To determine capillary diameter and red blood cell (RBC) velocity in the nailfold, the intravital microscope, as discussed in section 3.2 .4 , was used. Due to magnification and image stability the maximum velocity that could be measured was $0.650 \mathrm{~mm} / \mathrm{s}$. 
Haemorheology. The haemorheological parameters haematocrit ( $\mathrm{Hct}$ ), RBC aggregation and plasma viscosity were determined, as discussed in section 3.2.3.

Thermography. The temperature of hands and fingers before and after treatment was determined with thermoplates $(3.2 .7)$.

Continuous wave Doppler. Velocity wave forms were recorded in the radial and ulnar arteries (3.2.6).

Blood pressure and heart rate. Systolic and diastolic blood pressure were measured in both arms using a standard cuff technique (3.2.1).

Staristical analysis. Differences between the values of the objective variables and parameters before and after treatment and the effect of cold provocation were evaluated for statistical significance, using Wilcoxon's signed ranks test (two tailed probability).

Protocol. The variables and parameters were measured after acclimatizing for 30 minutes in a climate room with constant temperature $\left(22^{\circ} \mathrm{C}\right.$ ) and humidity (control situation $=\mathrm{c}$.). Then the hands and fingers were immersed in water and ice for 2 minutes. Immediately after this cold provocation, $\mathrm{RBC}$ velocity was determined (3.2.4). Then the patients received Buflomedil tablets of $150 \mathrm{mg}$ with a dosage of 4 tablets a day. After 3 days of Buflomedil treatment all methods were repeated, except for cold provocation. After 3 months treatment with Buflomedil $150 \mathrm{mg}$ four times a day, the same protocol as in control situation, was performed again.

\subsubsection{Results}

Subjective findings. After 3 days of Buflomedil treatment no changes or improvements were observed. After 3 months Buflomedil treatment 8 out of the 11 patients reported improvement of their complaints, which meant permanently warm hands during the three months of treatment, while Raynaud's phenomenon, especially the reaction upon the regular daily cold provocation, had disappeared or the number of attacks was reduced remarkably. Adverse reactions after 3 months of Buflomedil treatment were headache, dizziness and nausea in 2 patients (both without subjective improvement).

Capillary microscopy. The median $\mathrm{RBC}$ velocity in the control situation was $0.115 \mathrm{~mm} / \mathrm{s}$ (table 5.4 ) which decreased to $0.030 \mathrm{~mm} / \mathrm{s}$ after cold provocation. Three days after Buflomedil treatment, the median $R B C$ velocity $(0.126 \mathrm{~mm} / \mathrm{s})$ had not changed significantly. After 3 months Buflomedil treatment, $R B C$ velocity increased significantly $(\mathrm{p}<0.01)$ to $0.199 \mathrm{~mm} / \mathrm{s}$. RBC velocity after cold provocation after 3 months Buflomedil treat ment was significantly higher $(\mathrm{p}<0.05)$ than after cold provocation in control situation.

The arterial and venous diameters of the capillaries did not differ before and after treatment.

Haemorheology. The results of the haemorheological investigations are shown in table 5.5. Treat ment with Buflomedil did not induce significant changes in Hct, RBC aggregation and plasma viscosity. 


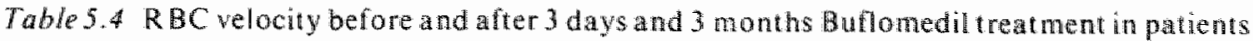
with primary Raynaud"s phenomenon $(n=11)$. The median values and 950 limits are presented.

Before treatment

$\longrightarrow$

After treatment

3 days $\quad 3$ months

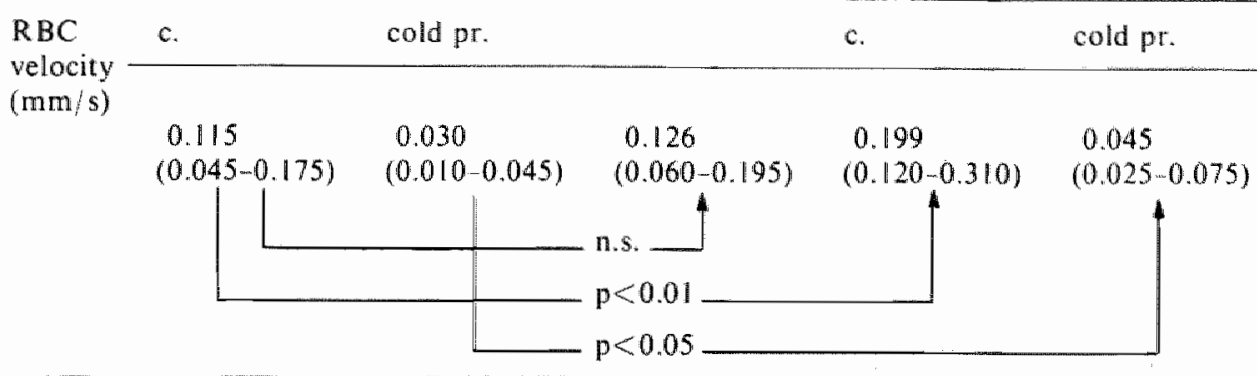

c. = control situation.

cold pr. = cold provocation.

n.s. $=$ not significant.

Table 5.5 Haemorheological parameters before, and after 3 days and 3 months Buflomedil treatment in patients with primary Raynaud's phenomenon $(n=11)$. The mean values and standard deviations are presented.

\begin{tabular}{lccc}
\hline & c. & 3 days & 3 months \\
\hline Haematocrit $(\%)$ & $43.0 \pm 2.8$ & $43.6 \pm 2.1$ & $43.7 \pm 1.4$ \\
R BC aggregation & $18.0 \pm 2.3$ & $18.4 \pm 3.1$ & $18.2 \pm 2.0$ \\
Plasma viscosity $(\mathrm{mPa} \cdot \mathrm{s})$ & $1.29 \pm 0.10$ & $1.27 \pm 0.09$ & $1.26 \pm 0.08$ \\
\hline
\end{tabular}

Thermography. Before treatment, the mean temperature of hands and fingers was $25^{\circ} \mathrm{C}$ which increased significantly to $26^{\circ} \mathrm{C}$ after 3 days $(\mathrm{p}<0.05)$ and to $28^{\circ} \mathrm{C}$ after 3 months $(p<0.01)$ treatment with Buflomedil.

Continuous wave Doppler. After 3 days and 3 months treatment with Buflomedil no changes could be detected in the shape of the velocity wave forms in the ulnar and radial arteries.

Blood pressure and heart rate. Systolic (mean $140 \mathrm{mmHg}$ ) and diastolic (mean $87 \mathrm{~mm} \mathrm{Hg}$ ) blood pressure and heart rate did not change significantly during and after treatment.

\subsubsection{Discussion}

Eight out of 11 patients with primary Raynaud's phenomenon responded favourably to treatment with Buflomedil. RBC velocity measurements in nailfold capillaries and 
thermography of hands and fingers could be used to evaluate the subjective improvements: RBC velocity and temperature increased significantly after treatment with Buflomedil. Capillary microscopy has also been used by Courbier et al. (39), who evaluated the effect of Buflomedil ( $50 \mathrm{mg}$ i. v.) on the number and morphology of the capillaries in the nailfold of patients with $\mathbb{R}$ aynaud's syndrome. They concluded that Buflomedil was significantly better than placebo.

To evaluate the effect of a drug in patients with Raynaud's phenomenon, it is important to use an uniforme nomenclature. Patients with primary Raynaud"s phenomenon have to be distinguished from patients with secondary Raynaud's phenomenon. In a preliminary study (102) and in this thesis we found that patients with primary Raynaud's phenomenon, who have no underlying disease, did not have haemorheological disturbances, in contrast to patients with secondary Raynaud's phenomenon, based on an underlying disease, in which these haemorheological parameters were highly significantly increased. Primary Raynaud's phenomenon is probably mainly caused by vasomotor disorders in which haemorheology plays no prominent role. In the patients of the present study, who all had primary Raynaud's phenomenon, the haemorheological parameters, $\mathrm{Hct}, \mathrm{RBC}$ aggregation and plasma viscosity were normal and did not change after Buflomedil treatment. The fact that RBC velocity, in the absence of a significant change in capillary diameter, and temperature increased in these patients after Buflomedil treatment indicates enhanced microcirculatory perfusion and suggests interference with vasomotor tone. However, it should be mentioned that this study was not double blind and that no conclusions can be drawn with regard to the efficacy of the drug. Evaluation of the beneficial effects of Buflomedil treatment, if any, in patients with Raynaud's phenomenon has to be subject to further studies with Buflomedil versus placebo. Haemorheological and microcirculatory investigations can be used to evaluate objectively the subjective changes following drug treatment.

\subsection{Plasmapheresis}

\subsubsection{Introduction}

In the past years plasmapheresis and plasmafiltration have been applied more frequently for various diseases and especially proved their value in the management of hyperviscosity syndromes $(52,114,115)$. After an elevated blood viscosity had been established in patients with Raynaud's phenomenon $(44,75,137,191)$, plasmapheresis has also been carried out in these patients, be it with alternating success.

In chapter 4 of this thesis it is described that blood viscosity disturbances are confined to patients with secondary Raynaud's phenomenon. In patients with primary Raynaud's phenomenon haemorheological parameters appeared to be normal. In a preliminary study (103), 7 patients with primary and 7 patients with secondary Raynaud's phenomenon were treated with plasma filtration. Patients with secondary Raynaud's phenomenon reacted favourably to plasma filtration with healing of skin 
ulcera and disappearance of Raynaud's phenomenon, while the results in patients with primary Raynaud's phenomenon were very poor. We concluded that in patients with primary Raynaud's phenomenon, in which blood viscosity does not play a prominent role, plasma filtration is not indicated. However, in patients with secondary Raynaud's phenomenon, improvement of disturbed blood viscosity by plasma filtration was believed to be effective. Therefore, in this part of the study, patients with secondary Raynaud's phenomenon were treated with plasmapheresis weekly, for 4 weeks. In order to evaluate the efficacy of the possible changes in viscosity, the changes in the haemorheological parameters, if any, were compared with the possible alterations in microcirculatory variables as induced by plasmapheresis.

\subsubsection{Patients and methods}

Twelve patients, 10 women and 2 men, with secondary Raynaud's phenomenon (mean age 50 years, range 32-67 years) were treated with plasmapheresis. All patients had progressive systemic sclerosis as underlying disease, proven by histological findings or esophagus $\mathrm{X}$-ray examination. All patients had been subnitted to thoracodorsal sympathectomy, at least one year prior to this study, with transient success. Four of the 12 patients complained of non-healing ulcers of the fingers.

The patients were treated by plasmapheresis of 2 liters of plasma weekly for a total of 4 treatments. Both femoral veins or one femoral and one cubital vein were used for the in- and outflow of the blood. The plasma exchange was carried out with human albumine $3 \%$ in Ringer solution with an Aminco Celltrifuge. In this celltrifuge, separation of blood components is effected on the basis of density differences in a gravitational force field created in the continuous-flow centrifuge.

Before and after plasmapheresis capillary microscopy (3.2.4) was performed to determine capillary diameters and $\mathrm{RBC}$ velocity in the nailfold.

The following laboratory investigations were carried out: the plasma content of fibrinogen, cholesterol, total protein, albumin, $\alpha_{1}$-globulline, $\alpha_{2}$-globuline, $\beta$-globuline and $\gamma$-globuline.

In order to evaluate the haemorheological behaviour of the blood, haematocrit. R BC aggregation and plasma viscosity $(3,2.3)$ were determined before and after each treatment.

Differences between the data obtained with the objective methods were evaluated for statistical significance, using Wilcoxon's signed rank test (two tailed probability).

\subsubsection{Results}

After 4 plasmaphereses, all patients $(n=12)$ claimed explicit improvement of their complaints. Raynaud's phenomenon and especially the reaction upon cold provocation had either disappeared or the number of attacks was reduced remarkably. The 
Table $5.6 \mathrm{RHC}$ velocily before and after 4 weeks treatment with plasma pheresis in patients with secondary Raynat's phenomenon $(\mathrm{n}=12)$. The mean walues and standard dewiations are presented.

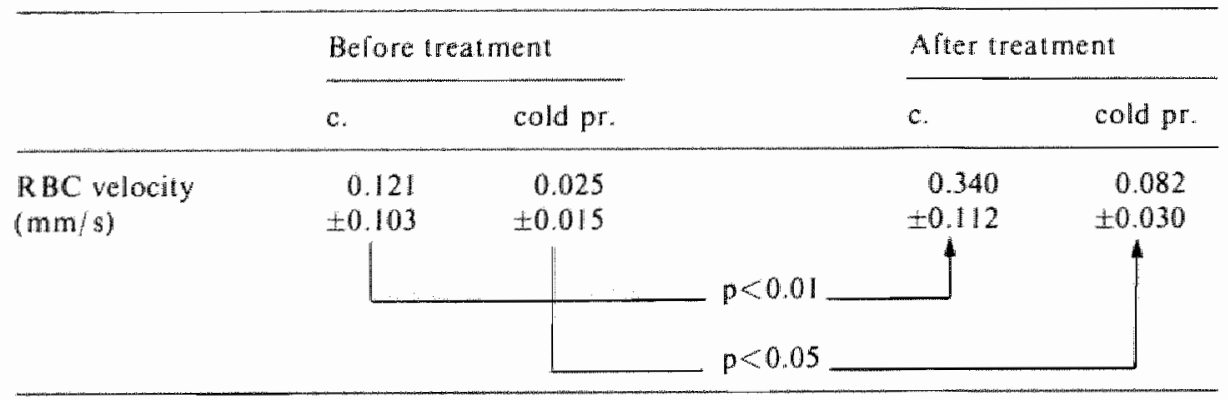

c. $\quad=$ control situation.

cold pr. $=$ cold prowocation.

four patients with ulcers had a good healing tendency during and after plasmapheresis. Not only the complaints of Raynaud"s phenomenon improved, but also changes in the skin occured. The skin, which had been taut and tense before plasmapheresis became supple thereafter. Patients could more easily use their extremities and fingers and their facial expression became livelier. In 2 patients an allergic reaction was observed during plasmapheresis which could be treated with intravenous administration of Tavegil, $2 \mathrm{mg}$ and Di-Adreson- $F, 25 \mathrm{mg}$.

Capillary microscopy. RBC velocity before and after treatment is shown in table 5.6. The mean RBC velocity before treatment was $0.121 \mathrm{~mm} / \mathrm{s}$ which increased significantly $(p<0.01)$ to $0.340 \mathrm{~mm} / \mathrm{s}$ after 4 weeks plasmapheresis. $R B C$ velocity after cold prowocation was significantly higher $(p<0.05)$ after than before treatment.

In all patients nailfold capillaries were extremely dilated. Large aggregates of red cells slowly moved through the capillaries. Plasmapheresis did not induce changes in capillary diameters, but the number and size of the RBC-aggregates decreased considerably.

Haemorheology. Before plasmapheresis no abnormal values were found for the laboratory investigations (table 5.7). After 4 sessions of plasmapheresis, the plasma content of cholesterol, fibrinogen, total protein, $\alpha_{1}, \alpha_{2,} \beta$, and $\gamma$-globuline decreased significantly $(\mathrm{p}<0.01)$. Plasma albumin increased as a consequence of treatment. The mean haematocrit was $40.1 \pm 4.5 \%$ which did not change during and after treatment (table 5.8). RBC aggregation (23.93 \pm 6.40$)$ and plasma viscosity $(1.65 \pm 0.60)$ were significantly increased, as compared to normal subjects. In table 5.8 the haemotheological data are presented before and after each treatment. RBC aggregation and plasma viscosity decreased significantly $(p<0.01)$ after each session. In some patients it was observed that after plasmapheresis no RBC aggregation occured at all. During the week between 2 treatments $\mathrm{RBC}$ aggregation and plasma viscosity increased, but never reached the initial value. After 4 treatments with plasma pheresis, red blood cells hardly aggregated and plasma viscosity was decreased to $1.05 \pm 0.14 \mathrm{mPa}$.s. The 
Table 5.7 Plasma contents of the biochemical variables before and after plasmapheresis in patients with secondary Raynaud's phenomenon $(n=12)$. The mean values and standard deviations are presented. Normal values are presented as well (in between parentheses).

\begin{tabular}{lccl}
\hline & Before & After & Significance \\
\hline cholesterol $(4.10-6.40 \mathrm{mmol} / \mathrm{L})$ & $5.20 \pm 1.48$ & $2.21 \pm 0.51$ & $\mathrm{p}<0.01$ \\
fibrinogen $(1.7-4.0 \mathrm{~g} \mathrm{~L})$ & $3.2 \pm 1.1$ & $1.2 \pm 0.4$ & $\mathrm{p}<0.01$ \\
total protein $(65-79 \mathrm{~g} / \mathrm{L})$ & $70 \pm 8$ & $52 \pm 8$ & $\mathrm{p}<0.01$ \\
albumin $(35-55 \mathrm{~g} / \mathrm{L})$ & $54 \pm 8$ & $71 \pm \pm 9$ & $\mathrm{p}<0.01$ \\
$\alpha_{1}$ globuline $(2.5-6.6 \%)$ & $3.2 \pm 0.4$ & $1.8 \pm 0.7$ & $\mathrm{p}<0.01$ \\
$\alpha_{2}$ globuline $(5.2-12.5 \%)$ & $9.4 \pm 2.2$ & $5.7 \pm 2.1$ & $\mathrm{p}<0.01$ \\
$\beta$ globuline $(12.0-17.5 \%)$ & $13.6 \pm 1.6$ & $8.0 \pm 1.5$ & $\mathrm{p}<0.01$ \\
$\gamma$ globuline $(13.0-22.0 \%)$ & $1.8 \pm 0.8$ & $1.2 \pm 0.8$ & $\mathrm{p}<0.01$ \\
\hline
\end{tabular}

differences between the R BC aggregation and plasma viscosity values before and after the last plasmapheresis were significantly at the level of $p<0.001$.

After the last plasmapheresis, patients were investigated every 6 weeks. At the moment of writing this thesis the follow-up was 14 months. After this period, 3 patients were free of complaints, while $\mathrm{RBC}$ velocity and the rheological parameters gradually returned to control levels. Figure 5.5 shows the changes in mean plasma viscosity during the 14 months after the first plasmapheresis. In 9 patients the

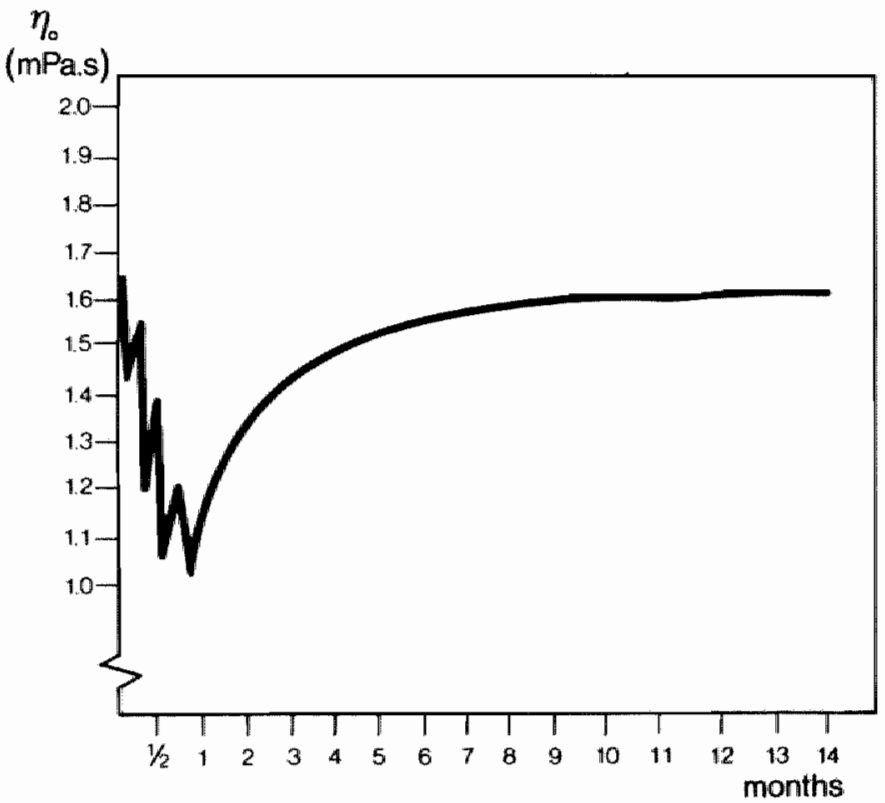

Figure 5.5 Mean plasma viscosity during and after treatment with plasmapheresis. 


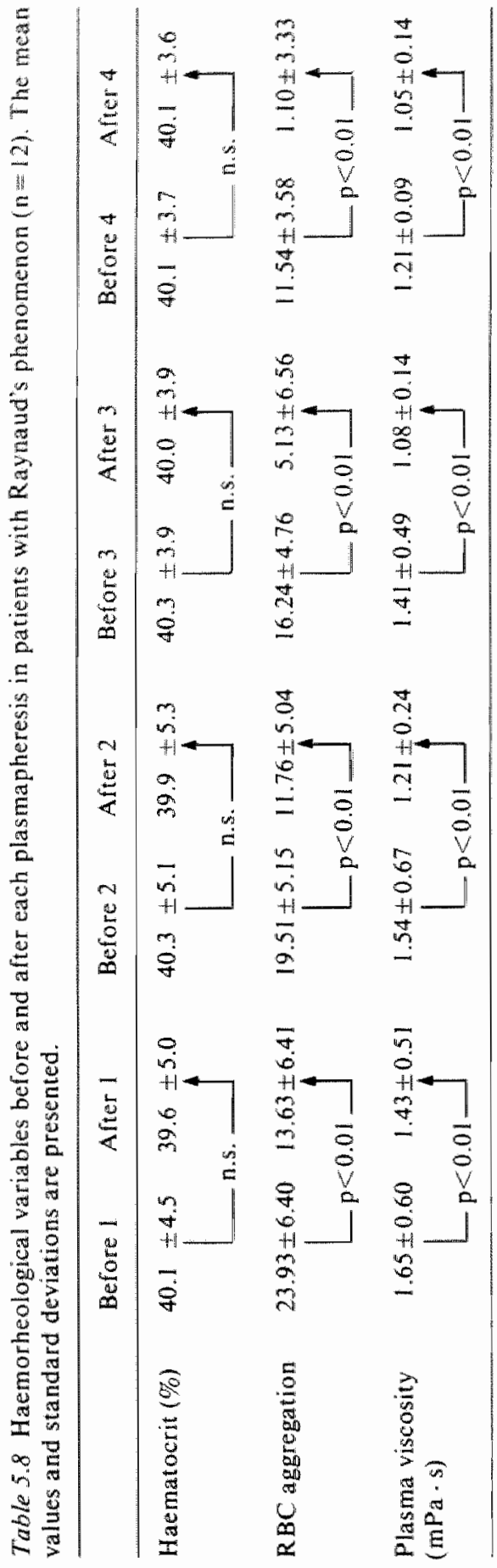


complaints of Raynaud's phenomenon reappeared after about 3 months, but the skin ulcera did not return. In 6 patients plasma pheresis was performed again with comparable clinical results. These subjective beneficial effects were confirmed by capillary microscopic and rheological findings.

\subsubsection{Discussion}

Altering the physical properties of the blood resulted in beneficial clinical effects and increased microcirculatory blood. flow in patients with secondary Raynaud's phenomenon based on progressive systemic sclerosis, indicating that in these patients rheological parameters do have pathophysiological and haemodynamic importance. This is entirely in concurrence with the idea that the physical properties of blood can cause rheological obstruction (200).

Removal of large molecular plasma components reduced $\mathbb{R B C}$ aggregation and plasma viscosity significantly. Especially after the third and fourth plasmapheresis, red cells hardly aggregated. It was in this period that the patients observed the most beneficial effects and that skin ulcers healled. The finding that the skin became more supple and pliable can likely not be explained by increased microcirculatory perfusion, but suggests the removal of another, yet unknown, plasma factor.

Dodd"s et al. (47) used plasmapheresis in patients with Raynaud's phenomenon based on scleroderma and in patients with idiopathic Raynaud's phenomenon. In the results, symptomatic and viscosity changes are discussed without distinguishing between the two groups of patients. Talpos et al. (214) described good results of plasmapheresis in patients with Raynaud's phenomenon. At the moment of investigation no underlying cause of the disease could be demonstrated. Hamilton et al. (85) and O'Reilly et al. $(180,181)$ noted improvement in finger blood flow after plasmapheresis but did not differentiate between patients with or without underlying disease. Klinenberg et al. (119) did not find improvement in 2 patients with Raynaud's phenomenon (with known underlying disease) which made him wonder if it is not primary Raynaud's phenomenon instead of secondary Raynaud's phenomenon which will react favourably to plasmapheresis. This hypothesis seems to be in disagreement with the results, as obtained in the present study. This discrepancy, however, can be related to misuse of the nomenclature of Raynaud's phenomenon. In patients with primary Raynaud's phenomenon, in whom the rheological properties of the blood appeared to be normal (chapter 4), only a limited effect of plasmapheresis can be expected. However, patients with primary Raynaud's phenomenon who do react favourably to plasmapheresis could possibly be patients developing a progressive systemic sclerosis, as it is known that Raynaud's phenomenon can be present several years prior to the development of evident progressive systemic sclerosis (221), The history of a patient in our clinic can be used as an example. The patient was a 38 years female with primary Raynaud's phenomenon: no underlying disease could be detected, the haemorheological parameters were normal and capillary microscopy showed a normal density of slightly dilated capillaries in which $R B C$ velocity was 
diminished. Because of the severity of Raynaud's phenomenon, plasmapheresis was performed with extreme clinical improvement. In the two years follow-up, rheological parameters gradually increased to pathological levels and capillary microscopy showed the development of avascular areas and giant capillaries. A skin biopsy and esophagus $\mathrm{X}$-ray pictures confirmed the suspected diagnosis progressive systemic sclerosis. This illustrates that, with regard to the diagnosis, treatment and prognosis of Raynaud's phenomenon, not only an uniform nomenclature should be used, but also that frequent revision of the diagnosis is required.

The conclusion of this study is that improving blood fluidity by plasmapheresis improves clinical symptomatology of patients with secondary Raynaud"s phenomenon which can be confirmed by haemorheological and capillary microscopic investigations.

\subsection{Stellate ganglion blockade and sympathectomy}

\subsubsection{Introduction}

Sympathetic surgery has been widely applied as therapy of choice in patients with Raynaud's phenomenon. It was a logical treatment since Raynaud himself hypothesized that digital ischaemia was the result of increased activity of the sympathetic nerwous system (193). Many different techniques to obtain maximal sympathetic denervation have been applied (5). However, with the increasing understanding of the multiple pathogenetic factors causing Raynaud's phenomenon in combination with an almost total lack of longlasting improvement after surgery (100), the use of sympathectomy has declined more and more. The only patients, who likely benefit from surgical sympathectomy, are the patients with a Raynaud's phenomenon on the basis of a central nervous disorder (37). A restricted indication for sympathectomy are the patients suffering from a severe and progressive Raynaud's phenomenon (73). The best indications for thoracodorsal sympathectomy en bloc are 1 ) ischaemic attacks of the hand and fingers on the basis of vasospastic diseases and occlusive diseases of the digital arteries, 2) pain and dystrophy of the hand and fingers in Südeck's disease and 3) severe Raynaud's phenomenon without scleroderma (135).

In this part of the study the effects of sympathetic elimination, by either sympathectomy or stellate ganglion blockade, on skin temperatures, blood flow velocity as measured with a LaserDoppler instrument and capillary $\mathrm{RBC}$ velocity as assessed microscopically were studied in patients with primary Raynaud's phenomenon. Furthermore, it was investigated whether the variables measured, especially capillary $\mathrm{RBC}$ velocity, could be used to objectivate the subjective changes.

\subsubsection{Methods and materials}

Nine women and one man with primary Rayna ud's phenomenon (mean age 37 years, range 22-49 years) were examined before and after stellate ganglion blockade. Six 
patients underwent thoracodorsal sympathectomy en bloc (135), with transient success in 3 patients, at least one year prior to this study.

Stellate ganglion blockade was performed in all patients at the site with the most severe complaints. In patients who underwent sympathectomy the not-operated site was chosen for stellate ganglion blockade.

Stellate ganglion blockade was performed through the anterior approach: lateral to the jugular incisura and medial to the sternocleidomastoid muscle. Bupivacaine (Marcaine $0.5 \%$ was used as local anaesthetic. Eight $\mathrm{ml}$ of this anaesthetic were injected at each blockade. The following symptoms were used as criteria for a well placed stellate ganglion blockade:

1. Horner's syndrome (ptosis, miosis, enophtalmus).

2. Increased perfusion of the cheek, face, neck and arm at the injected site, combined with a distinct injection of conjunctiva and sclera.

3. Anhidrosis.

The following methods were used to evaluate the effects of stellate ganglion blockade. Capillary microscopy (3.2.4). RBC velocity, before and after cold provocation, was determined before and I hour after stellate ganglion blockade.

Thermography. Before and $\mathbb{1}$ hour after blockade the temperatures of hands and fingers were determined with thermoplates (3.2.7).

Laser-Doppler flowmetry (3.2.5) was performed before and after treatment.

\subsubsection{Results}

Subjective findings. After stellate ganglion blockade all patients $(n=10)$ had the symptoms as described in section 5.5.2: Horner's syndrome, increased skin perfusion and anhidrosis. Eight patients claimed dramatic changes: painless and extreme warm hands and fingers. Two patients also had beneficial effects after the blockade, but less as compared to the others. (Both patients underwent unilateral sympathectomy with

Table 5.9 R BC velocity, before (c) and after cold provocation(cold pr.), before and I liour after stellate ganglion blockade. The mean values and standard deviations are presented.

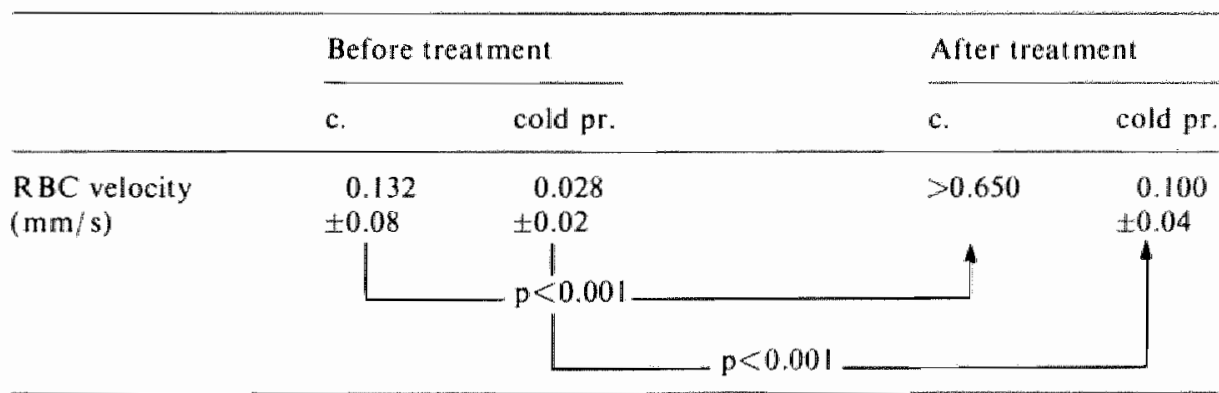


Table 5.10 Temperature of hand and fingers before and hour after stellate ganglion blockade. The mean values and standard devations are presented.

\begin{tabular}{lll}
\hline & Before \\
$\begin{array}{l}\text { Temperature } \\
\left({ }^{\circ} \mathrm{C}\right)\end{array}$ & $28.5 \pm 2.1$ & After \\
\hline
\end{tabular}

transient success). The time that the patients were free of complaints varied from 2 till 4 hours. No complications occurred after the blockade.

Capillary microscopy. The data on $\mathrm{RBC}$ velocity is shown in table 5.9. The mean velocity belore and after cold provocation was $0.132 \mathrm{~mm} / \mathrm{s}$ and $0.028 \mathrm{~mm} / \mathrm{s}$, respectively. After stellate ganglion blockade these velocities increased significantly $(p<0.001)$. In all patients, except the 2 patients who had less subjective improvement, the velocities increased above $0.650 \mathrm{~mm} / \mathrm{s}$. In the 2 less responding patients $R B C$ velocity did not change significantly after the blockade.

Thermography. The mean skin temperature before treatment was $29^{\circ} \mathrm{C}$ which increased significantly $(\mathrm{p}<0.001)$ in all patients (table 5.10 ) after treatment (mean $35^{\circ} \mathrm{C}$ ). These temperatures are higher than in other parts of the study because the blocks were not performed in the climate room.

Laser-Doppler. Figure 5.6 shows the change in laser-Doppler signals in one patient after stellate ganglion blockade. The $\mathrm{AC}$ and mean component increased in all patients $(\mathrm{p}<0.001)$, while the pulsatility index did not change significantly (table 5.11 ).

After these procedures, in 5 patients ( 3 patients with a permanent effect after previous contralateral sympathectomy and 2 patients who where never operated upon) thoracodorsal sympathectomy en bloc was performed. All patients had the same dramatic effects as after stellate ganglion blockade. These beneficial effects could be confirmed by capillary RBC velocity measurements, thermography and laserDoppler flowmetry. The follow-up till the moment of this thesis was 18 months. Three patients (all 3 with contralateral success) reported permanent warm hands and were free of Raynaud's phenomenon. In these patients the data on capillary $R B C$ velocities before and after cold provocation, thermography and laser-Doppler flowmetry was comparable to the data obtained after stellate ganglion blockade. Two patients

Table $5 . \mathrm{M}$ Data on Laset-Doppler flowmetry before and after stellate ganglion blockade. The mean values and standard deviations are presented.

\begin{tabular}{lccc} 
& Before & After & Significance \\
\hline AC component $(\%)$ & $1.9 \pm 0.7$ & $8.7 \pm 2.9$ & $p<0.001$ \\
Mean component $(\%)$ & $13.0 \pm 3.4$ & $57.1 \pm 15.7$ & $p<0.001$ \\
Pulsatility index & $0.31 \pm 0.12$ & $0.33 \pm 0.10$ & n.s. \\
\hline
\end{tabular}



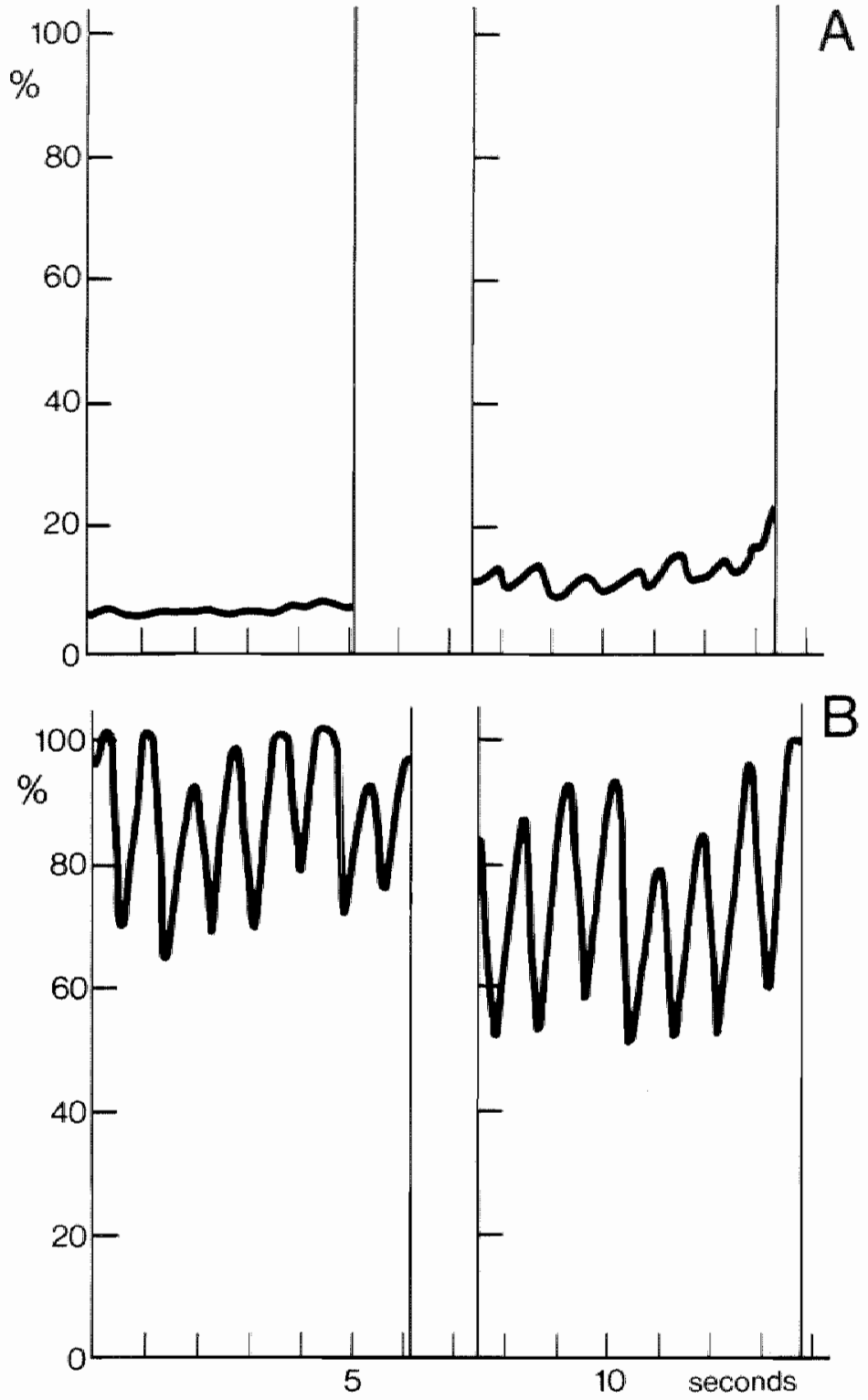

Figure 5.6 Change in Laser Doppler output before (A) and after (B) stellate ganglion blockade. Vertical axis: flow values expressed as percentage of full scale, horizontal axis: time in seconds.

gradually obtained the same complaints as before treatment after 5 and 11 months, respectively. Capillary $\mathrm{RBC}$ velocity, skin temperature and laser-Doppler recordings returned to the control levels in these patients. 


\subsubsection{Discussion}

It is beyond the scope of this study to discuss the indications and the short-and longlasting results of sympathectomy in patients with Raynaud's phenomenon. The indications for sympathectomy have been clearly described in other studies $(37,73,86,135)$. It was the aim of this part of the study to investigate microcirculatory changes after stellate ganglion blockade and sympathetic surgery in patients with primary Raynaud's phenomenon and to evaluate the usefulness of the variables measured to objectivate the clinical subjective changes.

Elimination of sympathetic influences resulted in a significant increase in RBC velocity, skin temperature and Laser-Doppler output combined with dramatic subjective changes. This indicates that not only nutritional flow, but also thermoregulatory flow (a-w shunt flow) increases after eliminating the vasospastic influence. While thermography is an indirect method to measure skin capillary blood flow, laser-Doppler flowmetry is described as a more direct method to determine skin blood flow $(54,93,178)$. In the skin, laser-Doppler flowmetry probably measures total blood flow, i.e. both nutritional and thermoregulatory flow (218). Capillary RBC velocity, however, specifically reflects nutritional blood flow.

In the 2 patients with less subjective improvement, skin temperature and the laserDoppler output increased to the same amount as in the other patients, indicating that the increase in thermoregulatory flow is relatively more pronounced than the increase in nutritional flow. This is supported by the finding that $R B C$ velocity did not change in these 2 patients but increased in the other patients.

Evenso after sympathetic surgery the subjective changes, either improvement or worsening of the complaints, could be confirmed by capillary microscopy. Especially the fact that subjective changes, as reported by the patient, can be objectivated non-invasively by dynamic capillary microscopy, makes this method a superior one to study changes in nutritional skin blood flow as induced by therapy.

In conclusion, the findings in this part of the study also indicate that capillary RBC velocity measurements with the use of intravital microscopy can be considered as an asset in the evaluation of therapeutic interventions, which is in agreement with previous observations of Bollinger et al. (14). 


\section{Chapter 6}

\section{INTRODUCTION}

Intermittent claudication is the characteristic symptom of chronic occlusive arterial disease of the lower extremities, indicating an inadequate supply of arterial blood to contracting muscles. The symptom is described as pain, cramp, numbness or sense of fatique in certain muscles which develops only during exercise and relieves after rest. In claudication the blood flow is unable to adequately supply nutrients and to remove the waste products of metabolism sufficiently rapidly to maintain muscular function. The distance that the patient is able to walk before the distress develops varies with the extent and severity of the arterial obstruction. Rest pain, ulceration and gangrene are the result of more severe ischaemia of tissues.

The approach to treatment of patients with chronic occlusive arterial disease of the lower extremities depends on the severity and extent of the obstructive lesions. Arterial reconstructive surgery remains the most commonly applied method and is effective in restoring pressure and flow to a normal or near normal level. The aim of reconstructive vascular surgery is to increase tissue perfusion and the enhancement of arterial flow rate, which is achieved by restoring vascular geometry and improving pressure gradients.

The driving force for flow in the circulation is the difference in total fluid energy. In vascular obstructions there are three forms of energy losses due to blood flow: 1) inertial losses due to changes in blood flow velocity 2) viscous losses as a result of blood viscosity and 3) turbulence distal to the stenosis.

The rate of flow and perfusion in ischaemic tissue is also determined by pressure gradients and local wascular resistances; the latter primarily being dependent on the radius of the lumen. However, the local vascular resistance is not only determined by the inside radius but also, according to Poiseuille's law, by the viscosity of the blood. The extent to which changes in the blood itself may affect tissue perfusion can possibly explain the poor results of arterial surgery that occasionally occur.

Especially at low shear rates, like in ischaemic tissue, the viscosity of the blood could play a significant role in reducing microcirculatory blood flow. Disturbances in blood rheology have been described in atherosclerotic diseases as cerebrovascular accidents (182) and coronary artery disease (148). It has been suggested that increased haematocrit, $\mathrm{RBC}$ aggregation, plasma and blood viscosity could impair haemodynamic conditions in the microvasculature in addition to atherosclerotic narrowing of the vessels, changes in flow velocity gradients and insufficient collateral circulation. Since intermittent claudication is a symptom of an atherosclerotic disease, it was expected 
that in patients with occlusive arterial disease of the lower extremities haemorheological disturbances may occur (105). If these changes are clinically important, they might have a role in predicting the outcome in patients undergoing major arterial surgery.

The aim of this part of the study was:

1. To investigate the hat morheology in patients with occlusive arterial disease of the lower limbs (chapter 8), with special emphasis on

1.1 the blood viscosity determining parameters haematocrit, RBC aggregation and plasma viscosity in patients with chronic occlusive arterial disease of the lower limbs and, as comparison, in healthy subjects of comparable age without evidence of occlusive arterial disease.

1.2 the relation, if any, between haemorheological disturbances and the severity of the arterial obstruction. The latter was determined by Doppler ankle pressure measurements (ankle/arm index), which is supposed to be the most reliable non-invasive method to document arterial obstruction of the lower extremities. Ankle and arm pressures were measured with the use of Doppler ultrasound $(210)$.

1.3 the relation, if any, between haemorheological disturbances and the number of anatomical levels of the diseased arterial system of the lower limbs. The latter anatomic information was obtained by aorto-arteriography. The geometrical findings were compared with the results of the haemorheological measurements.

2. To investigate whether haemorheological disturbances are influenced by therapeutic intervention (chapter 9), with special emphasis on

2.1 surgery. In patients undergoing reconstructive vascular surgery, haemorheological parameters and ankle/arm pressure indices were determined one day before, and one day and six weeks after vascular surgery. 


\section{Chapter 7}

\section{METHODS AND MATERIALS}

\subsection{Patients}

The total number of patients in this study was 100 , with a $5: 1$ preponderance of men over women. All patients had a history and evidence of obstructive arterial disease in the lower extremities, varying from Fontaine II - IV. Intermittent claudication was the most frequent symptom in all patients with a wide variety of walking distance. The average age was 64.8 years with a range from 25 to 86 years. The lapse of time since the first symptom varied from 2 months to 19 years. At the time of the study, according to Fontaine, the patients could be divided as follows:

Phase I without complaints

Phase II pain after exercise

Phase III rest pain

Phase IV ulcerations and gangrene

Total
0 patients

54 patients

28 patients

18 patients

100 patients

Because of the influence on haemorheological parameters, heavy smokers (more than 10 cigarettes a day) and patients with insulin dependent diabetes were excluded from this study $(70,166)$.

Twenty-two of these patients were submitted to vascular surgery at the time of the study (chapter 9.1). In these patients haemorheological and ankle/arm pressure index measurements were performed before operation as well as one day and six weeks after surgery.

\subsection{Normal subjects}

This group consisted of 40 healthy volunteers of comparable age. The average age of the volunteers was 63.5 years (range 40 to 86 years) and their sex distribution was similar to that in the patients. The same criteria were used to exclude candidates from the study (more than 10 cigarettes a day and insulin dependent diabetes). All volunteers, who were chosen for the study, were without symptoms of cardiovascular diseases like myocardial infarction, cerebrovascular accidents and intermittent 
claudication, or other diseases which possibly could influence the measurements. The complete medical check-up, consisting of history, physical examination, chest $\mathrm{X}$-ray, ECG and biochemistry, of all controls was within the normal range.

\subsection{Physical examination}

A complete clinical history and physical examination of patients with chronic arterial occlusive disease of the lower limbs are essential for the diagnosis and evaluation of this disease. It is beyond the scope of this chapter to deal intimately with every symptom or physical finding. Instead, general principles of the physical examination of patients with peripheral occlusive disease of the lower limbs are discussed briefly. The examination was carried out after a time of acclimatizing in a room with constant temperature where vasoconstriction is minimized. In patients with generalised atherosclerosis a complete examination was carried out which includes ocular fundus inspection, blood pressure measurements (both arms), auscultation of the heart as well as palpation and auscultation of the carotid, subclavian and peripheral arteries.

\section{Inspection}

The colour of the skin represents the status of circulation, varying from pink-red in the normal situation to black in gangrene. The tint of the skin is influenced by the amount of blood and the colour of the blood. Localized cyanosis of the skin is a sign of deoxygenated blood in the capillaries and generally indicates decreased blood flow. The concurrent vasodilation due to ischaemia causes blood to suffuse the cutaneous plexus, imparting a particularly livid appearance to the skin.

Pallor, for example in sudden arterial occlusion or after elevation of the extremity, is likely to be the result of insufficient blood flow and inadequate collateral circulation. Colour changes of the skin after elevation of the legs and the duration of return of skin colour are an indication of the degree of impairment of the circulation.

Trophic changes are characteristic for chronic arterial occlusive disease of the lower limbs. The hair on the toes and dorsum of the foot is often absent, and the skin is athrophic, dry and shiny, causing fissures with the risk of infection and ulceration. Piling up under the toe nails and irregular growth and shape of the nails a re also often observed in these patients.

Ulcerations are most commonly caused by occlusive arterial disease. Other more common types of leg ulcers often observed are venous, embolic or neurothrophic. In origin, careful anamneses (onset of the lesion, pain, trauma, hypertension, aggravating and alleviating factors, previous treatment, family history) and clinical examination are extremely important to verify the etiology of leg ulcers. The location of an ulcer can be helpful in assessing the etiology. Upper extremity ulcerations, for example, are never caused by chronic venous insufficiency while ulcers due to arterial 
insufficiency are normally below the ankle. Tissue necrosis first becomes apparent in the most distal portions of the extremity and then stops proximally at a level where the blood supply is sufficient to maintain viability. Gangrene can occur as a complication of inadequate circulation and may affect digits and, in extreme situations, distal parts of the extremities.

\section{Palpation and auscultation}

The state of pulsations in the abdominal aorta as well as the iliac, femoral, popliteal, posterior tibial and dorsal pedis arteries should be estimated by finger palpation and, if necessary, followed by ultrasonic detection in cases like ankle edema where digital pulse detection can be impossible. Auscultation of the abdominal aorta and the liac and femoral arteries is performed to detect bruits, which may indicate partial occlusion. Local temperature of the skin of the feet depends on the rate of flow into the arteriovenous anastomoses which can vary tremendously. Warm skin indicates a high rate of blood flow and cold skin means decreased blood flow. This does not necessarily mean that changes in temperature are related to changes in nutritional blood flow. Local temperature of the feet is no indication of the state of blood flow in the entire extremity. A fall in skin temperature can best be detected by palpation with the dorsal surface of a distal phalanx of a finger. In this way differences in temperature from proximally to distally in the leg and between the two legs can be assessed. Delayed capillary refill and differences in refill between the two legs indicate diminished and disturbed circulation.

With the aid of reactive hyperaemia tests even minor arterial stenosis can be detected. In individuals who complain of claudication, but do not have abnormal findings at rest, exercise will sometimes produce peripheral pallor, an audible bruit or a decrease in pulse strength. These findings indicate the existence of an otherwise inapparent arterial stenosis. Beside examination of the arterial system, the venous and lymphatic systems should be examined.

\subsection{Haemorheology}

The haemorheological parameters haematocrit, R BC aggregation and plasma viscosity were determined in all patients $(n=100)$. The methods of determination have been described in section 3.2.3.

Haematocrit (Hct) was expressed in percentage, $\mathrm{RBC}$ aggregation $(\lambda)$ in arbitrary units and plasma viscosity $\left(\eta_{0}\right)$ in $\mathrm{mPa}$.s. In order to compensate for the interaction between RBC aggregation and plasma viscosity, the corrected rate constant (224) was calculated by the product of these two parameters $\left(\lambda \cdot \eta_{0}\right)$. With this corrected rate constant, the severity of haemorheological disturbances can be expressed as a number. 
Haemorheological parameters:
1. Haematocrit
2. RBC aggregation
3. Plasma viscosity
4. Corrected rate constant $\left(\lambda \cdot \eta_{\alpha}\right)$

\subsection{Ankle/arm pressure index measurements}

Systolic ankle/arm pressure measurements at rest and after standard tread mill exercise are generally accepted as the best non-invasive method to document arterial obstruction of the lower extremities (210). The systolic ankle/arm pressure index (229), expressed as a percentage, was calculated by dividing the systolic pressure as measured over the posterior tibial or the dorsal pedal artery by the systolic brachial artery pressure and multiplying this ratio by $100 \%$ (Table 7.1 ). The ankle/arm pressure index (API) was measured at rest. An index above $95 \%$ was considered to be normal.

The ankle and arm pressures were measured with a continuous wave (CW) Doppler instrument. This device uses a transducer containing two piezo-electrical crystals, one for continuous emission of ultrasound and one for subsequent reception of backscattered signals from moving $\mathrm{RBC}$, containing information about their velocity. The instrument which was used for this study was a bi-directional Doppler DI0 (Medasonics ${ }^{\bigotimes}$ ) with a zero-crossing circuitry. The bi-directional probe operates at an ultrasound emission frequency of $8 \mathrm{MHz}$.

After resting for 15 minutes in the supine position, the patients $(n=100)$ were investigated with the $\mathrm{CW}$-Doppler instrument. A standard blood pressure cuff, attached to a blood pressure meter, was wrapped around the upper arm and around the two ankels above the malleoli. The width of the cuff was $14 \mathrm{~cm}$. The systolic pressure was recorded at the moment of return of the flow signals during deflation of the cuff. The ankle/arm pressure indices were classified as follows:
Group I: $\quad 0-29 \%$
Group 1I: $\quad 30-59 \%$
Group 111: $\quad 60-89 \%$
Group IV: $\quad 90-100 \%$

\section{Table 7.1}

Systolic ankle/arm pressure index (API), expressed in percentage $(\%)=$ systolic ankle pressure systolic brachial artery pressure $\times 100 \%$ 


\subsection{Arteriography}

In 65 of the 100 patients arteriographic visualization was performed by means of monoplanar translumbar a ortography. Aortography was obtained by direct puncture of the aorta, using Hexebrix $(60 \mathrm{cc})$ as contrast medium and a Philips Art 5 table with a maximus M 150 Philips generator. The arterial system of the lower extremities was divided into three anatomical levels: the aorto iliac-common femoral artery segment, the superficial femoral artery segment and the arterial segment below the knee. The arteries were classified as stenosed in case of a diameter reduction of more than $50 \%$ and as non-stenosed when the diameter was reduced less than $50 \%$. The peroneal artery was excluded from classification because it was usually poorly visualized on the arteriogram. Therefore, the arteries below the knee were classified as stenosed if the posterior tibial artery and/or the anterior tibial artery were stenosed more than $50 \%$. The reason to differentiate between stenoses less or more than $50 \%$ has been described elsewhere $(I \| 1)$. It is generally assumed that flow remains unimpeded if reduction of the vessel diameter is less than $50 \%$ (10).

It was not the aim of this study to use the aorto-arteriography as a standard reference to evaluate the other methods, but to investigate whether there was a relation between haemorheological disturbances and the extensiveness of the anatomical obstructive process.

\subsection{Statistical analysis}

The Wilcoxon signed ranks test (two-tailed probability) was applied to evaluate differences within a group. To evaluate for statistical significance between two groups the Mann-Whitney test was used. In the tables mean values, standard deviations and statistical differences are presented. In the figures schematic plots are used, showing median, interquartile range (box) and range (horizontal bars), minus those values which are straying out (see figure 3.7 ). 



\section{Chapter 8}

\section{RESULTS}

In this chapter the results of the haemorheological investigations in normal subjects and patients will be presented and discussed. Yet a comparison is made between the Doppler ankle/arm pressure index measurements and the angiography information.

\subsection{Haemorheology in normal subjects and patients}

The data on haematocrit, $\mathrm{RBC}$ aggregation, plasma viscosity and corrected rate constant is presented in the figures $8 . \Downarrow-8.4$, respectively. In patients the mean haematocrit was $43.72 \pm 4.87 \%$ (table 8.1 ), which was significantly different from the haematocrit in normal subjects $(42.03 \pm 3.52 \%)$ at the level of $\mathrm{p}<0.05$.

The mean $\mathrm{RBC}$ aggregation in patients was $22.12 \pm 3.91$, which was significantly higher $(p<0.001)$ than that in normal subjects $(17.99 \pm 2.65)$.

The mean plasma viscosity was significantly higher $(\mathrm{p}<0.001)$ in patients $(1.45 \pm 0.18$ $\mathrm{mPa} . \mathrm{s})$ than in normal subjects $(1.23 \pm 0.06 \mathrm{mPa}$.

\subsection{Haemorheology and Doppler ankle/arm pressure index measurements}

Eight patients had an ankle/arm pressure index between 0 and 29 (table 8.2), and could all be classified in Fontaine's phase IV. Forty-four patients had an ankle/arm

Table 8.1 Haemorheological parameters in normal subjects and patients with occlasive arterial disease of the lower extremities. The mean values and standard deviations are presented.

\begin{tabular}{lccc}
\hline & $\begin{array}{l}\text { Normals } \\
(\mathrm{n}=40)\end{array}$ & $\begin{array}{l}\text { Patients } \\
(\mathrm{n}=100)\end{array}$ & Significance \\
\hline Haematocrit & $42.03 \pm 3.52$ & $43.72 \pm 4.87$ & $\mathrm{p}<0.05$ \\
RBC aggregation & $17.99 \pm 2.65$ & $22.12 \pm 3.91$ & $\mathrm{p}<0.00 \|$ \\
Plasma viscosity & $1.23 \pm 0.06$ & $1.45 \pm 0.18$ & $\mathrm{p}<0.00 \|$ \\
Corrected rate constant & $22.12 \pm 3.80$ & $32.27 \pm 7.43$ & $\mathrm{p}<0.00 \|$ \\
\hline
\end{tabular}




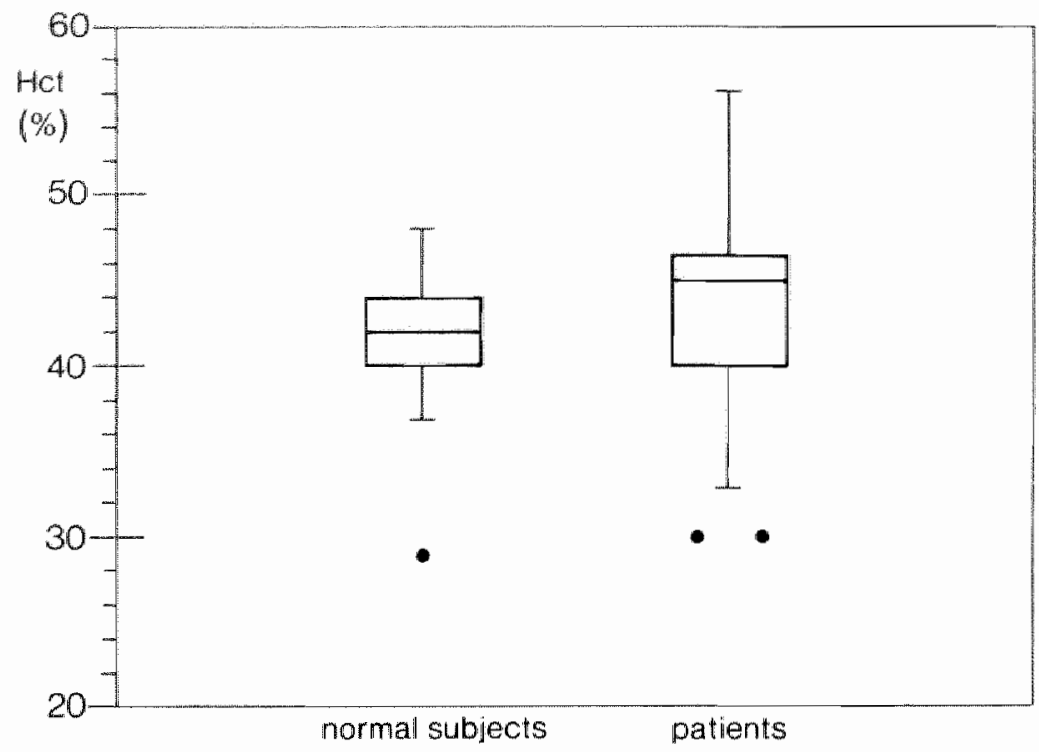

Figure 8. / Haematocrit ( $\mathrm{Hct}$ ) in normal subjects and patients (for explanation see figure 3.7$)$.

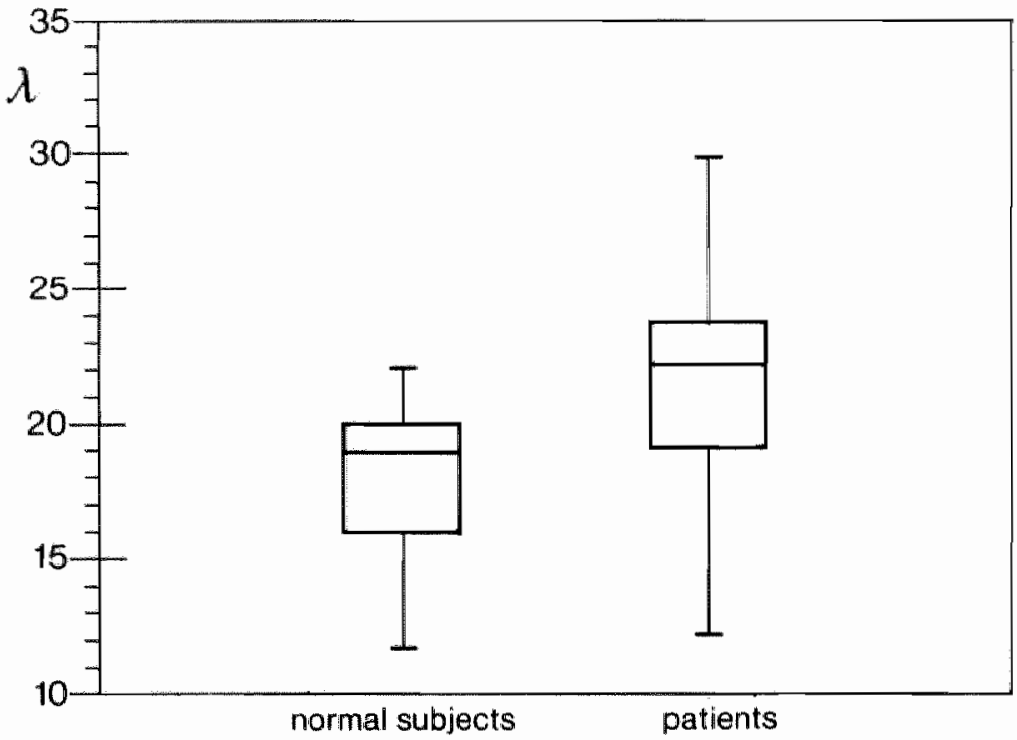

Figure 8.2 RBC aggregation $(\lambda)$ in normal subjects and patients. 


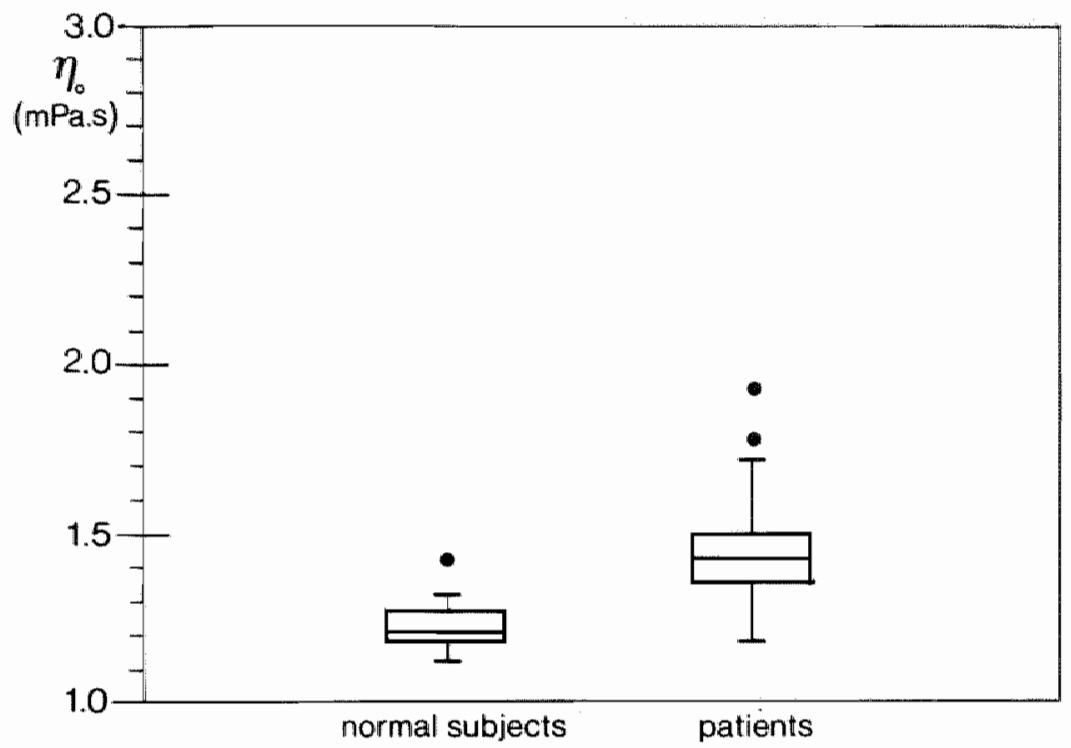

Figure 8.3 Plasma viscosity $\left(\eta_{0}\right)$ in normal subjects and patients.

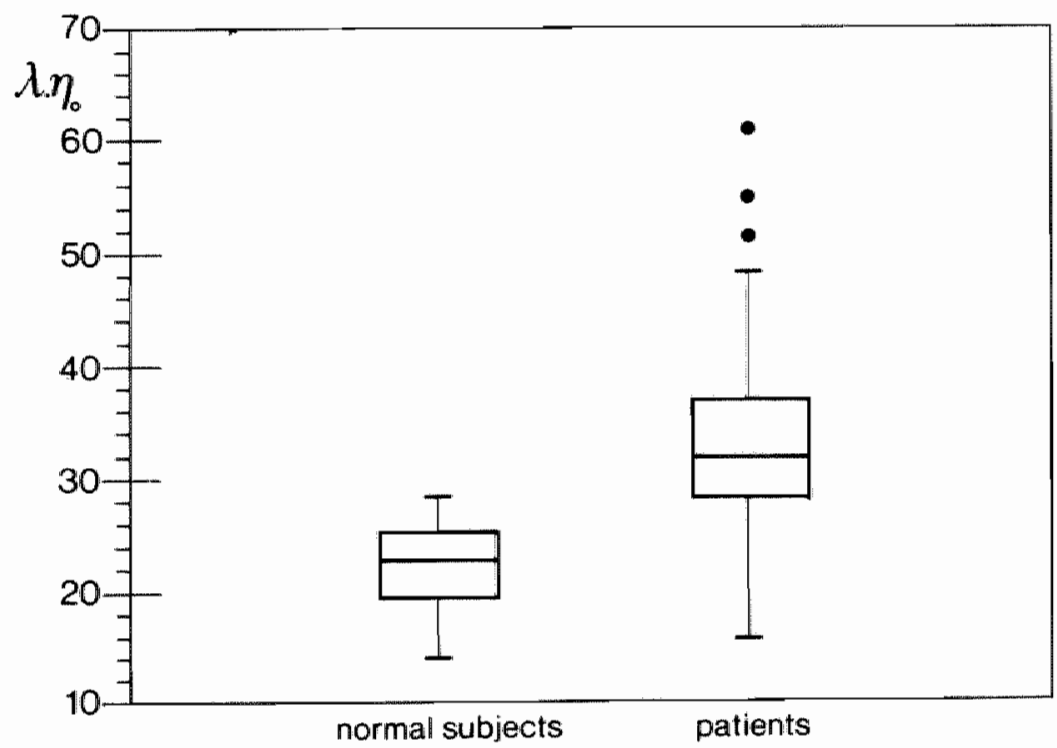

Figure 8.4 Corrected rate constant $\left(\lambda \cdot \eta_{0}\right)$ in normal subjects and patients. 
Toble 8.2 Systolic ankle/arm pressure indices $(\%)$ in patients $(n=100)$ with occlusive arterial discase of the lower extremities.

Croup I

Group 11

Croup $\| \Perp$

Croup IV

$\begin{array}{rr}0 & 29 \% \\ 30 & 59 \% \\ 60 & 89 \% \\ 90 & 100 \%\end{array}$

total
8 paticnts

44 paticuts

37 palitions

11 paticnts

100 patients

Table 8.3 Corrected rate constant $\left(A \cdot \eta_{0}\right)$ for each group of systolic ankle/arm pressure indices (API). The mean values and standard deviations are presented.

\begin{tabular}{|c|c|c|}
\hline & API & $\lambda \cdot \eta_{0}$ \\
\hline Group I & $0 \quad 29 \%$ & $40.3 \| \pm 7.24$ \\
\hline Group UI & $30 \quad 59 \%$ & $34.19+6.86$ \\
\hline Group U\|I & $6089 \%$ & $30.08 \pm 6.70$ \\
\hline Group IV & $90100 \%$ & $26.57 \pm 5.04$ \\
\hline
\end{tabular}

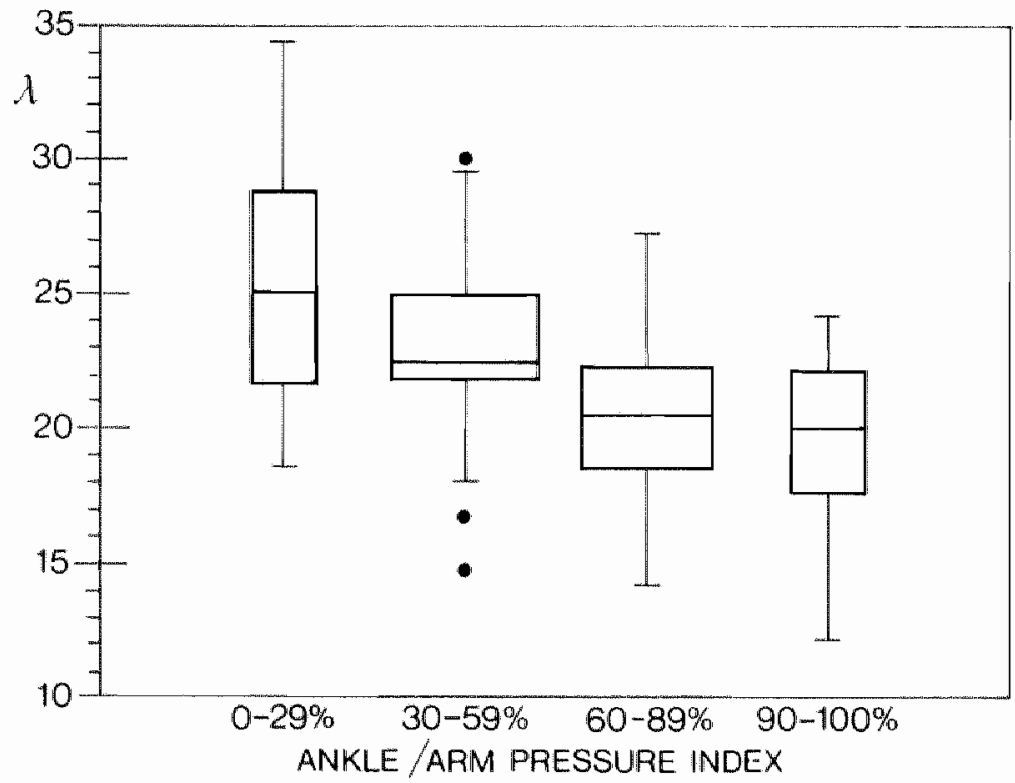

Figure 85 RBC aggregation (A) for each group of systolic ankle/arm pressure indices (for explanation see figure 3.7 ). 


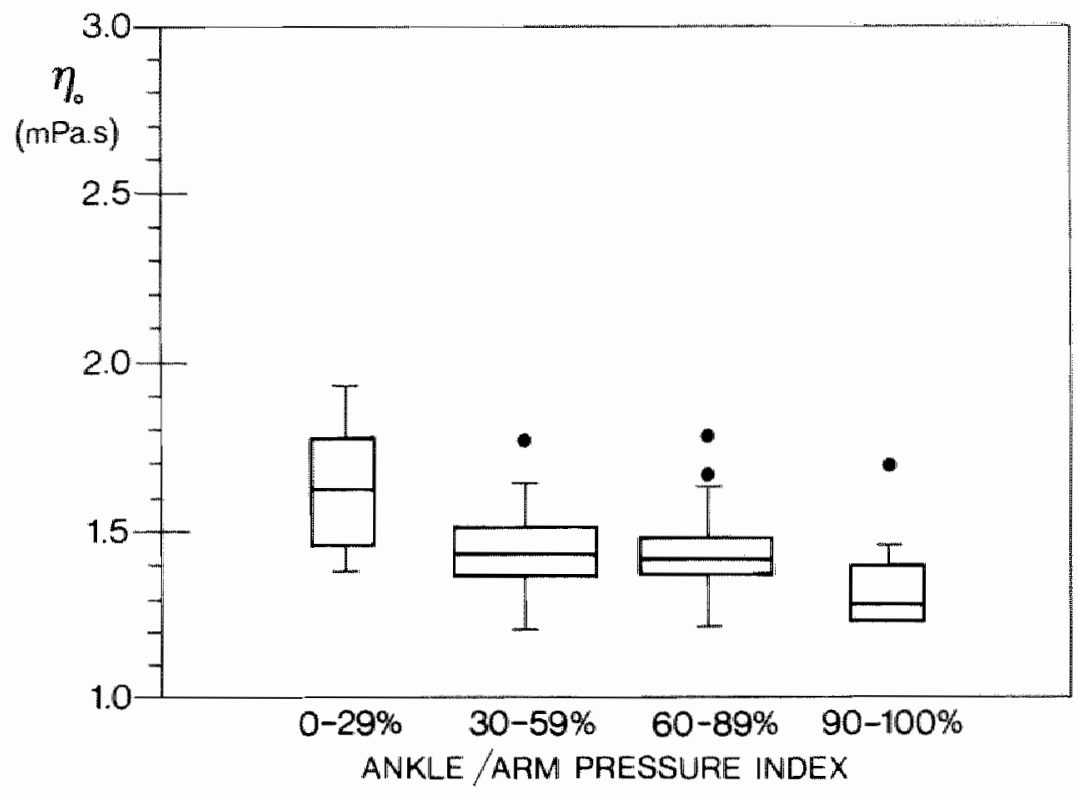

Figure 8.6 Plasma viscosity $\left(\eta_{0}\right)$ for each group of systolic ankle/arm pressure indices.

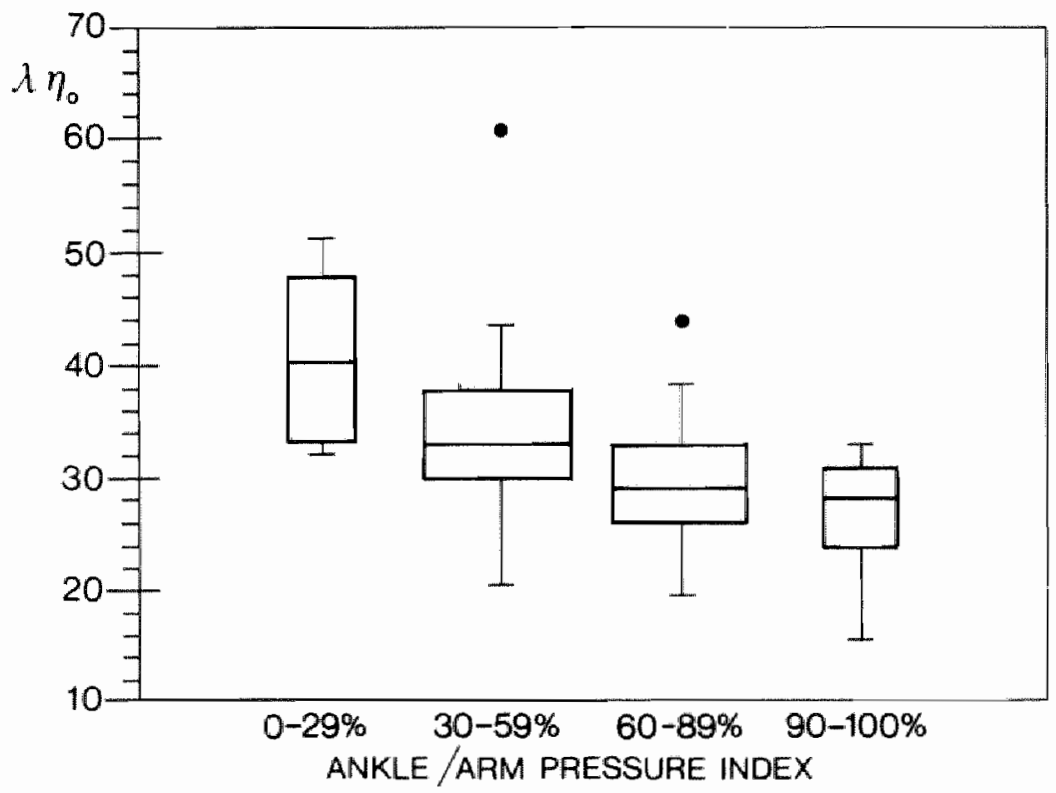

Figure 8.7 Corrected rate constant $\left(\lambda \cdot \eta_{0}\right)$ for each group of systolic ankle/arm pressure indices. 
pressure indes between 30 and $59 \%$ (10 Fontaine IV, 28 Fontaine 111,6 Fontaine II). Thirty-seven patients had an ankle/arm pressure index between 60 and $89 \%$ (all Fontaine II) and 11 patients between 90 and $100 \%$ (all Fontaine II).

To investigate whether haemorheological disturbances were related to the severity of the arterial obstruction(s) the haemorheological parameters were determined for each group of ankle pressure index. The data on RBC aggregation, plasma viscosity and corrected rate constant is presented in box plots for each group of ankle/arm pressure indices in the figures $8.5-8.7$, respectively. In table 8.3 the corrected rate constant was chosen to present the data in numbers.

It is obvious from these data that the lower the ankle/arm pressure index is, the higher the rheological disturbance will be. This indicates that patients with severe peripheral vascular disease do have a more pronounced disturbed haemorheological behaviour than patients with less severe disease. To evaluate these results by statistical analysis, the patients were divided into 2 larger groups of ankle/arm pressure indices, since the number of patients in group I and IV was too small to perform this analysis on the separate groups. The patients were divided into a group of ankle/arm pressure indices below $60 \%(n=52)$ and a group of indices above $60 \%(n=48)$. The haemorheological data of these two groups and the statistical differences are shown in table 8.4.

The significant differences between the 2 groups of patients support the results as shown in the figures $8.5-8.7$ that haemorheological parameters are more abnormal in patients with severe than in patients with moderate obstructive arterial disease.

Table 8.4 Haemorheological parameters in patients with systolic ankle/arm pressure indices above and below $60 \%$. The mean values and standard deviations are presented.

\begin{tabular}{lccc}
\hline & patients $(>60 \%)$ & patients $(<60 \%)$ & Significance \\
\hline Haematocrit & $44.73 \pm 4.74$ & $42.79 \pm 4.84$ & $p<0.05$ \\
RBCaggregation & $20.64 \pm 3.74$ & $23.48 \pm 3.59$ & $p<0.001$ \\
Plasma viscosity & $1.41 \pm 0.13$ & $1.49 \pm 0.22$ & $p<0.05$ \\
Corrected rate comstant & $29.23 \pm 6.53$ & $35.02 \pm 7.19$ & $p<0.001$ \\
\hline
\end{tabular}

Table 8.5 Corrected rate constant $\left(\lambda \cdot \eta_{0}\right)$ for each group of number of obstruction levels (O.L.). The mean values and standard deviations are presented.

\begin{tabular}{lll}
\hline O.L. & $\begin{array}{l}\text { Number of } \\
\text { patients }\end{array}$ & $\lambda \cdot \eta_{0}$ \\
\hline 1 & 18 & $31.95 \pm 8.54$ \\
3 & 33 & $33.40 \pm 9.80$ \\
& 14 & $33.56 \pm 10.29$ \\
\hline
\end{tabular}




\subsection{Haemorheology and angiography}

In 65 of the 100 patients arteriographic visualization was performed by translumbar a ortography, whereafter the arterial system was classiffed as being obstructed $>50 \%$ diameter reduction) or not obstructed ( $<50 \%$ diameter reduction) at one, two or three levels.

Eighteen patients had an obstruction at one level, 33 patients had an obstruction at two levels and 14 patients had obstructions at three levels.

The haemorheological data for each group of patients with one, two or three obstructed levels is shown in the figures 8.8-8.11 and in table 8.5. No statistical differences could be detected between the haemorheological parameters in the patients with one, two or three level disease.

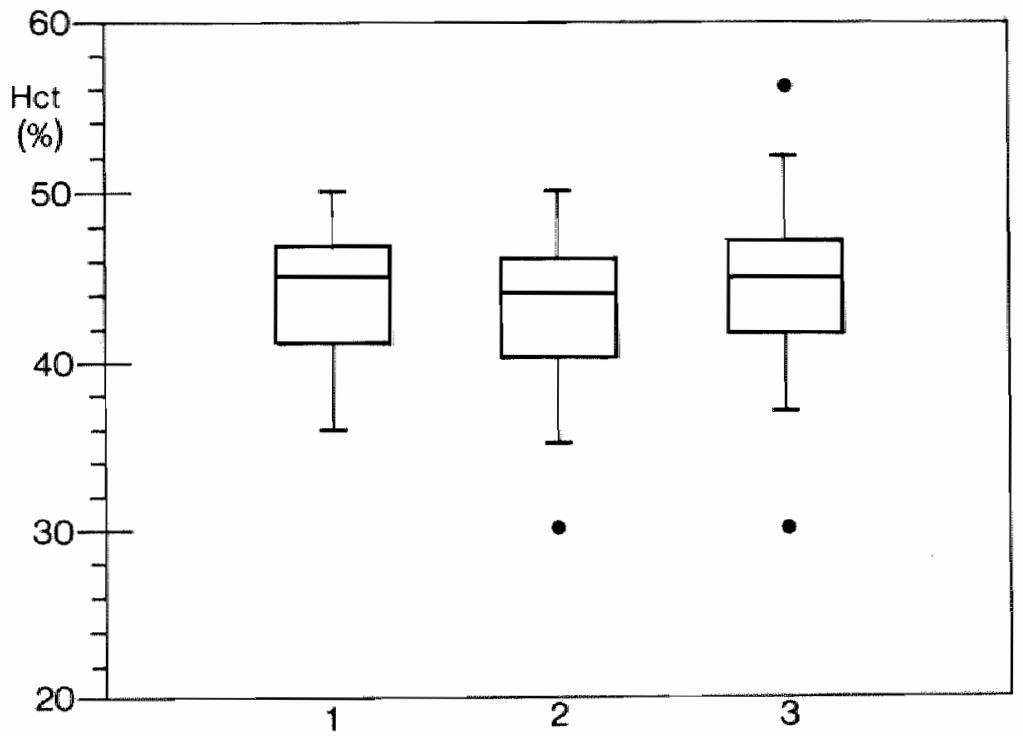

Figure 8.8 Haematocrit (Hct) for the patients with 1,2 or 3 obstruction levels (for explanation see figure 3.7 ). 


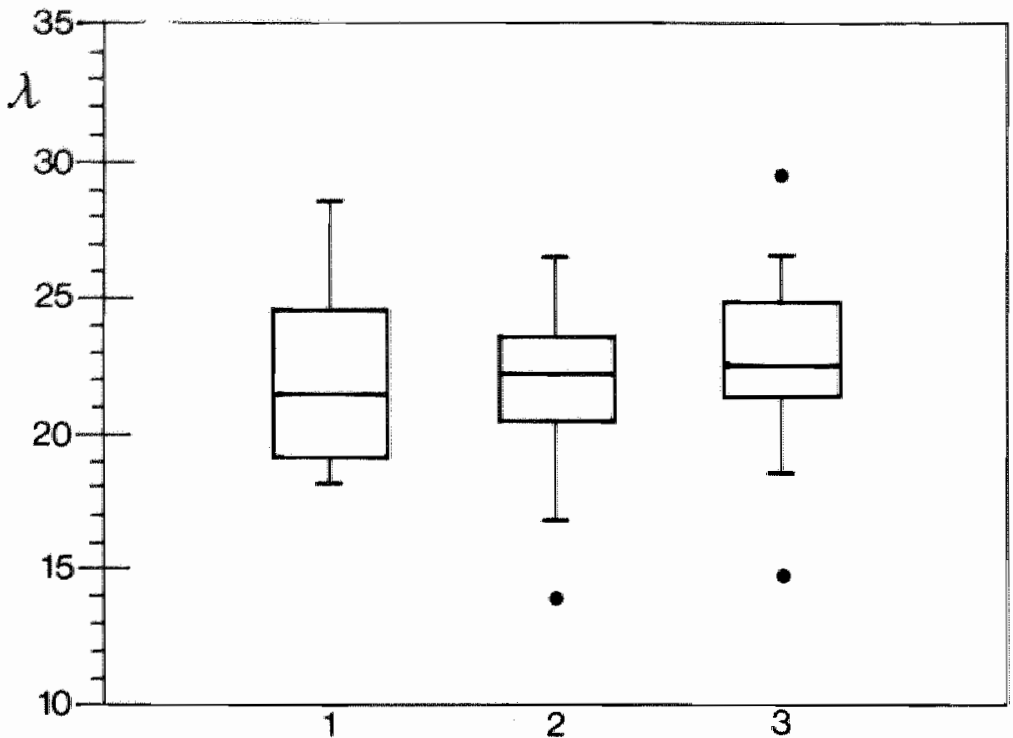

Figure 8.9 RBC aggregation ( $\lambda$ ) for the patients with 1,2 or 3 obstruction levels.

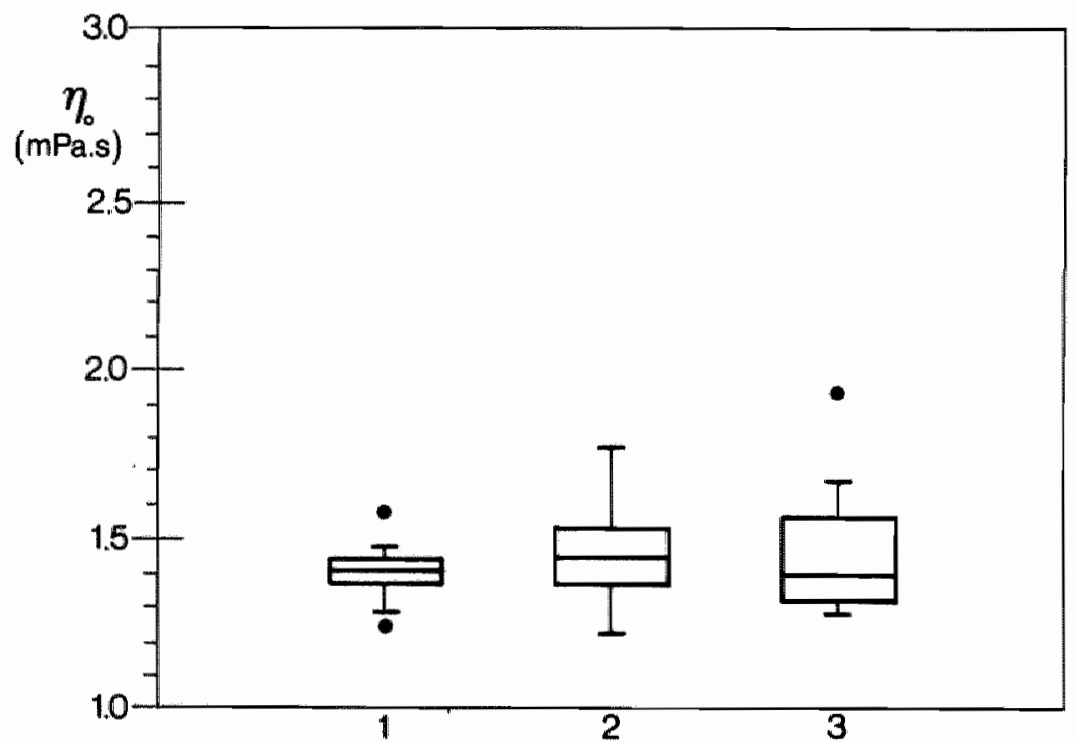

Figure 8.10 Plasma viscosity ( $\eta_{0}$ ) for the patients with 1,2 or 3 obstruction levels. 


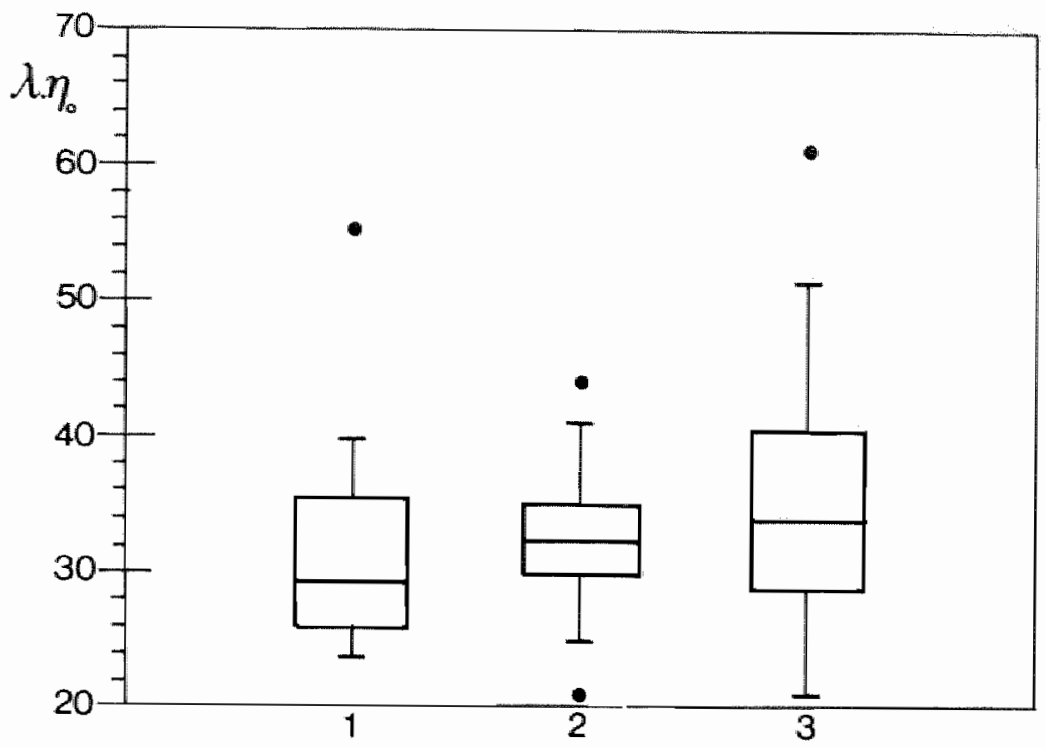

Figure $8.1 /$ Corrected rate constant $\left(\lambda \cdot \eta_{0}\right)$ for the patients with 1,2 or 3 obstruction levels. Corrected rate constant $\left(\lambda \cdot \eta_{0}\right)$ for the patients with 1,2 or 3 obstruction levels.

\subsection{Discussion}

The results of the present study demonstrate that patients with occlusive arterial disease of the lower limbs have an elevated $\mathrm{RBC}$ aggregation, plasma viscosity and haematocrit as compared to normal subjects. These findings are in concurrence with the results of Dormandy et al. (48) who described an elevated whole blood viscosity, at both high and low shear rates, in patients with occlusive arterial disease of the lower extremities and concluded that increased blood viscosity can be an important factor in reducing blood flow. Disturbances in blood rheology have also been described in other atherosclerotic diseases like coronary artery disease (148) and cerebrovascular accidents (182). In these studies it was suggested that increased viscosity might impair haemodynamics and affect flow resistance and oxygen transport. The rationale in atherosclerotic diseases is that states of low blood flow arises distal to arterial stenosis, causing reduced shear stresses followed by increased RBC aggregation and local blood viscasity. These local aggregates and increased viscosity further reduce the blood flow, contributing to clinical manifestations of ischaemia. This blood flow reduction initiates a further increase in $\mathrm{RBC}$ aggregation and viscosity, and hence a vicious circle. This was also described by Di Perri (46) who provided evidence that ischaemia, caused by atherosclerosis, may secondarily increase blood viscosity, which in turn execerbates ischaemia. The finding in the present study that patients with the most severe obstructive arterial disease had the most pronounced haemorheological disturbances supports the previous mentioned rationale that blood viscosity is higher at reduced blood flow and shear stresses. However, il should be noted that the 
rheological parameters were determined in systemic blood. The question remains as to whether these systemic values reflect the situation at the microcirculatory level in vivo and these disturbances really influence perfusion. Since the exact vascular geometry, the RBC velocities and the arterial-venous pressure differences are unknown, the influence of rheological changes on tissue perfusion can not be calculated, but only speculated upon.

An interesting finding in the present study was that the degree of haemorheological disturbances was related to the degree of narrowing, while there was no relation between haemorheological changes and the extensiveness (one or multilevel) of the disease. These findings indicate that there is a relation between atherasclerosis and disturbances in haemorheology, but not between these disturbances and the extensiveness of the disease. That the haemorheological disturbances are indeed an expression of generalized atherosclerosis is supported by the finding that these disturbances are also observed in patients with intermittent claudication, cerebrovascular accidents and coronary aretery disease $(48,148,182)$.

In further studies it is especially important to determine the in vivo haemodynamic and metabolic functions together with the local in vivo rheological behaviour of blood, so that the rolle of blood rheology can be properly interpreted in the context of the overall circulatory performance. 


\section{Chapter 9}

\section{THERAPY}

Information about peripheral circulation and the site and severity of arterial stenosis can be derived from ankle/arm pressure index measurements using Doppler techniques. In chapter 8 it was shown that the haemorheological disturbances in patients with occlusive arterial disease of the lower extremities were inversely related to ankle/arm pressure indices, indicating that the more severe the occlusive arterial disease is, the more pronounced the haemorheological disturbances will be. Therefore, it is interesting to know whether improved peripheral circulation following successful reconstructive vascular surgery will have an effect on the disturbed haemorheology pre-operatively. Improvement of peripheral circulation after reconstructive vascular surgery can, for example, be established by an increase in postoperative ankle/arm pressure index as compared to the pre-operative situation. In this part of the study we compared the ankle/arm pressure indices and the values of the haemorheological parameters before and after surgery.

\subsection{Vascular surgery}

In 22 of the 100 patients with intermittent claudication, there was an indication for reconstructive vascular surgery at the time of this study. The operations varied from femoral-popliteal, femoral-crural and axillo-bifemoral bypasses to aorto-bifurcation prostheses and cross-over techniques.

Haemorheological and ankle/arm pressure index measurements were performed before as well as one day and six weeks after surgery.

In all patients $(n=22)$ the preoperative rheological parameters were significantly different from the control group. The mean haematocrit was $43.55 \pm 5.06 \%$, the mean $\mathrm{RBC}$ aggregation was $23.88 \pm 3.67$ and the mean plasma viscosity was $1.50 \pm 0.21$ $\mathrm{mPa}$.s. The mean ankle/arm pressure index was $42.82 \pm 15.10 \%$.

In table 9.1 and in the figures 9.1-9.4 the data on haemorheological parameters and ankle/arm pressure indices before and one day and six weeks after vascular surgery are presented. One day after surgery the mean ankle/arm pressure index increased significantly $(\mathrm{p}<0.001)$ from $42.82 \%$ to $78.68 \%$ while the haemorheological para- 
Table 9.1 Haematocri (HC). RBC aggregation (A). plasma viscosity ( $7_{0}$ ) and systolic ankle arm pressure indices (API) before and after reconsiructive vascular surgery. The mean values and standard deviations are presented.

\begin{tabular}{|c|c|c|c|}
\hline & Befare surgery & $\begin{array}{l}\text { lday after } \\
\text { surgery }\end{array}$ & $\begin{array}{l}6 \text { woeks after } \\
\text { surgery }\end{array}$ \\
\hline Het & $43.55 \pm 5.06$ & $42.73 \pm 3.25$ & $42.73 \pm 2.71$ \\
\hline$\lambda$ & $23.88 \pm 3.67$ & $23.84 \pm 2.71$ & $23.87 \pm 3.14$ \\
\hline$r_{0}$ & $1.50+0.21$ & $1.50 \div 0.13$ & $1.48 \pm 0.10$ \\
\hline API & $42.82 \pm 15.10$ & $78.68 \pm 22.83$ & $\begin{array}{c}84.77 \pm 26.14 \\
4\end{array}$ \\
\hline
\end{tabular}

meters did not change significantly. Six weeks after surgery all patients were free of complaints. The mean systolic ankle/arm pressure index had further increased $(84.77 \%)$ and was even higher $(\mathrm{p}<0.05)$ than the value measured one day postoperatively. The haemorheological data had not changed 6 weeks after surgery.

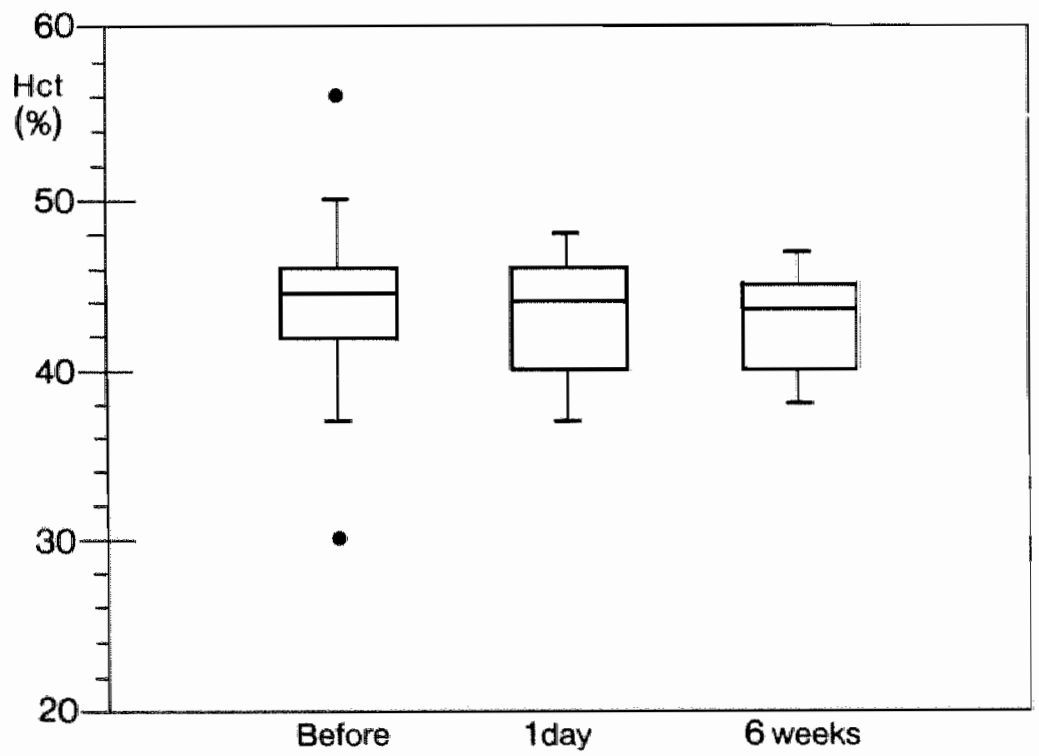

Figure 9.1 Haematocrit (Het) before, one day and 6 weeks after vascular surgery (for explanation see figure 3.7 ). 


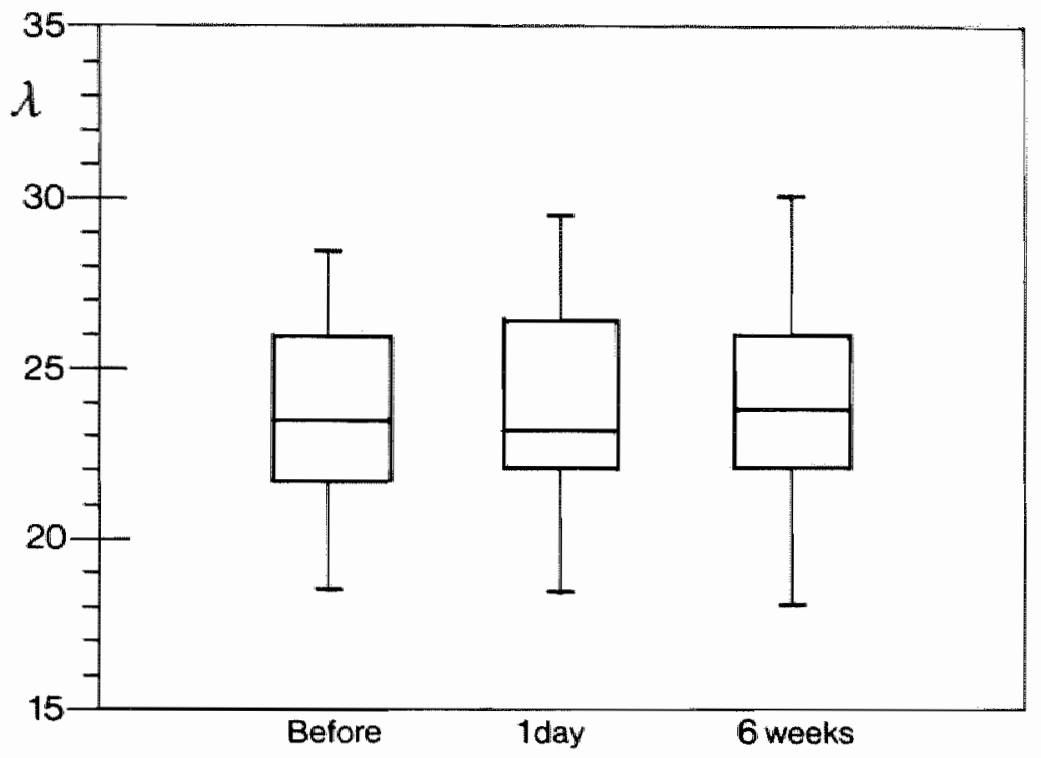

Figure 9.2 RBC aggregation ( $\lambda$ ) before, one day and 6 weeks after vascular surgery.

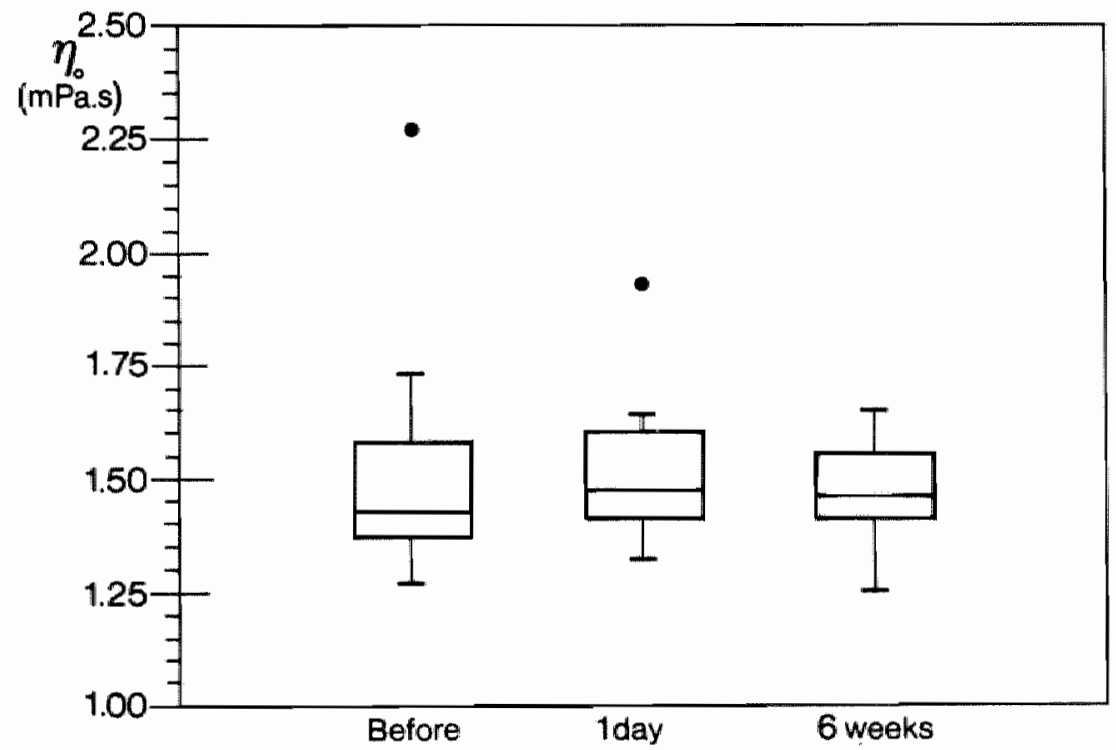

Figure 9.3 Plasma viscosity $\left(\eta_{0}\right)$ before, one day and 6 weeks after vascular surgery. 


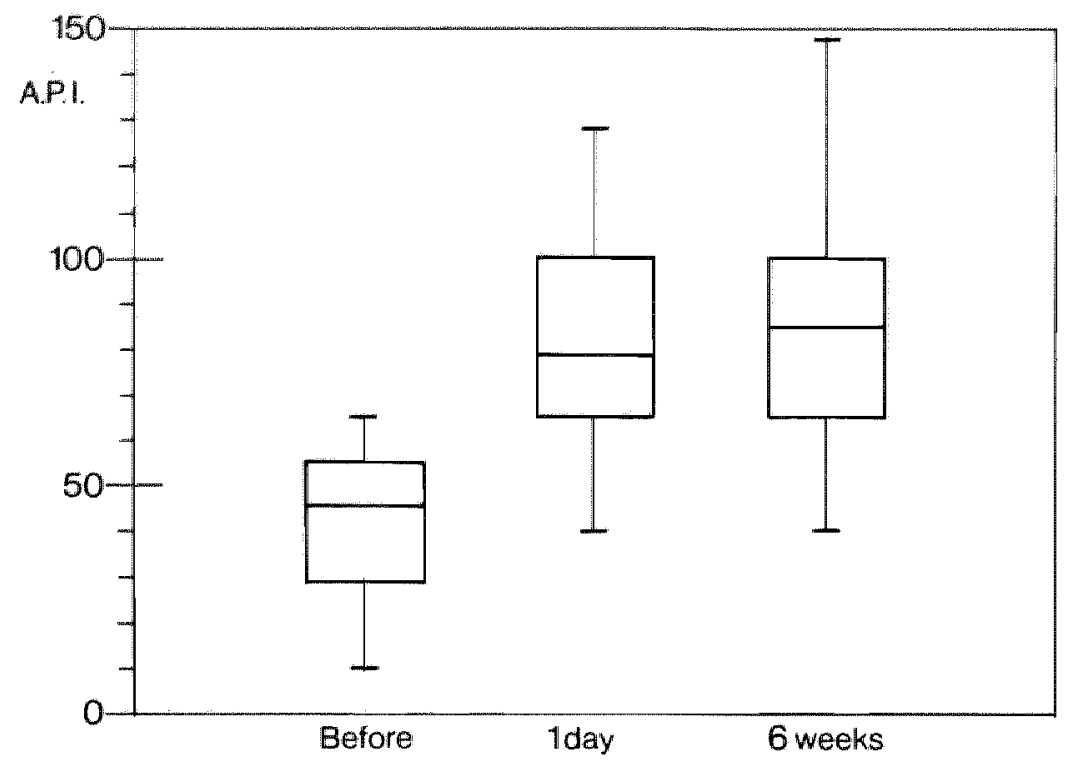

Figure 9.4 Doppler systolic ankle/arm pressure indices (API) before, one day and 6 weeks after vascular surgery.

\subsection{Discussion}

Improved peripheral circulation, as evidenced by the increase in ankle/arm pressure index, after restoring vascular geometry caused clinical improvement, but had no effect on the rheological parameters measured.

Although patients with the most severe obstructive arterial disease had the most pronounced haemorheological disturbances, this does not necessarily mean that these disturbances aggravate ischaemia. The finding that the patients, undergoing surgery, improved both clinically and by ankle/arm pressure indices but did not show changes in the rheological parameters, suggests that ischaemia per se is not responsible for the changes in blood properties as measured. This raises the question as to whether

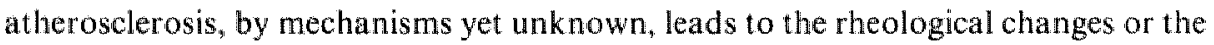
alterations in the blood play a role in the development of atherosclerosis. This question cannot be answered at the present state of the art. Disturbed haemorheology is probably not the primary causing factor of intermittent claudication, but more an expression of generalized atherosclerosis (see also section 8.4).

Another clinically important question is whether correction of the rheological changes results in an improvement of peripheral circulation and, if so, whether this correction would further enhance peripheral circulation.

Since blood viscosity is one of the major determinants of blood flow resistance, improving haemorheology should theoretically be followed by reduced resistance and thus enhanced tissue perfusion. In practice, however, the clinical effects of diminish- 
ing blood viscosity by haemodilution or plasmapheresis are in conflict. In several studies (204) flow improvement has been described, while in other studies (225) haemorheological changes were not associated with either subjective or objective improvement in walking distance, peripheral blood flow as measured by strain gauge plethysmography and Doppler ankle/arm pressure index measurements. The present study does not provide any evidence in favour or against the idea that diminished blood viscosity would lead to enhanced tissue perfusion.

Based upon the data of this study, it might be concluded that it is of clinical importance to investigate the effects of altering the rheological changes in cases where surgery is contraindicated or fails to result in improvement of the patients symptoms and signs. 



\section{GENERAL DISCUSSION AND CONCLUSIONS}

The main purpose of the first part of this thesis was to study haemorheological parameters and capillary microscopic variables and parameters in patients with vasospastic and ischaemic phenomena of hands and fingers in order to investigate whether these parameters could be used to provide a more accurate nomenclature of these phenomena.

After Maurice Raynaud (193) described the clinical symptoms of symmetrical or bilateral discolouration of hands and fingers in response to cold stimuli, nomenclature of this phenomenon has always been a point of discussion. Raynaud himself contributed to this confusion since he did not differentiate between local asphyxia and symmetrical discolouration. In an attempt to create a more useful nomenclature, Allen and Brown (3) were the first to review and modify Raynaud's original criteria. However, such wascular diseases of hands and fingers as asphyxia due to local arterial anatomical obstructions, are still classified as Raynaud's phenomenon, hampering the differentiation between the various vasospastic and ischaemic hand phenomena. To get more insight into the etiology and pathophysiology of the disturbed digital circulation and to improve diagnosis, several techniques have been developed. Techniques like angiography $(40,116,149,196)$, measurement of digital blood pressure $(120,175,216)$, radioisotope clearance $(35,122,123)$, plethysmography $(16,36,51,108)$ and Doppler ultrasound (211) are commonly used in the clinic. These methods, however, are macrocirculatory methods which enable the study of global haemodynamics in a region, but are not sensitive enough for evaluating the disturbed skin microcirculation as occurs in patients with vasospastic and ischaemic hand phenomena.

Investigation of the morphology of nail-fold capillaries by capillary microscopy, already described since the beginning of this century $(27,174)$, has shown to be useful to distinguish between Raynaud's phenomenon with and without underlying disease $(87,154)$. The introduction of television capillary microscopy (14) allows the noninvasive investigation of blood flow in nutritional skin capillaries.

An abnormal high blood viscosity in patients with Raynaud's phenomenon was first described by Pringle et al. (191). An increase in blood viscosity, particularly at low shear rates and low temperatures, was also found by other investigators $(44,75,217)$. In these studies, however, no distinction was made between primary and secondary Raynaud's phenomenon. This seems to be important because increased viscosity may be a causative factor in secondary Raynaud's phenomenon, but not in primary 
Raynaud's phenomenon (107).

The findings in the present study show that patients with primary and secondary Raynaud's phenomenon, acrocyanosis and asphyxia manus et digitorum can be distinguished on the basis of clinical criteria as confirmed by haemorheological and capillary microscopic investigations. Rheological disturbances were confined to patients with secondary Raynaud's phenomenon. In addition to abnormal smooth muscle tone and alterations in the microvasculature the rheological factors are suggested to further deteriorate the blood supply to the skin in these patients. Enhancing blood Rluidity by plasma pheresis improved both clinical symptomatology and nutritional capillary blood flow in patients with secondary Raynaud's phenomenon.

Morphological studies of the nail-fold capillaries showed to be useful to distinguish between normal subjects, patients with primary and secondary Raynaud's phenomenon, and patients with acrocyanosis. In patients with local digital asphyxia, the morphological parameters were the same as in normal subjects, but capillary red blood cell velocity was significantly reduced in the affected finger(s) compared to the non-affected fingers. In all groups of patients, capillary red blood cell velocity was significantly lower as compared to normal subjects, especially after cold provocation. Dynamic capillary microscopy showed to be a reliable method to study changes in nutritional skin blood flow, as induced by therapy. Subjective changes during and after treatment could be objectivated by measuring capillary red blood cell velocity. The therapeutic possibilities in patients with vasospastic and ischaemic hand phenomena are rather extensive, but the results obtained are still unsatisfactory with most of the treatments. In this study some beneficial effects of two vasoactive drugs are described, but additional double blind investigations are required to rate these findings at their true value. The first requisite in evaluating the results of therapy adequately is a common nomenclature. Moreover, reliable and reproducible methods have to be used to evaluate the clinical changes induced by therapeutical intervention. The results of the first part of the present study allow the following conclusions.

- Patients with primary and secondary Raynaud"s phenomenon, acrocyanosis and asphyxia manus et digitorum can be distinguished by combining haemorheological observations and microscopic investigations of the nailfold capillaries.

The nomenclature currently employed in the clinic can be used to define the different phenomena.

- Therapeutical intervention can be evaluated by dynamic capillary microscopy.

The main purpose of the second part of this thesis was to investigate haemorheological parameters in patients with occlusive arterial disease of the limbs with special emphasis on the talation, if any, between these parameters and the severity and extensiveness of the disease.

The approach to treatment of patients with occlusive arterial disease depends on the severity and extent of the obst ructive process. Reconstructive arterial surgery remains the most commonly applied method and is effective in restoring the pressure and fllow characteristics to a normal or near normal level. The extent to which changes in the 
blood itself may affect tissue perfusion is not precisely known but could explain the poor results occasionally obtained after vascular surgery.

Disturbances in blood rheology have been described in atheroselerotic diseases as cerebrovascular accidents (182) and coronary artery disease (148). Dormandy et al.(48) reported an elevated blood viscosity at both high and low shear rates in patients with occlusive arterial disease of the lower extremities. The findings in the present study also demonstrate that patients with occlusive arterial disease of the lower limbs have a higher plasma viscosity and $\mathrm{RBC}$ aggregation than normal subjects. Patients with the most severe obstructive arterial disease had the most pronounced haemorheological disturbances, which does not necessarily mean that these disturbances aggravate tissue perfusion. The finding that the patients who improved after surgery, both clinically and according to the increased ankle/arm pressure indices, had no changes in the rheological parameters, even after 6 weeks, suggests that ischaemia per se is not responsible for the haemorheological changes. It is suggested that the haemorheological disturbances are an expression of generalized atherosclerosis.

The most important question remains to which extent these rheological disturbances are responsible for the clinical symptoms and whether improvement of these disturbances is followed by improved symptomatology and enhanced peripheral blood flow. To be able to interpret the role of blood rheology in ischaemic vascular diseases properly, the assessment of vascular geometry, capillary aed blood cell velocity and arterial-venous pressure differences should be combined with in vivo investigation of the local, in vivo rheological behaviour of blood.

The results of the second part of the present study allow the following conclusions.

- Patients with occlusive arterial disease of the lower extremities have a higher RBC aggregation and plasma viscosity than normal subjects.

- The severity of the haemorheological disturbances is related to the severity of the arterial occlusive disease.

- Reconstructive vascular surgery has no significant influence on the disturbed haemorheological parameters. 

This thesis reports on haemorheological and nail-fold capillary microscopic investigations in patients with vasospastic and ischaemic hand phenomena. With the combination of these two techniques, patients with primary and secondary Raynaud's phenomenon, acrocyanosis and asphyxia manus et digitorum could be distinguished. This nomenclature can thus be used to define these different vasospastic and ischaemic hand phenomena. Haemorheological and capillary microscopic parameters and variables were also used to evaluate therapeutic intervention. Especially dynamic capillary microscopy showed to be a reliable noninvasive technique to objectivate clinical changes as induced by treatment.

In the second part of this thesis, haemorheological parameters were investigated in patients with occlusive arterial disease of the lower limbs with special emphasis on the relation, if any, between these parameters and the severity and extensiveness of the disease. These patients had a significant higher red blood cell aggregation and plasma viscosity compared to normal subjects. The severity of the haemorheological disturbances was related to the severity of the arterial occlusive disease.

Reconstructive vascular surgery had no significant influence on the disturbed haemorheological parameters.

In the introduction (chapter I) the present state of the art concerning patients with Raynaud's phenomenon and patients with intermittent claudication is surveyed. This chapter emphasizes the need for practical, reliable and objective methods to investigate the microcirculation in these patients.

In chapter 2, the general history of Raynaud's phenomenon is summarized, followed by a review of the literature concerning the aetiological and pathophysiological ideas about primary and secondary Raynaud"s phenomenon and acrocyanosis. In the same chapter the population of patients and normal subjects as studied in this thesis is described. Our clinical classification was used to differentiate between primary and secondary Raynaud's phenomenon, acrocyanosis and asphyxia manus et digitorum. In chapter 3 the most important techniques are reviewed and the methods as used in this thesis are described. In the review it is concluded that most methods are macrocirculatory methods which are not sensitive enough to evaluate the disturbed skin microcirculation in the patients under investigation. Haemorheological and capillary microscopic investigations were chosen as the principal methods to study patients with vasospastic and ischaemic hand phenomena.

In chapter 4 the results of the haemorheological and capillary microscopic investigations on the normal subjects and the different groups of patients with vasospastic and ischaemic hand phenomena are presented. Red blood cell aggregation and plasma 
viscosity were normal in all groups except in patients with secondary Raynaud"s phenomenon in whom these parameters were significantly increased. Morphological studies of the nail-fold capillaries were found to be useful to distinguish between normal subjects, patients with primary and secondary Raynaud"s phenomenon, and patients with acrocyanosis. In patients with local digital asphyxia, the morphological parameters were the same as in normal subjects, but capillary red blood cell velocity wass significantly reduced in the affected fingers. In all groups of patients, capillary red blood cell velocity was significantly lower as compared to normal subjects, especially after cold provocation. It is concluded that these findings show that patients with primary Raynaud's phenomenon, secondary Raynaud's phenomenon, acrocyanosis and as phyxia manus et digitorum can be distinguished on the basis of haemorheological and capillary microscopic investigations. This clinical nomenclature can thus be used to define these different phenomena.

In chapter 5 the haemorheological and microcirculatory techniques are used to evaluate the effects of two vasoactive drugs, plasmapheresis and stellate ganglion blockade. The main purpose of this part of the study was to explore whether these techniques could be used to objectivate subjective changes as induced by the treatment. Dynamic capillary microscopy showed to be a reliable method to study changes in nutritional skin blood flow, as induced by therapy. Subjective changes during and after treatment could be objectivated by measuring capillary red blood cell velocity. In chapter 6 the aim of the second part of this thesis is presented. The main purpose was to assess the haemorheological parameters in patients with occlusive arterial disease of the lower limbs and in normal subjects.

In chapter 7 the methods and materials are discussed. Systolic ankle/arm pressure indices, as measured with a continuous wave Doppler instrument, were determined to investigate the relation, if any, between the degree of haemorheological disturbances and the severity of arterial occlusive disease. Aorto-arteriography was performed to investigate the relation, if any, between haemorheological disturbances and the number of anatomical levels at which arterial disease of the lower limbs could be detected.

In chapter 8 the results of the haemorheological investigations in normal subjects and patients with occlusive arterial disease of the lower extremities are presented as well as the results of the systolic ankle/arm pressure index measurements and angiography. Red blood cell aggregation, plasma viscosity and haematocrit were significantly increased in these patients as compared to normal subjects. The degree of haemorheological disturbances was related to the severity of the arterial occlusive disease, but not to the extensiveness (one or multilevel) of the disease. These findings indicate that there is a relation between atherosclerosis and disturbances in haemorheology.

In chapter 9 the systolic ank le/arm pressure indices and the values of the haemorheological parameters are compared before and one day and six weeks after reconstructive vascular surgery. After surgery the mean systolic ankle/arm pressure index increased significantly while the haemorheological parameters were not affected, suggesting that ischaemia per se is not responsible for the measured changes in the blood. It is suggested that the haemorheological disturbances are an expression of 
generalized atherosclerosis.

In chapter 10 the most prominent findings of this study are discussed and the conclusions are presented. 

In dit proefschrift worden haemorheologische studies en capillair microscopische onderzoeken van de nagelriem beschreven bij patiënten met vasospastische en ischaemische verschijnselen aan de handen.

Met behulp van deze twee methoden kunnen patiènten met een primair-en secundair fenomeen van Raynaud, acrocyanose en asphyxia manus et digitorum worden onderscheiden. Deze nomenclatuur kan dus gebruikt worden om de verschillende vasospastische en ischaenxische aandoeningen van de handen te karakteriseren. De haemorheologische en capillair microscopische parameters en variabelen werden bovendien gebruikt om therapeutische interventies te evalueren. Vooral dynamische capillairmicroscopie bleek een betrouwbare niet-invasieve techniek te zijn om de klinische resultaten van therapie te objectiveren.

In het tweede gedeelte van dit proefschrift werden haemorheologische parameters onderzocht bij patiënten met arterieel vaatlijden van de onderste extremiteiten met speciale aandacht voor de mogelijke relatie tussen de mate van haemorheologische veranderingen en de ernst en uitgebreidheid van de ziekte. Vergeleken met gezonde personen was bij de patiënten de erythrocytenaggregatie en plasmaviscositeit significant hoger. De mate van de haemorheologische stoornis bleek gerelateerd te zijn aan de ernst van het arterieel lijden. Reconstructieve vaatchirurgie had geen significante invloed op de gestoorde haemorheologische parameters.

In de introductie (hoofdstuk I) wordt geschetst dat het belangrijk is te beschikken over practische, betrouwbare en objectieve methoden om de microcirculatie te onderzoeken bij patiënten met het fenomeen van Raynaud en bij patienten met claudicatio intermittens.

In hoofdstuk 2 wordt de geschiedenis van het fenomeen van Raynaud beschreven, gevolgd door een overzicht van de literatuur betreffende de etiologische- en pathophysiologische ideeën over het primaire- en secundaire fenomeen van Raynaud en acrocyanose. In hetzelfde hoofdstuk worden de in dit proefschrift onderzochte gezonde personen en patiènten beschreven. Onze klinische classificatie werd gebruikt om onderscheid te maken tussen het primaire- en secundaire fenomeen van Raynaud, acrocyanose en asphyxia manus et digitorum.

In hoofdstuk 3 wordt een overzicht gegeven van de belangrijkste, in de literatuur beschreven onderzoekstechnieken en worden de in dit proefschrift gebruikte methoden beschreven. De conclusie wan het literatuuroverzicht is dat de meeste methoden niet gevoelig genoeg zijn om de gestoorde microcirculatie in de huid te bestuderen. Om patiënten met vasospastische- en ischaemische aandoeningen van de handen te onderzoeken, werden de haemorheologische-en capillair microscopische technieken 
gebruikt als referentiemethoden.

In hoofdstuk 4 worden de haemorheologische-en capillair microscopische resultaten gepresenteerd van het onderzoek bij de gezonde personen en patiënten met vasospastische-en ischaemische aandoeningen van de handen. De erythrocytenaggregatie en plasmaviscositeit waren normaal bij alle groepen, behalve bij patiënten met een secundair fenomeen van Raynaud, bij wie deze parameters significant verhoogd waren. Morfologische parameters, bepaald met behulp van capillairmicroscopie, waren significant verschillend bij patiënten met een primair-en secundair fenomeen van Raynaud, acrocyanose en asphyxia manus et digitorum. De erythrocytensnelheid voor en na koudeprovocatie was bij alle patiënten verlaagd. De conclusie van deze studie is dat met behulp van haemorheologisch-en capillair microscopisch onderzoek gedifferentieerd kan worden tussen patiënten met een primair-en secundair fenomeen van Raynaud, acrocyanose en asphyxia manus et digitorum en dat de gebruikte nomenclatuur toegepast kan worden om deze fenomenen te onderscheiden.

In hoofdstuk 5 zijn de haemorheologische-en microcirculatietechnieken gebruikt om de effecten te evalueren van twee vaso-actieve medicamenten, plasmaferese en ganglion stellatum blokkade. Het doel van dit deel van de studie was na te gaan of deze technieken gebruikt konden worden om eventuele subjectieve veranderingen ten gevolge van de therapie, te objectiveren. Dynamische capillairmicroscopie bleek een betrouw bare methode te zijn om veranderingen in de nutritieve huidd oorbloeding ten gevolge van de therapie te bestuderen. Subjectieve veranderingen tijdens en na behandeling konden worden geobjectiveerd met behulp van het bepalen van de stroomsnelheid van erythrocyten.

In hoofdstuk 6 wordt het doel van het tweede deel van dit proefschrift beschreven: haemorheologisch onderzoek bij patiënten met arterieel vaatlijden van de onderste extremiteiten en bij gezonde personen.

In hoofdstuk 7 worden de methoden beschreven. Om een mogelijke relatie tussen de mate van de haemorheologische stoornis en de ernst van het vaatlijden te onderzoeken werd bij iedere patient de systolische enkel/armdruk index bepaald, met behulp van een continuous wave Dopplerinstrument. Aorto-arteriografie werd verricht om een mogelijke relatie te vinden tussen de haemorheologische stoornissen en het aantal niveaus waarop het arteriële vaatstelsel was aangedaan.

In hoofdstuk 8 worden de resultaten gepresenteerd van het haemorheologische onderzoek, en de enkel/armdruk indexmetingen en de angiografieën. De erythrocytenaggregatie, plasmaviscositeit en haematocriet waren significant verhoogd bij patienten met arterieel vaatlijden van de onderste extremiteiten. De mate van de haemorheologische stoornissen bleek gerelateerd te zijn aan de ernst van het perifeer valtijden, maar niet met de uitgebreidheid (een of meerdere niveaus) van de ziekte. Deze bevindingen wijzen op een mogelijke relatie tussen atherosclerose en stoornissen in de haemorheologie.

In hoofdstuk 9 worden de systolische enkel/armdruk en de haemorheologische waarden voor en éen dag en zes weken na reconstructieve vaatchirurgie vergeleken. $\mathrm{Na}$ chirurgie was de gemiddelde enkel/arm index significant gestegen, terwijl de haemorheologische parameters niet veranderden. Deze resultaten doen vermoeden 
dat haemorheologische stoornissen een uitdrukking zijn van gegeneraliseerde atherosclerosis.

In hoofdstuk 10 worden de belangrijkste resultaten en conclusies van deze studie gepresenteerd. 
. 
1. Allen EV, Brown GE. Erroneous diagnosis of Raynaud's disease in obliterative vascular disease. Am J Med Sci 1927; 174: 319-329.

2. Allen EV, Brown GE. Raynaud's disease affecting men. Am Intern Med 1932; 5; 1384-1386.

3. Allen EV, Brown GE. Raynaud's disease: a critical review of minimal requísites for diagnosis. Am I Med Sci $1932 ; 183: 187-200$.

4. Armot RS, Boroda C, Peacock JH. Pathophysiology of capillary circulation: Raynaud's disease. Angiology 1978; 29(1): 48-52.

5. Arnulf $G$. Physiological basis of sympathetic surgery for the upper limb in Raynaud's diseases. J Cardiovase Surg 1976; 17: 354-357.

6. Ayres ML, Jarrett PEM, Browse NL. Blood viscosity, Raynaud"s phenomenon and the effect of fibrinolytic enhancement. Br I Surg 1981; 68: 51-54.

7. Barbee, $J \mathrm{H}$. The effect of temperature on the relative viscosity of human blood. Biorheology 1973 ; 10: $1-5$.

8. Barlow T. Three cases of Raynaud"s disease. Transactions of the clinical society of London 1883; 16 : $179-188$.

9. Bennett R, Bluestone R, Halt R.ML, Bywaters EGL. Survival in scleroderma. Am Rheum Dis 1971: 30: $58:-588$.

10. Berguer $\mathbb{R}, H$ wang NHC. Critical arterial stenosis: a theoretical and experimental solution. Ann Surg $1974 ; 180 ; 39-50$.

11. Beyer JA, Wright IS. The hyperabduction syndrome with special reference to its relationship to Raynaud's syndrome. Circulation $1951 ; 4(2) ; 161-172$.

12. Birnstingl M. The Raynaud syndrome. Postgrad Med J 1971; 47: 297-310.

13. Blain IIl A, Coller FA, Carrer GB. Raynaud's disease. A study of criteria for prognosis. Surgery 1951 ; 29(3): $388-398$.

14. Bollinger $A$, Butti $P O$, Barras JP, Trachsler $H_{*}$ Siegenthaler $W$. Red blood cell velocity in nailfold capillaries of men measured by a television microscope technique. Microvasc Res 1974; 7:61-72.

15. Bollinger A, Mahler F, Aniiker M. Velocity of red blood cells in human nailfold capillaries. Acta Chir Scand (Suppl) 1976; 465: 7-9.

16. Bollinger $A$, Schlumpf $H$. Finger blood flow in healthy subjects of different age and sex and in patients with primary Raynaud's disease. Acta Chir Scand (Suppl) 1976; 465:42-47.

17. Bollinger $A$, Mahler $F$ "Anliker $M$. Flow dynamics in human nailfolld capillaries. Blood Vessels, Springer-Verlag Berlin-Heidelberg 1976; 79-81.

18. Bollinger A, Mahler F, Meier B. Velocity patterns in nailfold capiliatics of normal subjects and patients with Raynaud"s disease and acrocyanosis. Bibl Anat 1977; 16: 142-145.

19. Bollinger A, Jager $\mathrm{K}$, Sqier $F$, Geser A. Micro-angiopathy in scleroderma evaluated by dymamic fluorescence videomicroscopy. Microvase Res 1979; 17: S164.

20. Bollinger $A$, Jäger $\mathbb{K}$, Roten A, Timens C, Mahler F. Diffusion, pericapillary distribution and clearance of Na-fluorescence in the human naillold. Pfluegers Arch 1979; 382: 137-143.

21. Bollinger A, Jäger K. Television techniques in man. Bibl Anat 1981; 20:5-11.

22. Bollinger A. Pathophysiologie des Raynad-Phenomens. Dtsch Med Wochenschr 1982; 45: 1699. 1701.

23. Bollinger A, Frey J, Jäger K, Furrer J, Seglias N, Siegenthaler W. Patterns of diffusion through skin capillaries in patients with long-term diabetes. N Engl J Med 1982; 307: 1305.1310. 
24. Bollnger A, Frey J. Jäger K, Franzeck UK. Diffusion through skin capillarles in patients with long-tem diabetes, scleroderma and chronic venous incompetence Inter Angio 198\%; 2: 159-165.

25. Bouhoutsos J, Morris $\mathrm{T}$. Martin P. Unilateral Raynats phenomenon in the hand and its signifcance. Surgery $197 \% ; 82(5) ; 547-551$.

26. Mranemark Pl, Jonsson L. Determination of the velocity of corpuscles in blood capillaries. A nying spot device. Biorhedogy $1963 ; 1: 143-146$.

27. Brown GE. The skin capilaries in Raynaud's disease. Arch Intern Med 1925: 35:56-73.

28. Bucharan 18, Humpston DJ. Wail-fold capillaries in connective-Lissue disorders, Lancet 1968; 1 : 845-84\%

29. Burch GE, Harb JM, Sun CS. Fine structure of digital vascular lesions in Raynaud"s phenomenon and disease. Angiology 1979; 30(6): $361-376$.

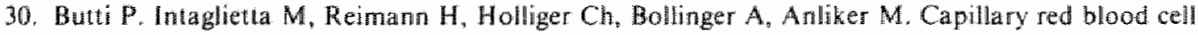
wellocity measurements in human nailfold by videodensitometric method. Microvasc Res 1975; 10 : 220-227.

31. Butt $P$, Fagrell $B$, Fronek $A$, Intaglieta $M$. The response of blood fow welocity in finger nailfold capillaries to contra-lateral cooling. Int J Microcire: Clin Exp 1982; 1: 19-27.

32. Chicn $\mathrm{S}$, Usami $\mathrm{S}$, Dellenback $\mathrm{RJ}$. Shear-dependant interaction of plasma proteins witherythrocytes in blood theology. An J Physiol 1970; 219: 143-153.

33. Clifford PC, Martin MFR, Sheddon EJ, Kirby JD, Baind RN, Dieppe PA. Treatment of vasospastic disease with prostaglandin EI. Br Med J 1980;281:1031-1034.

34. Coccheri S, Pureti G, Poggi M, Tricarico MG. Improwements in the rhealogical properties of blood indiced by medium-term treatment with Buflomedil in dabetic patients. J Int Med Res 1982: 10 : $394-398$.

35. Coffman JD, Cohen AS. Tolal and capil lary fingertip blood fow in Raynaud's phenomenon. Engl J Med 197I; 285: 259-263.

36. Coffman JD. Total and nutritional blood flow in the finger. Cli Sci 1972: $42: 243-250$.

37. Coffman JD, Dawies WT. Vasospastic diseases: A review. Prog Cardiovase Dis 1975; 118: 123-146.

38. Coffman JD. Vasodilator drugs in peripheral vascular disease. N Engl J Med 1979; 300(13), 713-717.

39. Courbier R, Bergeron P, Fouque R. Double-blind capillaroscopy study of the activity of Buflomedil in Raynaud's syndromet a report on 80 cases. Angiology $1981 ; 32: 676-678$.

40. Dabich L, Bwokstein JJ, Zweifler A, Zarafonetis CJD, Arbor A. Digital arteries in patients with scleroderma. Arch Intern Med 1972; 130: 708-714.

41. Dale WA. Raynaud's phenomenon due to arterial oeclusiwe disease of the wrist and hand. J Tenm Med Assoc 1976; 22-28.

42. Dale WA, Lewis MR. Management of ischemia of the hand and fingers. Surgery 1970;67(1):62-79.

43. Davis E. Clinical aspects of acrocyanosis. Adw Mícrocitc 1982; 10: 101-109.

44. Dintenfass L. Hemorheological factors in Raynaud's phenomenon. Angiology 1977; 28: 472-481.

45. Dintenfass L. Haemorheology of Raynaud's phenomenon. Adv Microcirc 1982; 10:60-72.

46. Di Perri T. Haenorbeological changes in vascuhopathic patients as a consequence of the ischaemia. Clinical Haemorheology. 2nd Eur Conf 1981; 153

47. Dodds AJ O'Reilly MJG, Yates CJP, Cotton LT, Flute PT, Dormandy JA. Haemorheological response to plasmit exchange in Raynatud"s syndrome. Br Med J 1979; 2: 1186-1187.

48. Dormandy $\llbracket \mathrm{A}$, Hoare $\mathbb{E}$, Colley $\mathfrak{J}$, Arrowsmith DE, Dormandy TL. Clinical, haemodynamic, rheological and biochemical findings in 126 patients with intermittent claudication. Bu Med J 1973:4: $576-581$.

49. Do:mandy JA, Ernst E. Effects of Bufhomedil on erythrocyte deformability. Angiology $1981 ; 32$ : $714-716$.

50. Dowd PM, Kirby JD, Holborow EJ, Cooke ED, Bowcock SA. Detection of immune complexes in systemic sclerosis and Raynaud's phenomenon. Br J Dermatol 1984; 105: $179-188$.

51. Downey JA, Frewin DB. The effect of cold on blood flow in the hand of patients with Raynaud's phenomenon. Cli Sci $1973_{\sharp 44: 279-289 .}$

52. Dwash IL, Giles A R, Ford PM, Pater J L., Anastassiades. TP. Plasmapheresis therapy in rheumatoid 
arthritis. N Engl J Med 1983; 308(19): 1124-11129.

53. Ehrly AM. Treatment of patients with secondary Raynauds symdrome. Acta Chir Scand (Suppl) $1976: 465: 92-96$.

54. Engelhari M, Kristensen JK. Ewaluation of cutaneous blood flow responses by 133 Kenon washout and a Laser-Doppler flowmeter. J Inwest Dermatol 1983; 80: 12.15.

55. Fagrell B. Vital capillaroscopy. Angiology 1972; 23; 284-298.

56. Fagrell B. Wital capillary microscopy. A clinical method for studying changes of the nutritional skin capillaries in legs with arteriosclerosis obliterans. Scand J Clin Lab Invest 1973; $31(3): \mathbb{- 5 0}$

57. Fagrell $B$. The skin microcirculation and the pathogenesis of ischaemic necrosis and gangrene, Scand J Clin Lab Invest 1977; 37: 473-476.

58. Fagrell Bintaglietta $M$. The dynamics of skin microcirculation as a tool for the study of systemic diseases. Bibl Anat 1977; 16:231-234.

59. Fagrell B, Fronek A. Intaglietta M. Capillary flow components and reactive hyperemia in human skin capillaries studied by dinical television microscopy. Bibl Anat 1977; 16:112-11.15.

60. Fagrell B, Fronek A, Intaglietta M. A microscope television system for studying flow velocity in human skin capilliaries. Am J Physiol 1977; 233(2): H318-H321.

61. Fagrell B. Postocclusive reactive hyperemia response in human skin capillaries. Bibl Anat $1981 ; 20$ : $671-674$.

62. Fagrell B, Östergren J. Reactiwe hyperemia response in human skin capillaries after varying ocolusion duration. Bibl Anat 1981; 20:692-696.

63. Fagrell B, Svedmanm $\mathrm{P}$, Ostergren $J$. The infuence of hydrostatic pressure and contralateral cooling on capillary blood cell velocity and transcuta neous oxygen tension in fingers. Int I Microcirc: Cli Exp 1982; 1: $163-171$.

64. Fagrell B. Monitoring the effects of vasoactive drugs by capillaroscopy and capillary blood now velocity measurements. Inter Angio 1983;2:153*159.

65. Fagrell B, Tooke J, Óstergren J. Vital capillaroscopy for evaluating skin microcirculation in humans. Prog appl Microcirc 1984; 6: 129-140.

66. Farmer RG, Gifford RW, Himes EA. Prognostic significance of Raynaud"s phenomenon and other

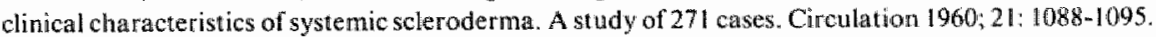

67. Forconi $S$, Guerrini M, Agmusdei D, Laghi Pasini F, Di Perri T. Abnormal blood wiscosity in Raynaud's phenomenon. Lancet 1976; $2: 586$.

68. Forconi $S$, Guemini $M$, Rossi $C$, Pechi $S$. Local increase of blood wiscosity during cold induced Raynaud's phenomenon. VASA 1979; 8: 116-120.

69. Franzeck UK, Isenring G, Frey J, Bollinger A. Videodensitometric pattern recognition of Na-fluorescein diffusion in nailfold capillary areas of patients with acrocyanosis, primary vasospastic and secondary Raynaud's phenomenon. Inter Angio 1983; 2: 143-152.

70. Galea G, Davidson RJL. Haemorheological changes and cessation of cigarette smoking. Clinical Haemorheology $1983 ; 3(3): 312$.

71. Gerber L. Biofeedback for patients with Raynaud"s phenomenon. JAMA 1979; 24266):509-510.

72. Gifford RW, Hines EA. Raynaud's disease among women and girls. Circulation $1957 ; 16: 1012-1021$.

73. Gifford RW. Hines EA, McKCraig W. Sympathectomy for Raynaud's phenomenon. Circulation $1958 ; 17: 5 \mathrm{~m} 13$.

74. Gilje O, Olleary PA, Baldes El. Capillary microscopic examination in skin diseases. AMA Arch Derm Syph $1953 ; 68: 136-147$.

75. Goyle KB, Dormandy JA. Abnormal blood viscosity in Raynaud"s phenomenon. Lancet 1976; 1 : 1317-1318,

76. Guerrini M, Acciaratti A. Materazzi M, Rossi C, Del Bigo C, Forconi S, Di Perni T. Protentive effecs of Buflomedil against exercise-induced reductions in regional erythrocyte deformability of patients with peripheral arterial disease. J Int Med Res $1982 ; 10: 387-393$.

77. Guglielmi RS, Roberts AH, Patterson R. Skin temperature biofeedback for Raynaud's disease: A double blind study. Biofeedback Self Regul 1982; 7(1): 99-119.

78. Gumtheroth WG, Morgan BC. Harbinson IA, Mullins GL. Raynaud's disease in cltildren. Circulat- 
tion $196 \% ; 36: 724-729$

79. Haavik Nison K. Malcolm IV Jasson. Cutaneous microcirculation in systemic sclerosis and response

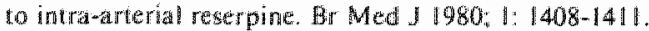

80. Haavik Nilson K. Pathophysiological classification of Raynaud's phenomenon. Br J Dermatol 1980 : $102(1): 1-5$.

81. Halperin JL. Drug therripy for cold sensitivity. VD\& $\mathrm{T} 1983 ; 4(4): 21-30$

42. Halperin JL. Coffman JD. Pathophysiologyy of Raynand's disease. Arch Intern Med 1979; 139:89-92.

83. Halperin $\mathrm{IL}$, Cohen $\mathrm{R}$ A, Coffman JD. Digital vasodilatation during mental stress in patients with Haynaud's disentse. Cardiovase Res 1983; 17:671-677.

84. Halpern A, Kuhn PH, Shaftel HE, Stmuels SS, Shaftel N, Selman D, Birch HG. Raynatud"s disease, Raynaud's phenomenon and serotonin. Angiology 1960; 11:151-167.

85. Hamilton WAP. Dodds AJ, Hancock MEJ, Roberts VC, Vergani D. Cotton LT. Circulatory Improvement in Rayna ud's phenomenon following plasma exchange. Plasma Exchange Sieberth HG (ed) Schattauer Verlag 1980; 301-307.

86. Harper FE, LeR oy EC. Raynaud's phenomenon: an update on treatment. J Cardiowasc Med 1982; 7: 3-10.

87. Harper FE, Maricq HR, Turner RE, Lidman RW, Le Roy EC. A prospective study of Raynaud"s phenomenon and early connective tissue disease. A rive year report. Am J Med 1982; 72(6):883-388.

88. Hawley PR, Johnston A W, Rankin IT. Association between digital ischaemic and malignant disease. Br Med J 1967; 3: 208-212.

89. Heidrich H, Malchus R. HLA-Antigen in the dilferential diagnosis of the Raynaud phenomenon. VASA 1982; II: 29-31.

90. Hendriksen $\mathrm{O}$, Kristensen JK. Reduced systolic blood pressure in Vingers of patients with generalized scleroderma (acroselerosis). Acta Derm Venereol 1981; 61: 531-534.

91. Hines EA, Christensen NA. Raynaud's disease among men. J Am Med Assoc 1945; 129(1): 1-4.

92. Hoare M, Miles $C$, Girwen $\mathbb{R}$, Ramsden $\mathbb{V}$, Needham $T$, Pardy B, Nicolaides $A$. The effect of local cooling on digital systolic pressure in patients with Raynaud's sydrome. Br J Surg 1982; 69 (suppl.): 527.528 .

93. Holloway GA, Watkins DW. Laser doppler measurements of cutaneous blood flow. J Invest Dermatol 1977; 69: 306-309.

94. Holloway GA. Cutaneous blood flow responses to injection trauma measured by laser doppler velocitymetry. II Invest Dermatol 1980; 74: 1-4.

95. Hooker DR. The functional activity of the capillaries and venules. Am J Physiol 1920;54:30-54.

96. Hornstein * B. Hypothenar-hammer-syndrom bei Aneurysma versus der A. ulnaris. VASA 1978; 7: 199-204.

97. Hunt JH. The Raynaud phenomena: a critical review. Q Jl Med 1936; $17(5)$; 399-444.

98. Hurwitz AL, Duranceau A, Postlethwait RW. Esophageal dysfunction and Raynaud"s phenomenon in patients with scleroderma. Dig. Dis 1976:21(8): 601-606.

99. Hutchinson J. Raynaud"s phenomenon. Med Press Circ 1901; 123; 402-405.

100. Hyndman DR, Wolkin J. Raynat's disease. A review of ats mechanism, with evidence that it is primarily a vascular disease. Am Heart J 1941,535-554.

101. Intaglietta M, Silvermann NR, Tomkins WR. Capillary tlow vellocity measurements in vivo and in situ by television methods. Microvase Res 1975; 10: 165-179.

102. Jacobs M.I, Slaaf DW, Reneman RS, Schmid-Schönbein H, Lemmens. HAJ. Correlation between capillary microscopy and haemorheology in patients with ischaemic handsyndromes. Clin Hemorrheology $1983 ; 3(3): 307$.

103. Jacobs M.JHM, Rhede vd Kloot E.HH, Lemmens HAJ. Plasma filtratie bij patienten met het fenomeen wan Raynaud. Ned Tijdschr Geneeskd 1984; $128(20)$ : 982.

104. Jacobs MJHM, Lemmens HAJ. Microcirculatory changes in patients with primary Raynaud's phenomenon after treatment with Buflomedil. Int $J$ Microcirc: Cli Exp, in Press.

105. Jacobs MJHM, Bresla PJ, Greep JM, Lemmens HAJ. Clinical and rheological studies in patients with intermittent claudication. Atherosclerosis, in Press. 
106. Jiger K. Gieser A. Bollinger A. Videodensitometrische Megsurg der transkapillaren passage und gewebsverteilung von Na-Fluoreszen in menschlichen Hautkapillaren. WAA 1980; 132-136.

107. Jahnsen T. Nielsen SL, Skovborg F. Blood viscoshty and local response to cold in primary Raynaud's phenomenon. Lancet $197 \% ; 2: 1001-1002$.

108. Jamieson GG, Ludbrook J, Wilson A. Cold hypersensitivity in Raynatuds phenomenon. Circulation $197: 19: 254-264$

109. Janevski BK. Angiography of the upper extremity. The Hague, Boston, London, Martinus Nihoff Publishers, 1982 .

110. Johnston ENM. Summerly R, Birnsting M. Prognosis in Raynaud's phenomenon after sympathectomy. Br Med J 1965; 1: $962-964$.

111. Johnston $\mathrm{KW}$. Maruzzo $\mathrm{BC}$. Cobbold $\mathrm{RSC}$. Doppler methods for quantitative measurement and localisation of peripheral arterial occlusive disease by analysis of the blood flow velocity wave form. Ultrasound Med Biol 1978; 4: 209-223.

112. Jones BM, Mayou BJ. The laser Doppler flowmeter for microvascular monitoring: a preliminaryi report. Br J Plast Surg 1982; 35: 147-149.

113. Kallenberg $\mathrm{CGM}$, Wouda $\mathrm{Aa}_{4}$ The TH. Systemic involvement and immunologic findings in patients presenting with Raynaud"s phenomenon. Am J Med 1980:69: 675-680.

114. Kater L. Indications and limitations of therapeutic plasmapheresis. Neth J Med 1981: 24: 206-208.

115. Kater L, Derksen RHWM, Howwert DA, Hene R. Struyenberg A Gmelig Meyling FH.J. Verroust P. Erect of plasmapheresis in active systemic lupus erythematosus. Neth J Med 1981; 24: $209-216$.

116. Kent SJS, Thomas ML., Browse NL. The value of arteriograplyy of the hand in Raynaud's syndrome. $\rrbracket$ Cardiovasc Surg 1976; 17: 72-80.

117. Ketanserin: a novel serotonin $\$ 2$-receptor blocking agent. Investigational new drug brochure. Siventh edition 1983, 42. Janssen Pharmaceutica, Beerse Belgium.

118. Kim, YK, Heidrich H. Stereotaxic hypothalomotomy in Raynaud's disease. Central-Rhythmic and Regulation Hippokrates Verlag Stuttgart 1974; 285-289.

119. Klinenberg JR. Wallace D. Plasmapheresis in Raynaud's disease. Lancet 1978; 1: 1310-1311.

120. Krähenbuhl B, Nielsen SL, Lassen NA. Closure of digital arteries in high vascular tone states as demonstrated by measurement of systolic blood pressure in the fingers. Scand J Clin Lab lnvest 1977 ; 37: $71-76$.

121. Kristensen JK, Engelhard $M$, Nielsen T. Laser-doppler measurement of digital blood flow regulation in normals and in patients with Raynaud"s phenomenon. Acta Dermatovener 1983;63; 43-47.

122. Kristensen JK. Finger skin perfusion pressure in generalized scleroderma. Acia Derm Venereol $1978 ;$ S8: $491-493$.

123. Kristensen $J K$. Local regulation of blood flow in cutaneous and subcutaneous tissue in paticnts with generalized scleroderma. Acta Derm Venereol 1980; suppl. 90: $1-39$.

124. Kristensen JK. Blood how in fingers in generalized scleroderma with Raynaud's phenomenon: influence of arterial blood pressure reduction and proximal vasodilatation. I Invest Dermatol 1981: 77: $373-376$

125. Lafferty K. De Trafford $1 C$, Robents VC Colton L. Kaynad's phenomenon and hemal entainment: an objective test. Br Med $I 1983 ; 286 ; 90-92$

126. Lafferty K, De Traflord IC, Roberts VC, Cotton LT. On the nature of Randads shenomenom: tho role of histamine. Lancet $1983 ; 1: 313-314$.

127. Episodic Digital Vasospasm - the legacy of Maurice Raynaud. Lancet 1977; $1039-1040$.

128. Landau $J$, Dawis $E$. Capillary thinning and high capilary blood-pressure in bypertension. labsot $1957 ; 1: 1327-1330$.

129. Landau J, Davis E. The small blood wessels in acrocyanosis and Raynand"s disease. Bibl Arat 1961: 1: $198-202$.

130. Langauer-Lewowicka $H$, Dudziak Z, Byczkowska Z. Marks J. Cryoglobullinemia in Rutyaud"s phenomenon due to Vinyl Chloride. Int Arch Occup Environ Health 1976; 36: 197-207.

131. Larrabee WF, Holloway GA. Trachy RE, Sutton D. Skin flap tension and wound slough cortelation with laser doppler velocimetry. Otolaryngol Head Neck Surg 1982; 90: 185-187. 
132. Lemmens HAJ. Raymad-Phanomen-Asphyxia manus ed digionam; Digitus mortus sive Digitus moriens. VASA 1977 ; 6 (3): 295-299

13. Lemmens HAJ. Costo-clavicular compression and dying digits. Paim in shoulder and arm. Eds. Greep JM, Lemmens. HAJ, Roos DB, Urschel HC, Martinus Nijhof Publishers 1979; 217-219.

134. Lemmens HAJ. Nomenclature of ischemic handsyndromes. Raynaud"s phenomenon, TM Verlag, Ed: Heidrich $\mathrm{H}$, Berlin. 1979; 19-23.

135. Lemmens HAJ, Thoraco dorsal sympathectomy en bloc. Vasc Surg 1979; 13: 33.1-335.

136. Lemmens HAJ. Clinical and rongenologic features of the hand and fingers in thoracic outlet syndrome. Vasc Surg 1980; 1.4: 87-91.

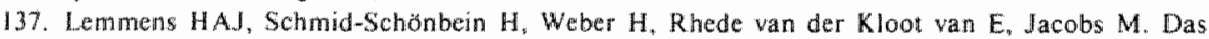
Raynaud Phărnomen: ein waskuläres oder ein intravaskuläres Problem. Angio 1983; 5(2): 85-90.

138. Le Roy EC, Downey JA, Cannon P.J. Sk in capillary blood flow in scleroderma. I Clin Invest 1971; 50 . $930-939$.

139. Lewis $T$. Landis EM. Observations upon the vascular mecharism in acrocyanosis. Heart 1930; 15 : $230-246$

140. Lewis T, Landis EM. Further obserwations upon a wariety of Raynaud"s disease; with special reference to arteriolar defects and to scleroderma. Heart 1929-1931; 15:329-350.

141. Lewis $T$. Experiments relating to the peripheral mechanism involved in spasmodic arrest of the circulation in the fingers, a variety of Raynaud's disease. Heart 1929-1931; 15:7\%101.

142. Lewis T. Observations upon the reactions of the vessels of the human skin to cold. Heart 1930; 15: $177-208$.

143. Lewis T, Raynaud's disease. N Engl IMed 1932; 206: 1192-1198.

144. Lewis $T$, Pickering GW. Observations upon maladies in which the blood supply to digits ceases intermittently or permanently, and upon bilateral gangrene of digits: observations relevant to so called "Raynaud's disease", Cli Sci 1934; I: 328-366.

145. Lewis $\mathrm{T}$. The pathological changes in the arteries supplying the fingers in warm handed people and in castes of so called Raynaud's disease. Cli Sci 1938; 3: 287-319.

146. Lindscheid RL, Petorson LFA, Juergens J L. Carpal-tunnel syndrone associated with wasospasm. J Bone Joint Surg 1967; 49A: 1141-1146.

147. Lombard WP. The blood pressure in the arterioles, capillaries and small veins of the human skin. Am J Physiol 1911;29:335-362.

148. Lowe GDO, Drummond MM, Lorimer AR, Hutton I, Forbes CD, Prentice CRM, Barbenel JC. Relationship between extent of coronary artery disease and blood viscosity. Br Med J 1980b; 1: $673-677$.

149. Lymn $\mathbb{R B}$, Steiner RE, Wyck van FAK. Arteriographic appearances of the digital arteries of the hands in Raynaud's disease . Lancet 1955; 1: 471-474.

150. Mahler $F$, Bollinger A. Die Kapillarmikroskopie als Untersuchungsmethode in der klinischen Angiologie. Disch Med Wochenschr 1978; 103: 523-527.

151. Mahler $\mathbb{F}$, Bollinger A. Flow velocity and pressure patterns in human nailrold capillaries. Bibl Anat $1981: 20: 667-670$.

152. Mahler F, Saner $H$, Marth $D$, Ursenbacher B. Local cold exposure test for examination of the mailfold capillary circulation in Rayna wd"s syndrome. Inter Angio 1983;2:137-142.

153. Maricq HR, LeR oy EC. Patterns of finger capillary abnormalities in connective tissue disease by "Wide-Field" microscopy. Arthritis Rheum 1973; 16(5): 619-628.

154. Maricq HR, Spencer-Green $G$, LeRoy $\mathbb{E} L$. Skin capillary abnormalities as indicators of organ involvement in scleroderma (systemic sclerosis), Raynaud's syndrome and dermatomyositis. Am J Med 1976; 61: 862-870.

155. Maricq HR, Weinberger AB, LeR oy EC. Predictive value of capillary microscopy in patients with Raynaud's phenomenon. Arthritis Rheum 1976; 23: 716-721.

156. Maricq HR. Variations in the skin microvascular patterns of the hand. Bibl Anat 1977; 16:164-169.

157. Maricq HR, LeR oy EC, D"Angelo WA, Medsger TA, Rodnan GP, Sharp GC, Wolfe JF. Diagnostic potential of in vivo capillary microscopy in scleroderma and related disorders. Arthritis Rheum 1980; 
$23,2: 183-188$

158. Maricg HR LeRoy EC. Microvascular changes in connective tisude diseases. Bibl Anat 1981: 20: $649-652$.

159. Maricq HR. The microcirculation in scleroderma and allied diseases. Adv Microcire 1982: 10:17-52.

160. Maricq HR. Microangiopathy in systemic scleroderma and related disorders. Iner Angio $1983 ; 2$ : $119-128$.

161. Marshall AJ, Roberts CJC, Barrith DW. Raynaud"s phenomenon as side effect of beta-blockers in hypertension. Br Med J 1976; 1: 1498-1499.

162. Matoba T, Kusomoto H, Mizaki $\mathrm{Y}, \mathrm{K}$ uwahara $\mathrm{H}$. Inanaga $\mathrm{K}$, Takamatsu Ml Clinical leatures and laboratory findings of vibration disease: a review of 300 cases. Tohoku J Exp Med 1977; 123:57-65.

163. McGill R. Tukey JW, Larsen WA. Variations of box plots, Anerican Statistician 1978; 32: 12-16.

164. McGrath MA, Peek R. Penny R. Blood hyperviscosity with reduced skin blood flow in scleroderma. Ann Rhewm Dis 1977: 36:569-574.

165. McGrath MA, Penny $R$. Blood hyperviscosity in cryoglobulinaernia: temperature sensitivity and correlation with reduced skin blood flow. Aus J Exp Bio Med Sci 1978; 56: 127-137.

166. McMillan DE. Plasmaprotein changes, blood viscosity and diabetic microanghography, Diabetes $1976 ; 25: 858-863$.

167. McNamara MF, Tahaki HS, Yao JST. Bergan JJ. A systemic approach to severe hand ischemia. Surgery $1978 ; 83(1): 1-11$.

168. Medical Staff Conference. Progressive systemic sclerosis. Calif Med 1973; $119: 35-42$.

169. Mendlowitz M, Naftchi $N$. The digital circulation in Raynaud"s disease. Am J Cardiol 1959; 4: 580-584.

170. Merlen JF. Paradoxes of acrocyanosis. A Review. Adv Microscire 1982; 10: 95-100.

171. Meulen wan der J, Wouda AA. Mandema E, The TH. Immune complexes in peripheral blood polymorphonuclear leucocytes of patients with Raynaud's phenomenon. Clin Exp Immunoll 1979. 35: $62-66$.

172. Meulen vander J, Voort wd-Beelen JM, D'Amaro J, The TH. HLA-B8 in Raynaud's phenomenon. Tissue Antigens 1980; 15: 81-85.

173. Müller LR. Studien über den Dermographismus und dessen diagnostische Bedeutung. Dtsch Zeitschr für Nervenheilkunde 1913; 47: 413-435.

174. Muller $O$. Die Kapillaren der menschlichen Körperoberfläche in gesunden und kranken Tagen. Ferdinand Enke Verlag 1922, Stuttgart.

175. Nieisen SL, Lassen NA. Measurement of digital blood pressure after local cooling. J Appl Plyysiol $1977 ; 43(5): 907-910$.

176. Nielsen SL, Christensen NJ, Olsen N, Lassen NA Raynaud's phenomenon: peripheral catecholamine concentration and effect of sympathectomy. Acta Chir Scand 1980; 502: 57-62.

177. Nilsson GE, Tenland T, Oberg PA. A new instrument for continuous measurement of tissue blood now by light beating spectroscopy. IEEE Trans Biomed Eng 1980:27(1): $12-19$.

178. Nilsson GE, Tenland T. Oberg PA. Evaluation of a laser Doppler flowmeter for measurement of tissue blood flow. IEEE Trans Biomed Eng 1980: $27(10): 597-604$.

179. Nobin BA. Nielsen SL, Eklov B. Lassen NA. Reserpine treatment of Raynad's disearse. Ann Surg $1978 ; 187(1): 12-16$

180. OReilly MJG, Talpos G, Roberts VC, White JM, Cotton LT. Controlled eriat of plasma exehange in treatment of Raynaud's syndrome. Br Med J 1979: I: I113-1 \|15.

181. O'Reilly MJG, Dodds AJ, Roberts VC. Cotton LT. Plasma exchange and Raynaud's phenomenon -its assessment by Doppler ultrasound velocity. Br J Surg 1979; 66: 712-715.

182. Ot EQ. Lechner $\mathrm{H}$, Aranibar A. High blood viscosity syndrome in cerebral infaretion Suroke 1974; 5: $330-333$.

183. Parrisius W. Kapillarsudien bei Vasoneurosen. Dtsch Zeitschr fur Nervenheilkunde 1921: 72 : $320-358$

184. Peacock JH. Vasodilatation in the human hand. Observations on primary Rayraud's diseaste and acrocyanosis in the upper extremities. Cli Sci $1957: 17: 575-581$. 
185. Peacock $1 \mathrm{H}$. Puripheral wevas blood concentration of epinephrine and norepinephrine in primary Raynaudis discase. Cinc Res 1959; 7:821.827.

186. Peacock $\mathrm{JH}$. The treatment of primary Raynaud"s dicease of the upper limb. Lancet 1960; $1: 65-68$.

187. Peacock $\mathbb{J} H$. The effect of changes in local temperature on the blood hows of the normal hand. primary Raynad's disease and primary acrocyanosis. Cli Sci 1960; 505-512.

18\%. Porter JM, Smider RL, Batala EJ, Rosch J, Eidemiller LR. The diagnosis and treatment of Raynadus phenomenon. Surgery $1975 ; 77: 11-23$.

189. Porter JM, Rivers $S \mathrm{P}$, Anderson $\mathrm{CJ}$, Baur $\mathrm{GM}$. Evaluation and management of patients with Raynaud's syndrome. Am J Surg 1982; 142: 183-189.

190. Porter J M, Bardana EJ, Batur OM, Wesche DH, Andrasch RH, Rösch I, The clinical significance of Raynaud"syndrome. Surgery 1976; 8066); 756-764.

191. Pringle R, Walder DN, Weaver JPA. Blood wiscosity and Raynaud's disease. Lancet 1965; 1 : 1086-1089.

192. Ratschow M. Angiologie, Pathologie, Klinik und Therapie der peripheren Durchbiutungstörungen. Georg Thieme Verlag, Stutgart, 1959.

193. Raynatud M. De lasphyxie locale et de la gangrene symetrique des extremites. Thesis. L Leclerc. Libraire-Editeur, Paris, 1862.

194. Reid HL, Dormandy JA, Barnes AJ. Lock PJ, Domandy TL. Impaired red cell deformability in peripheral vascular disease Lancet 1976; 1; 666-667.

195. Richards RL. Vasospastic disorders of the limbs. Br J Hosp Med 1978; $513-517$.

196. Rivers SP. Porter JM. Clinical approach to Raynaud's syndrome. VD \& T 1983; 15-24.

197. Rodeheffer KJ. Rommer JA, Wighley F, Smith CR. Controlled double-blind trial of nifedipine in the treatment of Raynad's phenomenon. N Engl J Med 1983; 308(15): 880-883.

198. Rösch J. Porter JM, Gralino B.I. Cryodynamic hand angioguaphy in the diagnosis and management of Raynatud"s syndrome. Circulation 1977; 55 : 807-814.

199. Schatfer E. Raynaud-5yndrom: Kinische Relevanz curkulierender Immunkomplexe Med Klin 1982; $77: 527.529$.

200. Schmid-Schónbein H. Critical closing pressure or yield shear stress as the cause of disturbed peripheral circulation. Acta Chir Scan (Suppl) 1976; 465: 10-20.

201. Schmid-Schönbein H, Gallaschi, Gosen v J, Volger $\mathbb{E}$, Klose HJ. Red cellaggregation in blood flow. Il new methods of quantilication. Klin Wochenschr 1976; 54: 149-157.

202. Schrnid-Schubein H, Gallasch G, Gosen v J Volger E, Klose HJ. Red cell aggregation in blood flow. II effect on apparent viscosity of blood. Klin Wochenschr 1976; 54: 159m167.

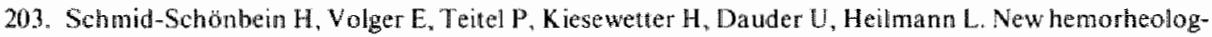
ical techniques for the routime labonatory. RACD 1981;2: 27-39.

204. Schmid-Schönbein H, Messmer $K$, Rieger H. Hemodilution and flow improvement. Bibl Haematol $1981 ; 47$.

205. Seibold JR, Jagenau AHM. Treatment of Raynad's phenomenon with Ketanserin, a selective antagonist of the serotonin 2 (5-HT2) receptor. Arthritis Rheum 1984; $27(2): 139-146$.

206. Shagan 18 P, Wriedman SA. Raynat's phenomenon and Thynoid deficiencey. Arch Inter Med 1980; $140: 832-833$.

207. Sivula A. Vuscular reactions in acrocyanosis. Angiology 1966:17:269-274

208. Stern ES. The actiology and pathology of acrocyanosis. Br J dermatol Syph 1937 , 49: 100-106.

209. Stranden E, Roald OK, Krohg K. Treatment of Raynaud's phenomenon with the 5 -HT -receptor $^{-}$ antagonist ketanserin. Br Med J 1982; 285: 1069-1071.

210. Sumner DS, Strandness DE. The relationship between calf blood flow and ankle blood pressure in patients with intermittent claudication. Surgery 1969; 65: 763-769.

211. Sumner DS, Strandness $\mathbb{D E}$. An abnormal finger pulse associated with cold sensitivity. Ann Surg 1972:175:294-298.

21.2. Sunder-Plassmen L. Messmer $\mathrm{K}$. Becker HM. Tisste $\mathrm{pO}_{2}$ and transcutaneous $\mathrm{pO}_{2}$ as guidelines in experimental and clinical drug exaluation. Angiology 1981: 32:686-698.

213. Takats de G, Fowler EF. Raynaud's phenomenon. JAMA 1962; 179(1): 99-106. 
214. Talpos G. Horrocks M, White JM, Coton L. T. Plasmapheresis in Raynaud's disease Lanced 1978 : 416417.

215. Tenland T. On laser Doppler Flowmetry nethods and intrawascular applications. Thesis 1982, Linköping.

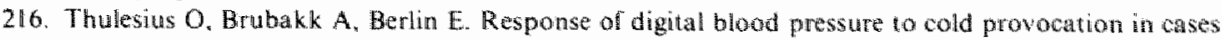
with Raynaud phenomena. Angiology 1981: 32: 113-118.

217. Tietjen GW. Chien S, Le Roy El, Garras 1, Garras H, Gump FE Blood viscosity plasma proteins. and Raynaud syndrome. Arch Surg 1975; 110:1343-1346.

218. Tooke JE. Ostergren J. Fagrell B. Synchronous assessment of thuman skin microcinculation by laser-Doppler howmetry and dynamic capilaroscopy. In J Microcir: Clin Exp 1983:2:277-284.

219. Treacy W L.. Baggenstass AH. Slocumb CH. Code ChF. Scleroderma of the esophagus. A correlation of histologic and physiologic tindings. Ann lntern Med 1963; 59:35॥-356.

220. Trübestein $G$. Balzer $K$, Bister $H$, Kluiken $H$, Mayfond $Y$, Müller-Wiefel $H$, Unkel B, Ziegler $W$. Buflomedil bei arterieller Verschlusskrankheit. Disch Med Wschr 1982; 107: 1957-1901.

221. Tufanelli DL. Wirkelman RK. Systemic scleroderma: a clinical study of 727 cases. Arch dermatol $1961 ; 84: 359-367$.

222. Tyml K. Ellis CG. Evaluation of the flying spot technique as a television method for measuring red cell velocity in microvessels. Int I Microcinc Clin Exp 1982; 1: 145-155.

223. Velayos EE, Robinson H. Porciuncala FU, Masi AT. Clinicall correlation analysis of 137 patients with Raynaud's phenomenon. Am J Med Sci 1971, 262(6): 347-356.

224. Volger $E$, Schmid-Schonbein $H$, van Gosen J, Klose $H . J$. Kline KA. Microrheology and ligh transmission of blood. The kinetics of artilicial red cell aggregation induced by dextran. Phitgers Arch 1975; 354: 319-337.

225. Walker RT, Matrai A, Dormandy JA, Flute PT. Haemorheological and functional changes in intermittent claudication followng plasmapheresis with haemacell. Clinical Hacmorheology 1983; 3(3): 338 .

226. Wenting GJ, Man in "t Veld AJ, Woittiez AJ, Boomsma $\mathbb{F}$, Schalekamp MADH. Treatment of hypertension with ketanserin, a new selective $5-\mathrm{HT}_{2}$ receptor antagonist. Br Med J 1982; 284: $537-539$.

227. Winship DH. Management of esophageal problems in patients with collagen vascular disease. Mod Treatment 1970; $7: 1241-1249$.

228. Wouda AA. Raynaud's phenomenon. Acti Med Scand 1977: 201: 519-523.

229. Yao ST, Hobbs JT, 1rvine W.T. Ank le systolic pressure measurements in arterial disease affecting the lower extremities. Br J Surg 1969; 56: 676-679. 



\section{Appendix}

The predicting abilities of the variables density (d), arterial diameter (Da), red blood cell aggregation $(\lambda)$ and plasma viscosity $\left(\eta_{0}\right)$ with respect to prediction of the categories primary Raynaud's phenomenon (PRP), secondary Raynaud's phenomenon (SRP) and acrocyanosis (AC) was assessed by performing discriminant analyses for all possible subsets of the predictors, utilizing module P7M of the statistical program package BMDP (1).

It turned out that in both the two- and the three category case, variable Da is the best one, i.e. Da gives the highest percentage correct classified patients. Adding one or more of the other variables to $\mathrm{Da}$ does not improve the predictive value.

For each category the predictive value and its one sided $95 \%$ confidence interval, based on the binomial distribution, were calculated $(2,3)$. The confidence intervals are simultaneous Bonferroni intervals so that the confidence level for the correctness of all statements simultaneously is $95 \%$ (4).

\section{References to this appendix:}

1. Dixon WJ. Brown MB. Biomedical computer program P-series (BMDP-81). University of Califormia Press, Berckley, CA 1981: 519.

2. Koopman AR. Sensitiviteit, specificiteit, aannemelijkheidswerhoudingen en voorspellende waarden van diagnostische testen. Kwantitatieve Methoden 1983; 9: 39.

3. Liemert GA. Verteilungstreie Methoden in der Biostatistik. Tafelband, Verlag Anton Hain, Meisenheim an Glan 1975: 293 .

4. Miller RG. Simultaneous Statistical Inference. Springer Verlag, New York 1981:67. 
Categories PRP, SRP:

\begin{tabular}{l|c|c|c|c}
\hline \multirow{2}{*}{ True category } & \multicolumn{2}{|c|}{ Predicted category } & \multirow{2}{*}{ Total } & \multirow{2}{*}{$\%$ correct } \\
\cline { 2 - 5 } & PRP & SRP & & \\
\hline \multirow{2}{*}{ PRP } & 43 & 0 & 43 & 100 \\
\hline SRP & 13 & 13 & 100 \\
\hline Total & 43 & 13 & 56 & 100 \\
\hline
\end{tabular}

Variable

Estimation Simultaneous $95 \%$ confidence interval

Prob [true PRP|pred PRP], predictive value for PRP: $100 \% \quad \geqslant 91 \%$ Prob [true SRPlpred SRP], predictive value for SRP: $\quad 100 \% \quad \geqslant 75 \%$

Categories PRP, SRP, AC:

\begin{tabular}{l|c|c|c|c|c}
\hline \multirow{2}{*}{ True category } & \multicolumn{3}{|c|}{ Predicted category } & \multirow{2}{*}{ Total } & \multirow{2}{*}{$\%$ correct } \\
\cline { 2 - 6 } & PRP & SRP & AC & & \\
\hline \multirow{2yyyyy}{*}{ PRP } & 40 & 0 & 3 & 43 & 93 \\
\hline SRP & 0 & 12 & 1 & 13 & 92 \\
\hline AC & 1 & 0 & 5 & 6 & 83 \\
\hline Total & 41 & 12 & 9 & 62 & 92 \\
\hline
\end{tabular}

Variable

Prob [true PRP|pred PRP], predictive value for PRP: $93 \%$ Prob [true SRP|pred SRP], predictive value for SRP: $\quad 92 \%$ Prob [true AClpred $\mathrm{AC}$ ], predictive value for $\mathrm{AC}$ :
Estimation Simultaneous 95\% confidence interval

$\geqslant 77 \%$

$\geqslant 60 \%$

$\geqslant 30 \%$ 


\section{Acknowledgements}

Many persons supported me in my activities resulting in the publication of this thesis. It is impossible to thank everyone personally but I should like to express my gratitude to those who enabled me to complete this thesis.

Prof. Lemmens introduced me into the world of angiology. I greatly appreciate his teaching efforts and I am honored to have had the opportunity to be involved in his life-work.

I am indebted to Prof. Rob Reneman, whose expert and dynamic guidance was invaluable. With his unique gentleness and intelligence he has showed me the way. Prof. Greep made it possible for me to work on the subject of this thesis. I am grateful for his encouragements.

I would like to express my deep appreciation towards Dr.Paul Breslau and Dr. Dick Slaaf. They introduced me into the methodology of peripheral vascular and microcirculatory research and spend many hours on discussing problems related to my work. Our collaboration meant a great deal to me.

For critical reading of the manuscript $\mathbb{1}$ specially like to thank the referees Prof. Bollinger, Prof. Schmid-Schönbein and Prof. Struyker-Boudier.

The valuable help of L. Volovics, A. de Koning and Ir. A. Muytjens in analysing the data statistically is greatly acknowledged. I am thankful to Rinus Alewijnse for his indefatigable assistance in the microcirculatory laboratory.

Dr. Paul Jörning, I have appreciated your interest in my work and your encouragement.

I thank Chris Voskamp for making the illustrations and the fine cover design.

I feel much obliged to Mechteld Frank and especially Marie-Josẽ Blondeau for their patience and help in preparing the manuscript and to Marcia van Puijenbroek and Henk Jas for processing the manuscript to the computerized typesetter.

Finally, 1 like to thank my colleagues of the surgical department for their support and friendship.

Last but not least I would like to mention my greatest gratitude to Mirjam, Caroline and Harm for giving me the opportunity to write this thesis during the "family-hours". 



\section{Curriculum Vitae}

Michael Jacobs was born on April 11 th 1957 in Baghdad, Irak. He attended high school in Maastricht, St. Maartens College (Atheneum B). In 1976 he went to Medical School at the University of Limburg and graduated in 1982. From July 1982 till January 1984 he was a research fellow at the Department of Surgery at the University of Limburg. He performed his microcirculatory work in the Laboratory for Microcirculation (Department of Physiology and Biophysics). At present he is surgical resident at the Surgical Department of the St.Annadal Hospital, University of Limburg, Maastricht (Head: Prof,Dr.J.M. Greep). 